\title{
AVALIAÇÃO DO POTENCIAL FISIOLÓGICO DE SEMENTES DE CEBOLA E SUA RELAÇÃO COM O DESEMPENHO DAS PLANTAS EM CAMPO
}

\section{ANGELICA BROD RODO}

Tese apresentada à Escola

Superior de Agricultura "Luiz de Queiroz", Universidade de São Paulo, para obtenção do título de Doutor em Agronomia, Área de Concentração: Fitotecnia.

PIRACICABA

Estado de São Paulo - Brasil

Janeiro - 2002 


\section{AVALIAÇÃO DO POTENCIAL FISIOLÓGICO DE SEMENTES DE CEBOLA E SUA RELAÇÃO COM O DESEMPENHO DAS PLANTAS EM CAMPO}

\section{ANGELICA BROD RODO}

Engenheiro Agrônomo

Orientador: Prof. Dr. JULIO MARCOS FILHO

Tese apresentada à Escola Superior de Agricultura "Luiz de Queiroz", Universidade de São Paulo, para obtenção do título de Doutor em Agronomia, Área de Concentração: Fitotecnia.

PIRACICABA

Estado de São Paulo - Brasil

Janeiro - 2002 
Dados Internacionais de Catalogação na Publicação (CIP) DIVISÃO DE BIBLIOTECA E DOCUMENTAÇÃO - ESALQ/USP

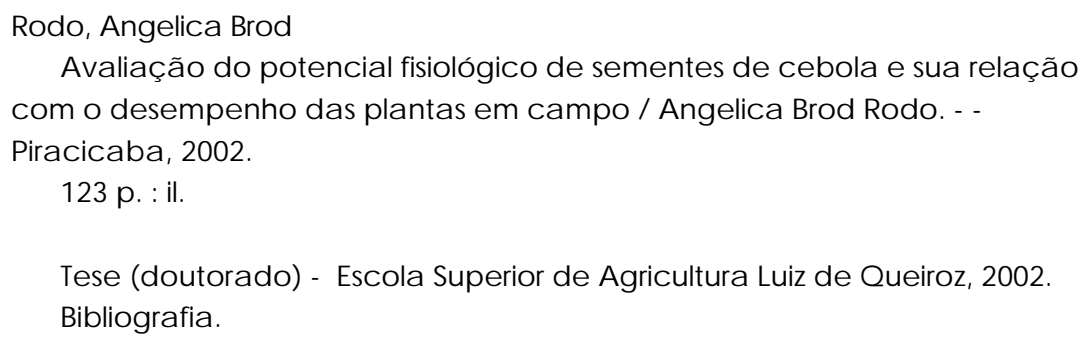

1. Cebola 2. Germinação de sementes 3. Sementes-vigor I. Título

CDD 635.25 
A Deus, fonte de sabedoria,
e a meus pais, Willy e Lia, dedico.

"Se não der frutos, valeu a beleza das flores.

Se não der flores, valeu a sombra das folhas.

Se não der folhas, valeu a intenção da semente." 


\section{AGRADECIMENTOS}

Ao Professor Julio Marcos Filho pela orientação, paciência, amizade e exemplo profissional, durante a realização do curso.

Aos Professores Sílvio Moure Cícero, Walter Rodrigues da Silva e Ana Dionísia da Luz Coelho Novembre, pelos ensinamentos adquiridos na área de Tecnologia de Sementes.

Aos Professores João Tessarioli Neto e Paulo César Tavares de Melo, pelo apoio e esclarecimentos prestados na área de Horticultura.

Aos Professores Maria Ângela André Tillmann e Francisco Amaral Villela, da UFPel, Pelotas-RS, pelo carinho e incentivo.

À Eng. Agr. MSc. Helena M. C. Pescarin Chamma pela amizade e acompanhamento nas análises de laboratório.

Aos funcionários do Departamento de Produção Vegetal, pelo auxílio na condução do experimento em campo.

Aos colegas do curso, pela convivência e companheirismo.

Ao CNPq pela bolsa de estudo concedida no primeiro ano e, a FAPESP, pela concessão da bolsa de estudo durante os demais anos de realização do curso.

Às secretárias Ilze Helena Neves, Maria Fernanda Meucci, Elisabete São João, Maria Ivete Almeida e Luciane Lopes, pelo atendimento e colaboração. À Empresa Hortec Sementes Ltda. pelo fornecimento das sementes. À família Tremocoldi pela acolhida e momentos compartilhados. Ao meu noivo Saulo pelo estímulo, amor e compreensão. A todos que contribuíram para a realização deste trabalho. 


\section{SUMÁRIO}

Página

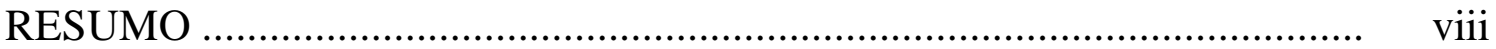

SUMMARY ............................................................................

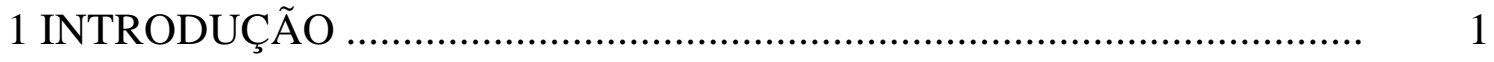

2 REVISÃO DE LITERATURA ...................................................... 3

2.1 Avaliação do vigor de sementes ................................................. 3

2.2 Vigor de sementes e desempenho de plantas ................................... 12

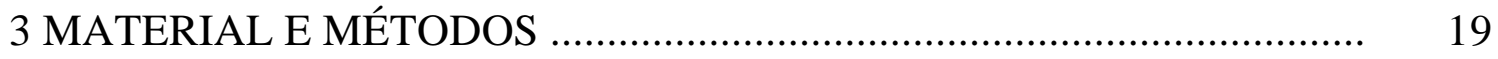

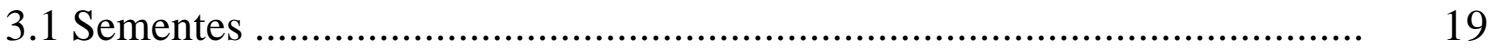

3.2 Avaliação do potencial fisiológico .................................................. 20

3.2.1 Determinação do grau de umidade ............................................. 20

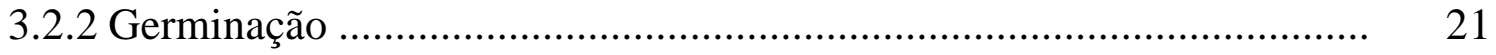

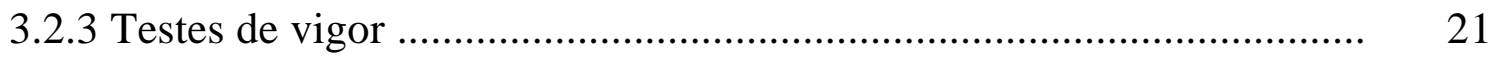

3.2.3.1 Primeira contagem do teste de germinação ................................. 21

3.2.3.2 Classificação do vigor de plântulas .......................................... 22

3.2.3.3 Condutividade elétrica ........................................................... 22

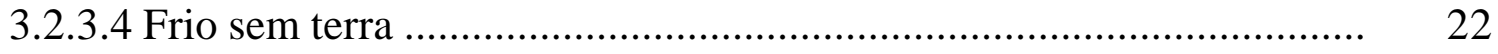

3.2.3.5 Envelhecimento acelerado .................................................. 23

3.2.3.6 Deterioração controlada .......................................................... 23 
3.3 Avaliação do desempenho das plantas .................................................... 24

3.3.1 Sistema de semeadura direta .......................................................... 24

3.3.1.1 Emergência de plântulas em campo …………………………........ 25

3.3.1.2 Avaliação do desenvolvimento vegetativo ......................................... 26

3.3.1.2.1 Altura de plantas ........................................................................... 26

3.3.1.2.2 Diâmetro na região do colo ........................................................... 26

3.3.1.2.3 Massa de matéria seca ................................................................. 27

3.3.2 Sistema de transplante de mudas .......................................................... 27

3.3.2.1 Emergência de plântulas em casa de vegetação ................................... 27

3.3.2.2 Avaliação do desenvolvimento vegetativo ....................................... 28

3.3.3 Avaliação da produção ....................................................................... 28

3.4 Procedimento estatístico .......................................................................... 29

4 RESULTADOS E DISCUSSÃO …………...................................... 31

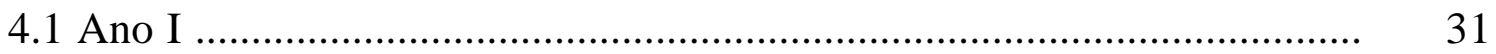

4.1.1 Avaliação do potencial fisiológico ....................................................... 31

4.1.1.1 Considerações gerais ........................................................................ 48

4.1.2 Avaliação do desempenho das plantas .................................................. 49

4.1.2.1 Sistema de semeadura direta ............................................................. 49

4.1.2.2 Sistema de transplante de mudas ...................................................... 61

4.1.2.3 Considerações gerais .................................................................... 70

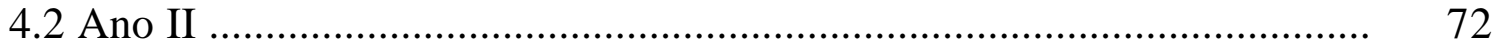

4.2.1 Avaliação do potencial fisiológico ...................................................... $\quad 72$

4.2.1.1 Considerações gerais .................................................................... 82

4.2.2 Avaliação do desempenho das plantas ................................................... 83

4.2.2.1 Sistema de semeadura direta ......................................................... 84

4.2.2.2 Sistema de transplante de mudas .................................................... 86

4.2.2.3 Considerações gerais ........................................................................ 92 
4.3 Ano III 93

4.3.1 Sistema de semeadura direta ........................................................... 93

4.3.2 Sistema de transplante de mudas ..................................................... 100

4.4 Considerações finais .............................................................................. 108

5 CONCLUSÕES .......................................................................... 111

REFERÊNCIAS BIBLIOGRÁFICAS _.................................................... 112 


\title{
AVALIAÇÃO DO POTENCIAL FISIOLÓGICO DE SEMENTES DE CEBOLA E SUA RELAÇÃO COM O DESEMPENHO DAS PLANTAS EM CAMPO
}

\author{
Autora: ANGELICA BROD RODO \\ Orientador: Prof. Dr. JULIO MARCOS FILHO
}

\section{RESUMO}

O potencial fisiológico de sementes, determinado pela germinação e vigor, é diretamente responsável pelo desempenho das sementes em campo, podendo até se refletir na produtividade de diversas espécies de hortaliças de importância econômica. Diante disto, o presente trabalho teve como objetivo avaliar a eficiência de diferentes métodos para determinação do potencial fisiológico de sementes de cebola (Allium cepa L.), visando destacar procedimentos adequados para utilização em programas de controle de qualidade; procurou-se, também, verificar a relação dos resultados obtidos em laboratório com a emergência das plântulas e o desempenho das plantas em campo. Para tanto, utilizaram-se seis lotes de sementes dos cultivares Aurora e Petroline, avaliados, em laboratório, quanto ao grau de umidade, germinação e vigor (primeira contagem de germinação, classificação do vigor de plântulas, condutividade elétrica, frio sem terra, envelhecimento acelerado tradicional e com solução salina e deterioração controlada). O desempenho das plantas foi 
verificado em ensaios de campo, utilizando-se dois sistemas de cultivo: semeadura direta e transplante de mudas; durante o desenvolvimento das plantas avaliaram-se, periodicamente, a altura, o diâmetro na região do colo e a massa de matéria seca das plantas. Após a colheita, determinou-se o rendimento final e efetuou-se a avaliação comercial dos bulbos. Concluiu-se que os testes de envelhecimento acelerado com solução salina $\left(41^{\circ} \mathrm{C} / 72 \mathrm{~h}\right)$, de deterioração controlada (ajuste do grau de umidade das sementes para $24 \%$ de água $/ 45^{\circ} \mathrm{C} / 24 \mathrm{~h}$ ) e de classificação do vigor de plântulas, são considerados eficientes para avaliação do potencial fisiológico de sementes de cebola. As relações entre o vigor de sementes de cebola e o desempenho das plantas manifestam-se apenas durante a fase inicial do desenvolvimento da cultura, principalmente quando as diferenças entre o potencial fisiológico dos lotes são mais acentuadas, mas não afetam diretamente a produção de bulbos. 


\title{
PHYSIOLOGICAL POTENTIAL EVALUATION OF ONION SEEDS AND ITS RELATION TO FIELD PLANT PERFORMANCE
}

\author{
Author: ANGELICA BROD RODO \\ Adviser: Prof. Dr. JULIO MARCOS FILHO
}

\section{SUMMARY}

Research has emphasized the relationship of laboratory germination and vigor to seedling emergence and stand establishment. In contrast, information relating seed vigor to plant performance is less available. This study was conducted to identify reliable procedures to rank onion (Allium cepa L.) seed lots according to their physiological potential and to select the most adequate procedures to be used in quality control programs. In addition, it was verified whether the differences in seed vigor influence plant performance in field conditions. Six seed lots of cultivars Aurora and Petroline were evaluated in laboratory for germination and vigor (first count, seedling vigor classification, electrical conductivity, cold test, traditional and saturated salt accelerated aging and controlled deterioration). Field experiments to detect differences in plant development were performed by direct sowing and transplant systems; after the determination of seedling emergence, plant vegetative development was evaluated by plant height, pseudo stem width and dry matter accumulation 
measurements. After harvest, the bulbs commercial classification and yield evaluation were provided. It was concluded that saturated salt accelerated aging $\left(41^{\circ} \mathrm{C} / 72 \mathrm{~h}\right)$, controlled deterioration $\left(24 \%\right.$ of water $\left./ 45^{\circ} \mathrm{C} / 24 \mathrm{~h}\right)$ and seedling vigor classification tests were the best procedures to assess the physiological potential of onion seeds. The initial plant development as measured by plant height and dry matter accumulation was affected by seed vigor mainly when the differences of seed physiological potential became wider as a result of the storage period. Influence of seed vigor did not persist during plant vegetative growth and yield was not related to seed vigor level. It was therefore concluded that the use of high vigor seed lots is justified to ensure adequate stand establishment under different environmental conditions. 


\section{INTRODUÇÃO}

O teste de germinação é empregado rotineiramente, em laboratório, para avaliação do potencial fisiológico de sementes; entretanto, tem fornecido resultados que podem superestimar o desempenho das sementes, sob condições ambientais menos favoráveis. Diante disso, o uso de testes de vigor, tem contribuído para identificar, com maior segurança, diferenças no desempenho de lotes de sementes, sob ampla faixa de condições de ambiente.

Existem testes considerados eficientes para avaliar o vigor das sementes que, no entanto, têm sido dirigidos, principalmente, a espécies de grandes culturas; as de hortaliças têm recebido menor atenção da pesquisa, apesar do elevado valor comercial. Assim, trabalhos direcionados à obtenção de resultados consistentes, procurando identificar a eficiência de diferentes testes de vigor, devem ser intensificados para estas culturas, sobretudo para aquelas de interesse econômico relevante para o País, como é o caso da cebola.

O cultivo de hortaliças é efetuado de maneira intensiva e seu sucesso depende do uso de sementes que germinem rápida e uniformemente, ou seja, de alto potencial fisiológico; este é responsável pelo desempenho das sementes em campo, podendo até se refletir na produtividade de diversas espécies (Marcos Filho, 1999a). Neste sentido, é amplamente reconhecida a importância fundamental do vigor de sementes durante o estabelecimento da cultura em campo, onde lotes mais vigorosos geralmente originam maior uniformidade de emergência de plântulas. 
Entretanto, ao passar do estádio de plântula para planta, considera-se que o efeito do vigor da semente sobre o desenvolvimento vegetativo é atenuado, havendo predomínio da influência da interação entre genótipo e ambiente. Ao mesmo tempo, é provável que, em espécies com ciclo relativamente mais curto, principalmente aquelas cujo produto comercial é uma estrutura vegetativa, o vigor da semente apresente influência mais acentuada, quando comparadas às espécies produtoras de grãos (Burris, 1976; Roberts, 1986; TeKrony \& Egli, 1991; Ellis, 1992; Finch-Savage, 1995; Carvalho \& Nakagawa, 2000). Contudo, poucos são os estudos realizados no sentido de se obterem informações mais detalhadas sobre os efeitos do vigor das sementes no desempenho das plantas em campo, especialmente no Brasil.

Diante do exposto, o presente trabalho teve como objetivo avaliar a eficiência de diferentes métodos para determinação do potencial fisiológico de sementes de cebola, visando destacar procedimentos adequados para utilização em programas de controle de qualidade; procurou-se, também, verificar a relação dos resultados obtidos em laboratório com a emergência das plântulas e o desempenho das plantas em campo. 


\section{REVISÃO DE LITERATURA}

Estudos sobre o vigor são de grande importância para a agricultura, pois permitem a obtenção de estimativa mais segura do potencial fisiológico das sementes, com a identificação de diferenças significativas entre os lotes, geralmente não detectadas pelo teste de germinação. Estas diferenças podem se refletir no desempenho das sementes durante o armazenamento e a emergência das plântulas, resultando em desuniformidade no estabelecimento do estande no campo, na qualidade de mudas para o transplante e, possivelmente, na qualidade comercial do produto, no caso de hortaliças.

Segundo Hampton \& Coolbear (1990), os testes de vigor são cada vez mais relevantes para muitas espécies de hortaliças, viabilizando a prática da semeadura de precisão, a eliminação do desbaste e a obtenção de maturação uniforme. Desta forma, a utilização de procedimentos eficientes para avaliação do vigor, complementando as informações fornecidas pelo teste de germinação na avaliação do potencial fisiológico de sementes de hortaliças, é fundamental em programas de controle de qualidade.

\subsection{Avaliação do vigor de sementes}

A avaliação do vigor de sementes tem evoluído à medida que os testes vêm sendo aperfeiçoados, em direção à obtenção de resultados reproduzíveis, constituindo base para a tomada de decisões destinadas à manutenção do potencial fisiológico das sementes após a maturidade. 
No entanto, os procedimentos disponíveis foram desenvolvidos para as sementes de grandes culturas. Os testes utilizados para hortaliças, muitas vezes, são adaptações baseadas em informações provenientes de estudos não específicos. Por outro lado, pesquisas realizadas no exterior demonstram que a atenção voltada ao desenvolvimento de testes direcionados para sementes de hortaliças, tem apresentado contribuições significativas para a indústria de sementes.

O teste de condutividade elétrica, por exemplo, foi proposto por Matthews \& Bradnock (1967) para o estudo do vigor de sementes de ervilha. Matthews (1980) também desenvolveu o teste de deterioração controlada, especialmente para sementes relativamente pequenas, como as das hortaliças. Mais recentemente, Jianhua \& McDonald (1996), adaptaram a metodologia do teste de envelhecimento acelerado, também para sementes pequenas.

No Brasil, o volume de pesquisas sobre testes de vigor para avaliação do potencial fisiológico de sementes de hortaliças é menos intenso, se comparado com outras culturas de interesse econômico.

Entretanto, nos últimos 10 anos, observa-se que diversas pesquisas foram realizadas para avaliação da eficiência de testes de vigor em sementes de berinjela (Miranda et al., 1992), brócolos (Mello et al., 1999; Mendonça et al., 2000), cebola (Lima, 1993; Idiarte, 1995; Piana et al., 1995; Torres, 1998), cenoura (Andrade et al., 1995; Spinola et al., 1998; Rodo et al., 2000), ervilha (Caliari \& Marcos Filho, 1990; Rech et al., 1999), feijão-de-vagem (Dias et al., 1998), maxixe (Silva et al., 1998; Torres et al., 1998; Torres et al., 1999), milho doce (Nascimento et al., 1994), pepino (Bhering et al., 2000), pimentão (Torres, 1996; Panobianco \& Marcos Filho, 1998; Torres \& Minami, 2000), quiabo (Dias et al., 1998; Torres \& Carvalho, 1998) e tomate (Nascimento et al., 1993; Rodo et al., 1998; Panobianco \& Marcos Filho, 2001). Porém, convém ressaltar que ainda há várias pesquisas realizadas com sementes de hortaliças no País, cujos resultados foram apenas apresentados em eventos científicos, limitando, assim, o 
acesso a novas informações e a evolução mais rápida do conhecimento. Contudo, as informações disponíveis ainda não são suficientes para o estabelecimento de procedimentos específicos e padronizados para estas e outras espécies olerícolas.

Nos primeiros trabalhos realizados com hortaliças no Brasil, era utilizado quase que somente o teste de primeira contagem do teste de germinação, como parâmetro para avaliar o vigor das sementes (Andrade \& Formoso, 1991). No entanto, conforme enfatizado em trabalhos com berinjela (Miranda, 1987), cenoura (Guedes \& Nascimento, 1988) e melancia (Alvarenga et al., 1984; Pedrosa et al., 1987), este teste não demonstra sensibilidade para detectar diferenças acentuadas de vigor entre lotes; assim, devido à facilidade de execução, pode ser utilizado na obtenção de informações menos rigorosas.

Atualmente, os pesquisadores têm se voltado para o estudo de testes que permitam a identificação mais precisa do nível de deterioração das sementes. Neste sentido, a avaliação do vigor pode ser realizada através de procedimentos que buscam detectar o estado metabólico atual das sementes ou a resposta quando submetidas a alguma condição de estresse.

O estado atual da semente pode ser avaliado diretamente, através de procedimentos baseados no desempenho das plântulas, como no teste de classificação do vigor de plântulas, ou ainda, indiretamente, através da integridade das membranas celulares ou da atividade enzimática, como nos testes de condutividade elétrica e de tetrazólio, respectivamente.

A primeira consequiência da deterioração, de acordo com a seqüência hipotética proposta por Delouche \& Baskin (1973), é a desestruturação dos sistemas de membranas celulares e a redução da permeabilidade seletiva. Membranas desestruturadas estimulam o processo de deterioração da semente e, possivelmente, deficiências no desempenho (Association of Official Seed Analysts - AOSA, 1983). Aceita essa hipótese, os testes que avaliam a 
integridade das membranas, como o teste de condutividade elétrica, seriam os mais sensíveis para estimar o vigor da semente (Marcos Filho, 1999a).

O teste de condutividade elétrica foi desenvolvido para detectar as causas de baixa emergência das plântulas em campo, em lotes de sementes de ervilha, que apresentavam alto percentual de germinação em laboratório (Matthews \& Bradnock, 1967).

Atualmente, destaca-se dentre os testes de vigor considerados mais eficientes na determinação do vigor, sendo utilizado em programas de controle de qualidade (AOSA, 1983; International Seed Testing Association - ISTA, 1995); além disso, apresenta elevado potencial para padronização, devido sua facilidade de execução e rapidez na obtenção dos resultados.

Para sementes de ervilha, de soja e de milho, de acordo com o procedimento tradicional, os resultados deste teste são obtidos após 24 horas de embebição; entretanto, este período pode ser reduzido para espécies que produzem sementes relativamente pequenas, como a maioria das hortaliças (Vieira \& Krzyzanowski, 1999). Em estudos com sementes de alface (Guimarães et al., 1993), cenoura (Andrade et al., 1995), maxixe (Torres et al., 1998), quiabo (Dias et al., 1998), tomate (Rodo et al., 1998) e pimentão (Torres \& Minami, 2000), resultados promissores foram obtidos após quatro horas de embebição.

Para sementes de cebola, Lima (1993) não obteve resultados confiáveis em leituras realizadas após quatro e 24 horas de embebição. Por outro lado, Piana et al. (1995) e Torres (1998), trabalhando com esta mesma espécie, consideraram que o período de 24 horas de embebição proporcionou informações seguras.

A obtenção de resultados discrepantes no estudo do teste de condutividade elétrica, dentro de uma mesma espécie, vem sendo atribuída a efeitos do genótipo e este fato pode estar associado a características do tegumento da semente. Thornton et al. (1990), trabalhando com brássicas, destacaram que o tegumento restringe, em grau variável, a liberação de eletrólitos durante a 
embebição, dependendo do cultivar analisado. Segundo McCormac \& Keefe (1990), a testa pode agir como barreira à entrada de água durante a embebição. Estes autores verificaram que as características do tegumento podem afetar os resultados do teste e se constituir na principal causa de variações das informações obtidas quando são avaliadas sementes de diferentes cultivares ou até amostras de um mesmo cultivar. Rech et al. (1999), verificaram que o teste foi eficiente para a avaliação do vigor de sementes de ervilha, cultivar Max, mas os resultados foram menos consistentes para o cultivar Crioula. Por outro lado, Panobianco et al. (2000), trabalhando com sementes de soja, verificaram que a condutividade elétrica da solução de embebição é influenciada pelo teor de lignina do tegumento da semente, característica variável de acordo com o cultivar; esta situação talvez seja verificada para sementes de diversas espécies de hortaliças, mas não há, ainda, pesquisas que permitam confirmar essa possibilidade.

Além disso, a temperatura de condução do teste, o número de sementes avaliadas e o volume de água de embebição, também são fatores estudados para padronização do teste de condutividade elétrica. A temperatura normalmente utilizada está no intervalo de 20 a $25^{\circ} \mathrm{C}$ (ISTA, 1995). Quanto ao número de sementes, Loeffler et al. (1988), recomendaram a utilização de quatro repetições de 50 sementes, pois assim, há redução do coeficiente de variação, obtendo-se maior uniformidade dos resultados. Já em relação ao volume de água, Hampton et al. (1994), verificaram que quanto maior o volume de água utilizado, menor é a interferência do número de sementes. Entretanto, para sementes de cebola, observam-se variações na relação destes fatores em estudos realizados por Lima (1993), Piana et al. (1995) e Torres (1998), os quais avaliaram, respectivamente, combinações de 25 sementes em $75 \mathrm{~mL}$ de água, a $20^{\circ} \mathrm{C} ; 50$ sementes em $25 \mathrm{~mL}$, a $25^{\circ} \mathrm{C}$; 25 sementes em $75 \mathrm{~mL}$, a $20^{\circ} \mathrm{C}$; estes demonstram que, para esta espécie, não há definição de procedimentos para o teste de condutividade elétrica. 
Assim, pode-se ressaltar a necessidade de estudos mais detalhados para o aprimoramento de procedimentos específicos para a condução do teste de condutividade elétrica, em sementes de hortaliças, visando a obtenção de resultados consistentes e o uso rotineiro em programas de controle de qualidade.

Métodos baseados na tolerância da semente a condições de estresse, como os testes de frio e de envelhecimento acelerado, também vêm sendo pesquisados para hortaliças.

O teste de frio foi desenvolvido inicialmente nos Estados Unidos, para avaliar o vigor de sementes de milho, simulando condições de solo frio e úmido que ocorrem durante a semeadura, na região conhecida como "Cinturão do milho". É conduzido, normalmente, com o uso de terra, mas, devido a dificuldades de padronização, foi proposta por Loeffler et al. (1985), a condução do teste utilizando apenas papel-toalha como substrato. Procurando manter os princípios básicos do teste, este procedimento avalia exclusivamente a influência de baixa temperatura e alta umidade; assim, os efeitos são menos severos que os observados em testes com terra que, geralmente, incluem a ação de microorganismos. A simplicidade de execução e a maior precisão dos resultados justificam o uso da metodologia proposta por Loeffler et al. (1985).

Para milho, o teste de frio sem terra é realizado em rolo de papel toalha, a $10^{\circ} \mathrm{C}$, por sete dias; entretanto, este mesmo procedimento tem sido adotado e demonstrado sensibilidade na avaliação do vigor de sementes de cebola (Lima, 1993; Torres, 1998).

$\mathrm{O}$ teste de envelhecimento acelerado foi desenvolvido com a finalidade de estimar a longevidade de sementes armazenadas, considerando que lotes de sementes de alto vigor mantém sua viabilidade quando submetidos, durante curtos períodos de tempo, a condições severas de temperatura e umidade relativa do ar (Delouche \& Baskin, 1973). 
Em cebola, pesquisadores tem estudado esse teste para avaliar o desempenho das sementes durante o armazenamento, indicando temperatura e período mais adequados; estes seriam $42^{\circ} \mathrm{C} / 48$ horas (Stumpf, 1993) ou $40^{\circ} \mathrm{C} / 48$ horas (Caneppele, 1994). A ISTA (1995), sugere a combinação $41^{\circ} \mathrm{C} / 72$ horas.

No entanto, além de estudos relacionando o teste de envelhecimento acelerado com o potencial de armazenamento das sementes, também têm sido realizados trabalhos para verificar a eficiência do mesmo na avaliação do potencial de emergência das plântulas em campo. Pesquisas conduzidas com sementes de cebola (Lima, 1993; Idiarte, 1995; Piana et al., 1995) e de outras hortaliças como cenoura (Spinola et al., 1998), tomate (Rodo et al., 1998) e brócolos (Mello et al., 1999), revelaram que, dentre os testes estudados, o envelhecimento acelerado foi o que apresentou relação mais estreita com a emergência das plântulas em campo.

Entretanto, para a maioria das hortaliças e outras espécies com sementes relativamente pequenas, o teste de envelhecimento acelerado pode apresentar certas limitações; a desuniformidade de absorção de água entre as amostras pode resultar em deterioração diferenciada, comprometendo os resultados da germinação pós-envelhecimento.

Neste sentido, Powell (1995) relatou que após 24 horas de envelhecimento acelerado ( $100 \%$ de umidade relativa a $45^{\circ} \mathrm{C}$ ) em lotes de sementes de cebola, houve variação acentuada no grau de umidade, de 11,8 a $24,0 \%$, sendo que a germinação após este período foi inversamente proporcional ao grau de umidade alcançado. Assim, Marcos Filho (1999b), recomenda que, sempre que possível, os lotes apresentem diferenças de apenas 1 a $2 \%$ no grau de umidade inicial; considera toleráveis variações de, no máximo, 3 a $4 \%$ após o envelhecimento. Cabe salientar que estas indicações são baseadas em trabalhos efetuados para sementes de grandes culturas, não havendo informações suficientes para sementes de hortaliças. 
Visando contornar esse problema, foi sugerida a substituição da água por soluções saturadas de sais, durante a realização do teste; nessa situação, há redução da umidade relativa do ambiente, no interior dos compartimentos individuais $(\mathrm{NaCl}-76 \% \mathrm{UR}, \mathrm{KCl}-87 \% \mathrm{UR}$ ou $\mathrm{NaBr}-55 \% \mathrm{UR})$, retardando a absorção de água pelas sementes. Este procedimento (SSAA - "Saturated Salt Accelerated Aging") foi proposto por Jianhua \& McDonald (1996) que, trabalhando com sementes de Impatiens wallerana Hook, verificaram eficiência do uso da solução salina no controle da absorção de água pelas sementes e na avaliação do vigor.

A viabilidade do uso dessa alternativa para detectar lotes de sementes com diferentes níveis de potencial fisiológico foi, também, verificada para pimentão (Panobianco \& Marcos Filho, 1998), cenoura (Rodo et al., 2000), pepino (Bhering et al., 2000) e tomate (Panobianco \& Marcos Filho, 2001).

Por outro lado, Ribeiro \& Carvalho (2001), não obtiveram resultados satisfatórios com esse procedimento, trabalhando com sementes de alface, brócolos e cenoura. Deve-se ressaltar, ainda, que não foi relatada nenhuma pesquisa utilizando essa técnica para condução do teste de envelhecimento acelerado, em sementes de cebola.

O estudo de procedimentos para identificar diferenças no vigor de lotes de sementes de hortaliças também tem envolvido o teste de deterioração controlada, baseado no mesmo princípio do teste de envelhecimento acelerado. Este foi desenvolvido com a finalidade de proporcionar maior precisão no controle da alta umidade e temperatura, às quais as sementes permanecem expostas durante a realização do teste. Dessa forma, enquanto no envelhecimento acelerado as sementes de uma amostra ganham água com diferentes velocidades durante a execução do teste, na deterioração controlada o grau de umidade inicial é ajustado para o mesmo nível, em todos os lotes, antes do período de exposição a altas temperaturas (Matthews, 1980). 
Inicialmente estudado para a avaliação de lotes de sementes de hortaliças (alface, beterraba, brassicas, cebola e cenoura) com desempenho deficiente em campo e baixo potencial de armazenamento (Matthews, 1980; Powell \& Matthews, 1981; Powell \& Matthews, 1984), o teste de deterioração controlada tem sido utilizado com sucesso para avaliar o vigor de sementes de ervilha (Powell et al., 1997), pimentão (Panobianco \& Marcos Filho, 1998), repolho (Strydom \& Venter, 1998), brócolos (Mendonça et al., 2000) e tomate (Alsadon et al., 1995; Rodo et al., 1998; Panobianco \& Marcos Filho, 2001).

Para sementes de cebola, é indicado ajuste do teor de água das sementes para $19 \%$ e condução do teste a $45^{\circ} \mathrm{C}$ (Powell \& Matthews, 1984; ISTA, 1995); em estudos realizados com esta espécie, Lima (1993), a partir deste procedimento proposto, obteve resultados satisfatórios na avaliação do vigor das sementes.

No entanto, verifica-se que, apesar de tentativas na adaptação dos procedimentos existentes para avaliação precisa do potencial fisiológico de sementes de hortaliças, o estudo do vigor para estas espécies deve ser intensificado. É fundamental, portanto, dar-se prioridade às consideradas mais problemáticas e de tamanho relativamente pequeno, que apresentam quantidades menos expressivas de reservas armazenadas e, portanto, maior propensão para a deterioração após a maturidade fisiológica. As sementes de cebola, além de representarem valor comercial indiscutível, se enquadram nestas características. Segundo George (1985), sementes desta espécie possuem baixa longevidade natural, perdendo viabilidade e vigor de forma mais acelerada que outras hortaliças. Diante disto, Thomazelli et al. (1990) e Stumpf (1993), ressaltaram a importância do uso de testes de vigor para o monitoramento do processo de deterioração de sementes de cebola.

O desenvolvimento de procedimentos baseados no princípio do teste de envelhecimento acelerado, como a deterioração controlada e a alternativa com uso de solução salina, vem de encontro a esse propósito. 
Ao mesmo tempo, deve-se dar atenção ao estudo do estado metabólico atual das sementes, através de métodos baseados na integridade das membranas celulares, devido à possibilidade de rápida obtenção das informações.

Deve-se salientar, contudo que, a eficiência dos testes de vigor depende da escolha adequada de procedimentos, em função dos objetivos pretendidos; além disso, existem testes mais promissores para cada espécie e, muitas vezes, para diferentes cultivares da mesma espécie. Assim, a tendência é a combinação de resultados de diferentes testes, pois o uso de apenas um teste pode gerar informações incompletas; sabe-se que o vigor pode ser refletido através de várias características, de modo que um teste isolado é considerado deficiente.

Portanto, a escolha dos testes deve ser realizada em função da sua rapidez, simplicidade, viabilidade econômica, objetividade, reprodutibilidade e, cujos resultados, sejam relacionados com a emergência das plântulas em campo (Marcos Filho, 1999a).

\subsection{Vigor de sementes e desempenho de plantas}

$\mathrm{O}$ vigor de sementes compreende um conjunto de características que determinam o potencial para a emergência e o rápido desenvolvimento de plântulas normais, sob ampla diversidade de condições de ambiente (AOSA, 1983). Conseqüentemente, entende-se que os lotes de sementes considerados vigorosos têm maior probabilidade de sucesso, caso o ambiente na época de semeadura, não seja totalmente favorável (Marcos Filho, 1999a).

Entretanto, estudos neste sentido, geralmente, têm se limitado a comparações entre o vigor das sementes e a emergência das plântulas em campo; porém, a qualidade das sementes pode afetar o posterior desempenho das plantas e, ainda, se refletir na produção final. 
De acordo com Ellis (1992), o vigor de sementes pode influenciar o desenvolvimento das plantas e a produção através de efeitos diretos e indiretos. Efeitos indiretos podem ocorrer devido à emergência mais precoce e uniforme de lotes de sementes com maior potencial fisiológico, além da produção de plântulas com maior crescimento inicial; esta diferença poderia se manter ao longo do desenvolvimento da cultura, influenciando a densidade populacional, a estatura de plantas, a produção de matéria seca e, consequentemente, a produtividade (Khah et al., 1989; Ellis, 1992).

Por outro lado, é possível que o vigor das sementes exerça efeito direto na capacidade dos tecidos da planta acumularem matéria seca. Entretanto, as estruturas da planta, presentes na semente, aparentemente são importantes apenas para o crescimento inicial da plântula, durante período relativamente curto após a emergência, pois, segundo Egli et al. (1990) e TeKrony \& Egli (1991), a maioria dos tecidos vegetais envolvidos na produção de matéria seca é formada após a emergência da plântula; assim, parece pouco provável que a influência do vigor da semente possa se estender à capacidade desses tecidos participarem de processos fisiológicos que culminam com o acúmulo de matéria seca.

No estádio de plântula, ou seja, quando o vegetal ainda depende essencialmente das reservas da semente, acredita-se que o vigor exerça efeito direto sobre o seu desenvolvimento (Khah et al., 1989; TeKrony \& Egli, 1991; Ellis, 1992); no entanto, ao atingir o estádio de planta, a influência do vigor da semente não seria tão clara e definida. De acordo com Carvalho (1986), o efeito do vigor da semente é atenuado com o decorrer do desenvolvimento da planta, passando a predominar a influência da interação entre genótipo e ambiente.

Dentro deste contexto, Burris (1976) relatou que o relacionamento entre o vigor de sementes e o desempenho de plantas, com conseqüientes efeitos sobre a produção, depende da época de avaliação do rendimento final, ou seja, no estádio vegetativo ou no início do estádio reprodutivo. 
Além disso, em condições de alta competitividade entre plantas, o vigor das sementes, teoricamente, teria pouca influência no desenvolvimento e na produtividade; porém, quando a competitividade é menos intensa, este efeito ainda pode existir (Roberts, 1986).

Assim, espera-se que o vigor das sementes influencie o desempenho inicial das plantas, podendo este efeito ser reduzido com a evolução do crescimento, afetando ou não a produção, dependendo do órgão da planta explorado comercialmente e do estádio em que é efetuada a colheita (Burris, 1976; Roberts, 1986; TeKrony \& Egli, 1991; Ellis, 1992; Finch-Savage, 1995; Carvalho \& Nakagawa, 2000). Neste sentido, para as culturas de hortaliças, em especial aquelas cujo produto é de origem vegetativa, como as produtoras de folhas, raízes ou bulbos, haveria maior probabilidade do vigor da semente exercer influência significativa sobre a produção final.

Em estudos realizados com alface, Smith et al. (1973) constataram que sementes de maior peso e qualidade, avaliada pelo teste de germinação, proporcionaram emergência mais uniforme de plântulas em campo e produtividade mais elevada; para esta espécie, Roberts (1986) e TeKrony \& Egli (1991) consideraram que o vigor das sementes é de grande importância, devido ao fato do órgão explorado ser produzido acima da superfície do solo, sob baixa densidade, evitando, assim, a influência da competitividade entre plantas.

Hanumaiah \& Andrews (1973), em trabalho realizado com nabo, verificaram que sementes de menor potencial fisiológico originaram menor emergência de plântulas, plantas com menor acúmulo de matéria seca de folhas bem como raízes de menor diâmetro e comprimento, determinando baixa produtividade. Esses mesmos autores, trabalhando com repolho, observaram que o maior vigor das sementes não influenciou a produção final. Vale ressaltar que, para avaliação do potencial fisiológico das sementes, foram realizados os testes de primeira contagem de germinação e de envelhecimento acelerado. 
Gamiely et al. (1990), estudando os efeitos da qualidade de sementes de cebola sobre o rendimento dos bulbos, em sistema de semeadura direta, destacaram a relação significativa entre sementes de maior vigor e produtividade; estes autores caracterizaram a qualidade das sementes pelo tamanho e peso e, como teste de vigor, utilizaram teste de germinação a $10^{\circ} \mathrm{C}$.

Ocana Gil et al. (1991), também trabalhando com cebola, em sistema de transplante de mudas produzidas em casa de vegetação, verificaram que sementes mais vigorosas ocasionaram maior velocidade na emergência e, consequentemente, plântulas maiores; esse efeito persistiu durante o desenvolvimento das plantas, mas não se relacionou à produção de bulbos. Porém, é importante salientar que, neste trabalho, foi realizada somente a separação dos lotes em diferentes níveis de qualidade, quanto ao peso e à germinação das sementes.

Assim, percebe-se que poucas pesquisas foram realizadas para espécies de hortaliças, buscando avaliar os efeitos do vigor de sementes no desempenho de plantas e seus possíveis reflexos na produção final.

Estas pesquisas, contudo, basearam-se somente em características físicas das sementes, como tamanho e peso, para caracterização dos lotes avaliados, ou ainda, em testes de germinação e de primeira contagem de germinação, os quais, segundo Marcos Filho (1999a), não apresentam sensibilidade suficiente para detectar diferenças pouco acentuadas no vigor das sementes; entretanto, embora em alguns trabalhos tenham sido utilizados testes mais sensíveis, como o de envelhecimento acelerado ou de germinação a $10^{\circ} \mathrm{C}$, não foi relatada a realização de estudos visando comprovar a eficiência destes na avaliação do potencial fisiológico das sementes, proporcionando desta forma, informações pouco seguras. Além disso, as diferenças de qualidade encontradas entre lotes eram mais acentuadas em alguns trabalhos e mais estreitas em outros. 
Portanto, nota-se que a caracterização do vigor das sementes nem sempre foi efetuada da mesma maneira em todas as pesquisas que procuraram relacionar vigor e desempenho de sementes em campo.

Outro aspecto importante a ser destacado é que, as condições experimentais de campo, principalmente relacionadas ao clima e ao solo, sob as quais são conduzidos experimentos desta natureza, foram muito variadas nas diferentes pesquisas relatadas. De acordo com Marcos Filho (1999a), o vigor das sementes responde diretamente à influência do meio ambiente, ou seja, em condições favoráveis para o desenvolvimento da cultura, a emergência das plântulas poderá corresponder aos resultados do teste de germinação e, assim, não seriam verificadas diferenças mais evidentes entre os lotes.

Diante disto, constata-se a dificuldade do esclarecimento da intensidade dos efeitos do vigor das sementes sobre o desempenho das plantas, especialmente em espécies olerícolas, as quais apresentam grande sensibilidade às condições de ambiente e cujos tratos culturais são realizados de maneira intensiva; isto dificulta a interpretação dos resultados, além de diminuir a possibilidade de comparação entre as informações obtidas por diferentes pesquisadores.

No Brasil, pesquisas visando relacionar o vigor das sementes e a produção de hortaliças, não foram encontradas; no entanto, cabe citar os trabalhos realizados por Stradioto Neto et al. (1992) e Piana et al. (1995), com sementes de cebola, os quais observaram relação direta entre o potencial fisiológico das sementes, a emergência das plântulas em campo e o desempenho das mudas; entretanto, estes estudos não buscaram os efeitos do vigor sobre o posterior desenvolvimento das plantas e o rendimento final.

Ainda, convém salientar que, Stradioto Neto et al. (1992), avaliaram a qualidade das sementes apenas pelo peso de mil sementes e testes de germinação e de primeira contagem de germinação. Por outro lado, Piana et al. (1995), além dos testes de germinação e de primeira contagem, efetuaram avaliações dos testes 
de condutividade elétrica, de frio com terra e de envelhecimento acelerado, verificando que, os resultados desses dois últimos, relacionaram-se diretamente com a emergência das plântulas em campo e com as diferenças observadas em relação à qualidade das mudas produzidas.

Para a cultura da cebola, cujo produto comercial é um órgão vegetativo, estudos desta natureza são de grande interesse. Além disso, a emergência de plântulas e a uniformidade de estande são consideradas críticas nesta espécie, visto que cada planta origina uma única unidade de exploração, estando esta intimamente relacionada à população de plantas.

De acordo com Fontes (1998), o estádio inicial do desenvolvimento das plantas de cebola, ou seja, logo após a emergência, é caracterizado como tipicamente vegetativo, havendo crescimento inicial lento, acompanhado de rápido incremento da parte aérea; este é afetado principalmente pela temperatura.

Conforme Shadbolt \& Holm (1956) e Wicks (1973), durante este estádio, a espécie apresenta baixo potencial competitivo pelos recursos do meio ambiente, devido ao lento crescimento inicial e à morfologia da planta, cujas folhas eretas não favorecem o sombreamento do solo, permitindo a germinação e o desenvolvimento de plantas daninhas, além de possuírem capacidade fotossintética limitada.

Portanto, o potencial fisiológico da semente constitui base fundamental para o desenvolvimento da cultura, onde o atraso na emergência ou as falhas no estande podem influenciar significativamente o desenvolvimento vegetativo das plantas e, possivelmente, a produtividade.

Entretanto, após o desenvolvimento inicial das plantas, ocorre o início da formação dos bulbos, onde estas passam pelo estádio de bulbificação, ainda na fase vegetativa da cultura, caracterizado pelo decréscimo da taxa de crescimento das folhas e aumento na produção de matéria seca; este processo é estimulado pela elevação da temperatura e fotoperíodo, de acordo com as exigências de cada 
cultivar (Fontes, 1998). Além desses fatores, a bulbificação pode ser influenciada pela competição entre plantas e pelas características destas, como tamanho e idade; porém, a interação desses fatores e a intensidade da influência do vigor das sementes, nesse estádio do desenvolvimento, ainda não foram elucidadas.

Convém ressaltar, ainda, que o cultivo de cebola no Brasil é conduzido, tradicionalmente, pelo sistema de transplante de mudas; o sistema de plantio por bulbinhos também é adotado em algumas regiões (Ferreira \& Castellane, 1988; Fontes, 1998).

No entanto, embora em pequena escala e diante da carência de trabalhos de pesquisa, a semeadura direta vem sendo adotada com a possibilidade do uso da semeadura de precisão e do controle mais eficiente de plantas daninhas. É considerado um sistema promissor, pois dispensa a formação e o transplante das mudas para o campo, possibilitando, dessa forma, a mecanização intensa da cultura e, consequentemente, menor custo de produção.

Entretanto, para qualquer situação, é fundamental a utilização de sementes de alto potencial fisiológico, seja para garantir a produção de mudas de alta qualidade como para assegurar uma população de plantas adequada, sob ampla faixa de condições de ambiente durante a emergência de plântulas.

Ao mesmo tempo, diante da introdução de novos cultivares e tecnologias, os quais impulsionaram o grande avanço da olericultura brasileira, assim como a crescente importância econômica nacional da cultura da cebola e demais hortaliças no País, poucos são os estudos realizados na busca de informações mais precisas sobre a qualidade das sementes destas espécies.

Para tanto, o aperfeiçoamento de métodos padronizados e reproduzíveis, visando a identificação do vigor de sementes de hortaliças deve ser priorizado; além disso, merecem ser elucidadas as relações existentes entre o vigor das sementes e o desempenho das plantas em campo, para melhor compreensão da influência deste importante parâmetro de avaliação do potencial fisiológico. 


\section{MATERIAL E MÉTODOS}

O presente trabalho foi realizado no Laboratório de Análise de Sementes e no Campo Experimental do Departamento de Produção Vegetal da Escola Superior de Agricultura "Luiz de Queiroz"/Universidade de São Paulo, em Piracicaba, SP, compreendendo o período de três anos consecutivos (1999-2001). Durante os dois primeiros anos experimentais, foram conduzidos testes para avaliação do potencial fisiológico de lotes de sementes de cebola, em laboratório, e para avaliação do desempenho das plantas, em casa de vegetação e em campo. No terceiro, foram conduzidos testes para avaliação do desempenho das plantas para confirmação da consistência dos resultados obtidos.

\subsection{Sementes}

Utilizaram-se seis lotes de sementes de cebola dos cultivares Aurora e Petroline, produzidos, respectivamente, nas safras de 96/97 e 98/99, pela empresa Hortec Sementes Ltda., Bagé - RS.

As sementes recebidas eram embaladas em latas hermeticamente fechadas; após homogeneização, foram separadas em quatro amostras, com auxílio de divisor de solo. Em seguida, as amostras foram acondicionadas em recipientes aluminizados e armazenadas em câmara a $19 \pm 1^{\circ} \mathrm{C}$ e $50 \pm 8 \%$ de umidade relativa do ar (UR). 
Durante o primeiro ano experimental, verificou-se que a qualidade inicial, elevada e uniforme, dos lotes de sementes do cultivar Aurora, dificultou a obtenção de resultados que permitissem detectar diferenças na sensibilidade dos testes de vigor conduzidos nesta pesquisa. Assim, visando aprimorar a qualidade das informações obtidas, foi adquirida maior quantidade de sementes de três dos seis lotes em estudo e realizado envelhecimento artificial destes três lotes, para que os mesmos apresentassem diferentes níveis de qualidade e poder germinativo superior ao mínimo estabelecido para comercialização. Esse procedimento foi realizado através da exposição das sementes, a $41^{\circ} \mathrm{C}$ e $100 \%$ de umidade relativa, durante 48 horas. Em seguida, os lotes que anteriormente apresentavam resultados entre 90 e $95 \%$ de germinação, passaram a apresentar valores entre 75 e 90\%. Desta forma, foi possível utilizar lotes com potenciais fisiológicos distintos, para este cultivar, a partir do segundo ano de experimento. Além disso, o uso de lotes de sementes envelhecidas artificialmente é interessante porque permite o controle mais adequado de variáveis, isto é, o monitoramento das diferenças de qualidade obtidas entre os mesmos.

\subsection{Avaliação do potencial fisiológico}

Para avaliação do potencial fisiológico dos lotes foram realizados, em laboratório, testes para a determinação do grau de umidade, germinação e vigor de sementes.

\subsubsection{Determinação do grau de umidade}

Realizada em estufa a $105 \pm 3^{\circ} \mathrm{C}$, durante 24 horas, conforme as recomendações das Regras para Análise de Sementes (Brasil, 1992), com duas 
repetições de aproximadamente 3,0g de sementes por lote. Os resultados foram expressos em percentagem média para cada lote (base úmida).

\subsubsection{Germinação}

Conduzido com quatro repetições de 50 sementes para cada lote, distribuídas em caixas plásticas $(11,0$ x 11,0 x 3,5cm) sobre duas folhas de papel (tipo mata-borrão) umedecidas com quantidade de água equivalente a 2,5 vezes o peso do papel seco, a $20^{\circ} \mathrm{C}$. As contagens foram realizadas aos seis e 12 dias após a semeadura, segundo os critérios estabelecidos pelas Regras para Análise de Sementes (Brasil, 1992). Os resultados foram expressos em percentagem média de plântulas normais para cada lote.

\subsubsection{Testes de vigor}

Foram conduzidos os testes de primeira contagem do teste de germinação, classificação do vigor de plântulas, condutividade elétrica, frio sem terra, envelhecimento acelerado e deterioração controlada.

\subsubsection{Primeira contagem do teste de germinação}

Realizado conjuntamente com o teste de germinação, registrando-se a percentagem de plântulas normais verificadas na primeira contagem do teste de germinação, efetuada no sexto dia após a semeadura, segundo as prescrições das Regras para Análise de Sementes (Brasil, 1992). 


\subsubsection{Classificação do vigor de plântulas}

Compreendeu a avaliação das plântulas normais no teste de germinação, sendo ambos os testes conduzidos concomitantemente. Na primeira avaliação, as plântulas normais que se apresentaram sadias, sem defeitos e com cotilédone e sistema radicular bem desenvolvidos, foram classificadas como plântulas normais "fortes" (Nakagawa, 1999). As demais permaneceram no substrato para segunda avaliação. Durante a segunda avaliação, as plântulas normais foram classificadas em "fortes" e "fracas". Os resultados do teste foram expressos em percentagem média de plântulas "fortes" para cada lote, considerando-se as duas avaliações.

\subsubsection{Condutividade elétrica}

Conduzido pelo método de massa, de acordo com o procedimento proposto pelo comitê de vigor da ISTA (1995). Foram utilizadas quatro repetições de 25 e 50 sementes, contadas e pesadas com precisão de 0,0001g. Em seguida, as amostras foram colocadas em copos plásticos contendo 25,50 ou $75 \mathrm{~mL}$ de água destilada e mantidas em incubadora a $20^{\circ} \mathrm{C}$ durante os períodos de 1, 2, 4, 8 e 24 horas de embebição. As leituras foram realizadas em condutivímetro Digimed DM-31 e os resultados expressos em $\mu \mathrm{mho} / \mathrm{cm} / \mathrm{g}$ de semente.

\subsubsection{Frio sem terra}

Utilizou-se como substrato rolo de papel toalha previamente umedecido com água destilada, na razão de 2,5 vezes o peso do papel, onde foram distribuídas quatro repetições de 50 sementes por lote. Os rolos foram colocados em sacos plásticos e permaneceram em câmara regulada a $10^{\circ} \mathrm{C}$, por sete dias (Loeffler et al., 1985). Em seguida, foram transferidos para germinador regulado 
a $20^{\circ} \mathrm{C}$, sendo a avaliação realizada após seis dias. Os resultados foram expressos em percentagem média de plântulas normais para cada lote.

\subsubsection{Envelhecimento acelerado}

Foram utilizadas caixas plásticas $(11,0$ x 11,0 x $3,5 \mathrm{~cm})$ como compartimento individual (mini-câmara), possuindo, suspensa em seu interior, tela de alumínio onde as sementes, após pesagem (aproximadamente 3,0g), foram distribuídas de maneira a formarem camada uniforme; no interior de cada compartimento individual foram adicionados $40 \mathrm{~mL}$ de água. As caixas, tampadas, foram mantidas em incubadora a $41^{\circ} \mathrm{C}$ por 48 e 72 horas. Ao término de cada período, as sementes foram submetidas a teste de germinação conforme descrito no item 3.2.2. As avaliações foram realizadas seis dias após a semeadura e, os resultados, expressos em percentagem média de plântulas normais para cada lote. Antes e após os períodos de envelhecimento, foi determinado o grau de umidade das sementes, visando avaliação da uniformidade das condições do teste.

Este mesmo teste foi também realizado utilizando-se o procedimento proposto por Jianhua e McDonald (1996), substituindo-se os 40mL de água adicionados em cada compartimento individual por igual quantidade de solução saturada de $\mathrm{NaCl}$ (40g de $\mathrm{NaCl} / 100 \mathrm{~mL}$ de água).

\subsubsection{Deterioração controlada}

Para a realização deste teste as sementes foram primeiramente umedecidas pelo método da atmosfera úmida (Rossetto, 1995), até atingirem 19 e $24 \%$ de água. Para tanto, no interior de caixas plásticas $(11,0$ x 11,0 x 3,5cm) foram adicionados $40 \mathrm{~mL}$ de água e, sobre tela de alumínio, colocadas amostras de aproximadamente 3,0g de sementes, distribuídas em camada uniforme. As caixas 
foram tampadas e mantidas em incubadora a $20^{\circ} \mathrm{C}$, realizando-se pesagens sucessivas para monitoramento do grau de umidade das sementes, até a obtenção dos valores desejados. Em seguida, as amostras foram acondicionadas em recipientes aluminizados hermeticamente fechados e mantidos em câmara fria, a 5- $8^{\circ} \mathrm{C}$, por cinco dias, para assegurar distribuição uniforme da água no interior das sementes. Decorrido este período, as amostras foram colocadas em banhomaria a $45^{\circ} \mathrm{C}$ por 24 horas (Powell, 1995). Em seguida, os recipientes foram imersos rapidamente em água fria para redução da temperatura e, em seqüência, instalado teste de germinação conforme descrição em 3.2.2. As avaliações foram efetuadas seis dias após a semeadura e, os resultados, expressos em percentagem média de plântulas normais para cada lote.

\subsection{Avaliação do desempenho das plantas}

As determinações para avaliação do desempenho das plantas foram realizadas em diversas etapas do desenvolvimento da cultura, pela condução de dois sistemas de cultivo: semeadura direta e transplante de mudas. Durante os três anos experimentais, seguiram-se os mesmos procedimentos para preparo do local e avaliação das plantas; no entanto, a área utilizada no primeiro ano foi alterada, devido à incidência de doenças que poderiam comprometer os resultados obtidos. Desta forma, optou-se pelo uso de outra área experimental.

\subsubsection{Sistema de semeadura direta}

Para este sistema de cultivo, foi realizado o preparo do solo com uso de encanteiradora para quebra de torrões e formação de canteiros de 1,2m de largura. 
Em seguida, foi efetuada adubação com $30 \mathrm{~kg} / \mathrm{ha}$ de $\mathrm{N}, 300 \mathrm{~kg} / \mathrm{ha}$ de $\mathrm{P}_{2} \mathrm{O}_{5}$ e $60 \mathrm{~kg} / \mathrm{ha}$ de $\mathrm{K}_{2} \mathrm{O}$, segundo recomendações obtidas através de análise prévia da fertilidade do solo. Posteriormente, os canteiros foram cobertos com esterco curtido e marcadas parcelas de acordo com o delineamento blocos ao acaso, em quatro repetições. A semeadura foi realizada em maio, no primeiro e no terceiro ano experimental e, em meados de junho, no segundo ano. Em cada parcela, foi distribuída quantidade de sementes calculada em função dos valores obtidos no teste de germinação para cada lote, procurando-se obter uniformidade de estande; ao término da semeadura, os canteiros foram cobertos com esterco peneirado. Em seqüência, foi aplicado herbicida $\operatorname{Ronstar}{ }^{\circledR}$, para controle das plantas daninhas, em pré-emergência; ao longo do desenvolvimento da cultura, seguiu-se o controle destas pela realização de capinas, a cada quinzena. A adubação em cobertura foi efetuada pela aplicação de uréia aos 30 dias após a semeadura. O controle fitossanitário foi realizado com aplicações de fungicida Dithane ${ }^{\circledR}$ para controle de doenças e inseticida Confidor ${ }^{\circledR}$ para o controle de tripes, seguindo-se as recomendações para a cultura. Para irrigação das parcelas foi instalado sistema de microaspersores, apropriado para o cultivo de hortaliças. Durante a fase de germinação e emergência das plântulas foram efetuadas duas irrigações diárias nos períodos da manhã e da tarde, segundo as necessidades verificadas para a cultura; na fase de desenvolvimento das plantas a irrigação continuou sendo realizada diariamente, porém, somente no período da tarde e, na fase final do ciclo, a mesma foi suspensa por ocasião da colheita.

\subsubsection{Emergência de plântulas em campo}

Foi conduzida em maio, nos três anos experimentais, com quatro repetições de 50 sementes, em canteiros preparados de maneira semelhante como 
descrito em 3.3.1. As avaliações foram realizadas aos 14 dias após a semeadura, através da contagem de plântulas que apresentavam altura igual ou superior a $1,0 \mathrm{~cm}$. Os resultados foram expressos em percentagem média de plântulas emergidas para cada lote.

\subsubsection{Avaliação do desenvolvimento vegetativo}

A primeira avaliação do desenvolvimento vegetativo foi realizada aos 28 dias após a semeadura, na qual foram colhidas amostras de oito plantas por repetição e efetuadas determinações da altura de plantas, diâmetro na região do colo e massa de matéria seca. A avaliação seguinte foi realizada aos 56 dias após a semeadura, amostrando-se seis plantas por repetição. Posteriormente, foi efetuada nova avaliação, aos 84 dias após a semeadura, com amostras de quatro plantas por repetição, observando-se a partir desta se já havia início da diferenciação dos bulbos. Seguiram-se as demais avaliações, em intervalos de 14 dias, até o momento da colheita, com amostras de três plantas por repetição.

\subsection{Altura de plantas}

Foi tomada a medida a partir da base da parte aérea da planta, com auxílio de régua milimetrada; os resultados foram expressos em $\mathrm{cm}$.

\subsection{Diâmetro na região do colo}

Foi tomada a medida do diâmetro da parte aérea, na região do colo, com auxílio de régua milimetrada; os resultados foram expressos em $\mathrm{cm}$. 


\subsection{Massa de matéria seca}

As plantas utilizadas para as avaliações de altura de plantas e diâmetro na região do colo foram colocadas em sacos de papel e mantidas em estufa com circulação de ar regulada a $70^{\circ} \mathrm{C}$, até atingirem massa constante. Após este período, o material seco foi pesado em balança com precisão de $0,0001 \mathrm{~g}$; a massa média de matéria seca por planta foi obtida pela divisão da massa de cada amostra pelo número de plantas avaliadas e, os resultados, expressos em gramas de massa de matéria seca.

\subsubsection{Sistema de transplante de mudas}

Primeiramente, foi realizado o teste de emergência de plântulas em casa de vegetação e, em seguida, as avaliações ao longo do desenvolvimento vegetativo das plantas. As mudas foram produzidas a partir das plântulas avaliadas no teste de emergência, permanecendo em casa de vegetação até o momento do transplante; este foi realizado em canteiros previamente preparados da mesma maneira e local para o sistema de semeadura direta, conforme descrito no item 3.3.1.

\subsubsection{Emergência de plântulas em casa de vegetação}

Foi conduzida em abril, nos três anos experimentais, sendo utilizadas quatro repetições de 100 sementes, distribuídas em bandejas de poliestireno com células individuais, contendo substrato comercial Plantimax ${ }^{\circledR}$. As bandejas foram cobertas por vermiculita expandida, para proteção contra evaporação excessiva, transferidas para casa de vegetação dotada de sistema de microaspersão e mantidas a $25^{\circ} \mathrm{C}$. As avaliações foram realizadas aos 14 dias após a semeadura, 
através da contagem de plântulas emergidas com altura igual ou superior a $1,0 \mathrm{~cm}$. Os resultados foram expressos em percentagem média de plântulas emergidas para cada lote.

\subsubsection{Avaliação do desenvolvimento vegetativo}

Após a avaliação da emergência de plântulas, foi realizada a primeira avaliação do desenvolvimento vegetativo, aos 28 dias após a semeadura. Foram tomadas amostras de oito plantas por repetição, as quais foram avaliadas pelos parâmetros altura de plantas, diâmetro na região do colo e massa de matéria seca, conforme descrito nos itens 3.3.1.2.1, 3.3.1.2.2 e 3.3.1.2.3. A segunda avaliação foi efetuada aos 42 dias após a semeadura, amostrando-se seis plantas por repetição; nessa ocasião, foi realizado o transplante das mudas para o campo. Posteriormente, seguiram-se as avaliações aos 84 dias após a semeadura, com amostras de quatro plantas por repetição, observando-se a partir desta se já havia início da diferenciação dos bulbos. As demais avaliações foram determinadas em intervalos de 14 dias, com três plantas por repetição, até o momento da colheita.

\subsubsection{Avaliação da produção}

Para ambos os sistemas de cultivo e, nos três anos experimentais, foi realizada colheita em outubro; esta foi caracterizada pelo secamento das folhas e tombamento das plantas. Foram amostradas 20 plantas por repetição e mantidas em galpão ventilado por 15 dias, para período de cura. Após este período, foi realizado o corte da raiz e do talo e posterior avaliação comercial dos bulbos quanto à massa e diâmetro transversal, segundo a Portaria $n^{\circ} 529$ (Vieira, 1995), adotada pela Associação Nacional de Cebolicultores. A partir destes resultados, foram calculados a produção média e o valor da produção de bulbos. 


\subsection{Procedimento estatístico}

Os resultados correspondentes aos testes realizados em laboratório foram analisados segundo o delineamento inteiramente casualizado, com seis tratamentos (lotes com diferentes níveis de vigor) e quatro repetições. Cada teste foi analisado separadamente, para cada cultivar, segundo esquema de análise de variância apresentado na Tabela 1. As variáveis medidas foram: germinação, primeira contagem, classificação do vigor de plântulas, frio sem terra, envelhecimento acelerado, deterioração controlada e condutividade elétrica; com exceção deste último, todas as variáveis foram transformadas em $\operatorname{arcsen} \sqrt{x / 100}$.

Tabela 1. Esquema de análise de variância para os testes realizados em laboratório.

\begin{tabular}{cc}
\hline Causas da variação & Graus de liberdade \\
\hline Lotes & 5 \\
Resíduo & 18 \\
\hline Total & 23 \\
\hline
\end{tabular}

Os testes realizados em casa de vegetação e em campo foram analisados segundo o delineamento em blocos ao acaso, com seis tratamentos (lotes com diferentes níveis de vigor) e quatro repetições. Cada teste foi analisado separadamente, para cada cultivar, segundo esquema de análise de variância apresentado na Tabela 2. As variáveis estudadas foram: emergência de plântulas, altura de plantas, diâmetro na região do colo, massa de matéria seca, número, massa e diâmetro médio de bulbos, produção e valor da produção de bulbos; a variável emergência de plântulas foi transformada em $\operatorname{arc} \operatorname{sen} \sqrt{x / 100}$. 
Tabela 2. Esquema de análise de variância para os testes realizados em casa de vegetação e em campo.

\begin{tabular}{cc}
\hline Causas da variação & Graus de liberdade \\
\hline Lotes & 5 \\
Blocos & 3 \\
Resíduo & 15 \\
\hline Total & 23 \\
\hline
\end{tabular}

Além da análise de variância, foi realizado teste de Tukey, a 5\% de probabilidade, para comparação múltipla de médias e, análise de regressão polinomial, para estudo da evolução do crescimento das plantas; esta compreendeu as determinações de altura de plantas, diâmetro na região do colo e massa de matéria seca, referentes ao primeiro ano experimental. Para execução das análises estatísticas, utilizou-se o "Sistema de Análise Estatística para Microcomputadores - SANEST" (Zonta \& Machado, 1984). 


\section{RESULTADOS E DISCUSSÃO}

\subsection{Ano I}

Os resultados obtidos durante o primeiro ano experimental, para os cultivares Aurora e Petroline, referentes a todos os procedimentos realizados para a avaliação do potencial fisiológico das sementes, em laboratório, e do desempenho das plantas, em casa de vegetação e em campo, serão apresentados e discutidos a seguir.

\subsubsection{Avaliação do potencial fisiológico}

Nas Tabelas 3 e 4, encontram-se, respectivamente, os resultados de testes de germinação e de vigor realizados em seis lotes de sementes de cebola, cultivares Aurora e Petroline.

Para o cultivar Aurora, os testes de germinação, de frio e de emergência de plântulas em casa de vegetação não indicaram diferenças significativas entre os lotes, revelando, assim, qualidade inicial elevada e uniforme das sementes deste cultivar. Entretanto, o teste de primeira contagem detectou o maior potencial fisiológico do lote 4 e o desempenho inferior dos lotes 1 e 6 . Por outro lado, o teste de classificação do vigor de plântulas, apesar de também apontar melhor qualidade para o lote 4 , indicou o lote 2 como o de menor vigor, de maneira semelhante ao teste de emergência de plântulas em campo. 
Tabela 3. Cultivar Aurora: resultados de testes de germinação (G), primeira contagem do teste de germinação (PCG), classificação do vigor de plântulas (CVP), frio sem terra (TF), emergência de plântulas em casa de vegetação (ECV) e emergência de plântulas em campo (EC), em seis lotes de sementes de cebola (Ano I).

\begin{tabular}{|c|c|c|c|c|c|c|}
\hline & G & PCG & CVP & TF & ECV & EC \\
\hline Lotes & \multicolumn{6}{|c|}{ 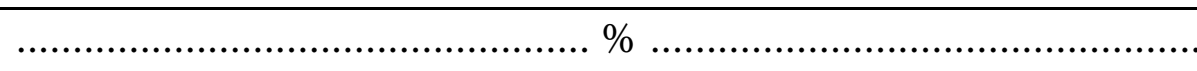 } \\
\hline 1 & $90 a^{*}$ & $73 \mathrm{c}$ & $88 \mathrm{ab}$ & $79 \mathrm{a}$ & $86 \mathrm{a}$ & $79 \mathrm{ab}$ \\
\hline 2 & $89 \mathrm{a}$ & $77 \mathrm{bc}$ & $83 \mathrm{~b}$ & $83 \mathrm{a}$ & $87 \mathrm{a}$ & $73 \mathrm{~b}$ \\
\hline 3 & $90 \mathrm{a}$ & $83 \mathrm{abc}$ & $90 \mathrm{ab}$ & $81 \mathrm{a}$ & $88 \mathrm{a}$ & $84 \mathrm{ab}$ \\
\hline 4 & $95 \mathrm{a}$ & $87 \mathrm{a}$ & $94 \mathrm{a}$ & $86 \mathrm{a}$ & $91 \mathrm{a}$ & $86 \mathrm{a}$ \\
\hline 5 & $94 \mathrm{a}$ & $84 \mathrm{ab}$ & $93 \mathrm{ab}$ & $86 \mathrm{a}$ & $86 \mathrm{a}$ & $77 \mathrm{ab}$ \\
\hline 6 & $90 \mathrm{a}$ & $72 \mathrm{c}$ & $94 \mathrm{ab}$ & $83 \mathrm{a}$ & $85 \mathrm{a}$ & $85 \mathrm{ab}$ \\
\hline $\mathrm{CV} \%$ & 4,7 & 5,2 & 7,0 & 8,1 & 7,2 & 6,3 \\
\hline
\end{tabular}

Em relação ao cultivar Petroline, com exceção do teste de primeira contagem, todos os demais acusaram o maior potencial do lote 14, acompanhado pelo lote 11 no teste de emergência de plântulas em casa de vegetação; o teste de primeira contagem considerou somente o lote 11 como o de melhor qualidade.

No entanto, verificou-se que não houve concordância entre os resultados desses testes quanto à indicação do lote de menor potencial fisiológico, embora os testes de emergência de plântulas em casa de vegetação e em campo, tenham detectado o desempenho inferior dos lotes 10 e 13; o teste de classificação do vigor de plântulas também revelou o pior desempenho do lote 10 . 
Tabela 4. Cultivar Petroline: resultados de testes de germinação (G), primeira contagem do teste de germinação (PCG), classificação do vigor de plântulas (CVP), frio sem terra (TF), emergência de plântulas em casa de vegetação (ECV) e emergência de plântulas em campo (EC), em seis lotes de sementes de cebola (Ano I).

\begin{tabular}{|c|c|c|c|c|c|c|}
\hline & G & PCG & CVP & $\mathrm{TF}$ & ECV & $\mathrm{EC}$ \\
\hline Lotes & ......... & . & ............... & ㄴ... & $\ldots$ & $\ldots \ldots . . .$. \\
\hline 10 & $79 b^{*}$ & $64 \mathrm{ab}$ & $61 \mathrm{c}$ & $75 \mathrm{~b}$ & $77 \mathrm{c}$ & $76 \mathrm{bc}$ \\
\hline 11 & $83 a b$ & $76 \mathrm{a}$ & $64 \mathrm{bc}$ & $87 \mathrm{ab}$ & $90 \mathrm{a}$ & $80 \mathrm{ab}$ \\
\hline 12 & $82 \mathrm{ab}$ & $61 \mathrm{~b}$ & $73 \mathrm{abc}$ & $77 \mathrm{~b}$ & $87 \mathrm{ab}$ & $74 \mathrm{bc}$ \\
\hline 13 & $80 \mathrm{~b}$ & $63 \mathrm{ab}$ & $72 \mathrm{abc}$ & $75 \mathrm{~b}$ & $80 \mathrm{c}$ & $65 \mathrm{c}$ \\
\hline 14 & $90 \mathrm{a}$ & $75 \mathrm{ab}$ & $80 \mathrm{a}$ & 89 a & $92 \mathrm{a}$ & $87 \mathrm{a}$ \\
\hline 15 & $80 \mathrm{~b}$ & $67 \mathrm{ab}$ & $73 a b$ & $82 \mathrm{ab}$ & $83 \mathrm{bc}$ & $71 \mathrm{bc}$ \\
\hline CV\% & 5,7 & 7,2 & 5,8 & 6,8 & 3,3 & 5,3 \\
\hline
\end{tabular}

Assim, constatou-se que os resultados obtidos nos testes de germinação, de primeira contagem, de classificação do vigor de plântulas, de frio e de emergência de plântulas, tanto em casa de vegetação como em campo, acusaram diferenças mais evidentes entre os lotes do cultivar Petroline, em relação às verificadas para os lotes do cultivar Aurora; neste, como as diferenças no potencial fisiológico eram mais estreitas, os testes, em geral, não proporcionaram informações semelhantes entre si, com exceção dos testes de classificação do vigor de plântulas e de emergência de plântulas em campo.

De certa forma, isto é esperado, pois segundo Marcos Filho (1999a), a manifestação do vigor das sementes responde diretamente à influência do meio 
ambiente e, portanto, testes baseados no desenvolvimento de plântulas, como os de germinação, de primeira contagem e de emergência de plântulas em casa de vegetação, geralmente não apresentam sensibilidade acurada a diferenças pouco acentuadas no potencial fisiológico, por serem conduzidos sob condições favoráveis de ambiente. Da mesma forma, as condições de estresse características do teste de frio, não foram suficientes para distinguir o vigor dos lotes de sementes do cultivar Aurora.

Para este mesmo cultivar, encontram-se nas Tabelas 5 a 10 os resultados do teste de condutividade elétrica.

Diante dos resultados obtidos, contatou-se que, em geral, todos os procedimentos estudados para este teste acusaram o lote 5 como de alta qualidade, seguido pelo lote 6; no entanto, houve variações entre estes em revelar os lotes de pior desempenho.

Tabela 5. Cultivar Aurora: condutividade elétrica - embebição de 25 sementes em $25 \mathrm{~mL}$ de água destilada, a $20^{\circ} \mathrm{C}$ (Ano I).

\begin{tabular}{|c|c|c|c|c|c|}
\hline & \multicolumn{5}{|c|}{ Períodos de embebição } \\
\hline & $1 \mathrm{~h}$ & $2 \mathrm{~h}$ & $4 \mathrm{~h}$ & $8 h$ & $24 \mathrm{~h}$ \\
\hline Lotes & & & $\mu \mathrm{mho} / \mathrm{cm} /$ & & \\
\hline 1 & $106,1 \mathrm{bc}^{*}$ & $136,1 \mathrm{bc}$ & $173,2 \mathrm{bc}$ & $216,6 \mathrm{~b}$ & $317,3 \mathrm{a}$ \\
\hline 2 & $119,0 \mathrm{c}$ & $149,8 \mathrm{c}$ & $186,8 \mathrm{c}$ & $230,2 \mathrm{~b}$ & $322,2 \mathrm{a}$ \\
\hline 3 & $114,9 \mathrm{bc}$ & $146,8 \mathrm{c}$ & $184,0 \mathrm{bc}$ & $224,0 \mathrm{~b}$ & $315,4 \mathrm{a}$ \\
\hline 4 & $112,9 \mathrm{bc}$ & $140,9 \mathrm{bc}$ & $180,2 \mathrm{bc}$ & $226,1 \mathrm{~b}$ & $321,6 \mathrm{a}$ \\
\hline 5 & 83,9 a & $106,3 \mathrm{a}$ & $141,0 \mathrm{a}$ & $184,8 \mathrm{a}$ & $271,5 \mathrm{a}$ \\
\hline 6 & $96,8 \mathrm{ab}$ & $120,0 \mathrm{ab}$ & $160,6 \mathrm{ab}$ & $205,7 \mathrm{ab}$ & $291,2 \mathrm{a}$ \\
\hline $\mathrm{CV} \%$ & 8,0 & 7,7 & 6,7 & 5,7 & 7,7 \\
\hline
\end{tabular}

* Comparação de médias dentro de cada coluna (teste de Tukey a 5\% de probabilidade). 
Tabela 6. Cultivar Aurora: condutividade elétrica - embebição de 50 sementes em $25 \mathrm{~mL}$ de água destilada, a $20^{\circ} \mathrm{C}$, Ano I.

\begin{tabular}{cccccc}
\hline & \multicolumn{5}{c}{ Períodos de embebição } \\
\cline { 2 - 6 } & $1 \mathrm{~h}$ & $2 \mathrm{~h}$ & $4 \mathrm{~h}$ & $8 \mathrm{~h}$ & $24 \mathrm{~h}$ \\
\hline Lotes & $\ldots \ldots \ldots \ldots \ldots \ldots \ldots \ldots \ldots \ldots \ldots \ldots \ldots \ldots \ldots \ldots \ldots \ldots \ldots \ldots \ldots \ldots \ldots \ldots \ldots \ldots \ldots \ldots \ldots \ldots \ldots \ldots \ldots \ldots \ldots \ldots \ldots \ldots \ldots \ldots$ \\
1 & $117,8 \mathrm{~b}^{*}$ & $142,1 \mathrm{~b}$ & $180,7 \mathrm{~b}$ & $219,6 \mathrm{~b}$ & $302,2 \mathrm{a}$ \\
2 & $106,5 \mathrm{~b}$ & $131,5 \mathrm{~b}$ & $167,5 \mathrm{~b}$ & $211,0 \mathrm{~b}$ & $291,9 \mathrm{a}$ \\
3 & $111,9 \mathrm{~b}$ & $135,9 \mathrm{~b}$ & $170,8 \mathrm{~b}$ & $215,5 \mathrm{~b}$ & $331,8 \mathrm{a}$ \\
4 & $115,9 \mathrm{~b}$ & $140,2 \mathrm{~b}$ & $176,0 \mathrm{~b}$ & $221,8 \mathrm{~b}$ & $326,7 \mathrm{a}$ \\
5 & $84,7 \mathrm{a}$ & $104,5 \mathrm{a}$ & $136,0 \mathrm{a}$ & $175,5 \mathrm{a}$ & $287,4 \mathrm{a}$ \\
6 & $86,7 \mathrm{a}$ & $107,7 \mathrm{a}$ & $140,3 \mathrm{a}$ & $178,6 \mathrm{a}$ & $293,1 \mathrm{a}$ \\
CV\% & 6,7 & 6,6 & 5,6 & 4,3 & 8,8 \\
\hline
\end{tabular}

* Comparação de médias dentro de cada coluna (teste de Tukey a 5\% de probabilidade).

Tabela 7. Cultivar Aurora: condutividade elétrica - embebição de 25 sementes em $50 \mathrm{~mL}$ de água destilada, a $20^{\circ} \mathrm{C}$ (Ano I).

\begin{tabular}{cccccc}
\hline & \multicolumn{5}{c}{ Períodos de embebição } \\
\cline { 2 - 6 } & $1 \mathrm{~h}$ & $2 \mathrm{~h}$ & $4 \mathrm{~h}$ & $8 \mathrm{~h}$ & $24 \mathrm{~h}$ \\
\hline Lotes & $\ldots \ldots \ldots \ldots \ldots \ldots \ldots \ldots \ldots \ldots \ldots \ldots \ldots \ldots \ldots \ldots \ldots \ldots \ldots \ldots \ldots \ldots \ldots \ldots \ldots \ldots \ldots \ldots \ldots \ldots \ldots \ldots \ldots \ldots \ldots \ldots \ldots \ldots \ldots \ldots \ldots \ldots \ldots \ldots \ldots$ \\
1 & $74,1 \mathrm{~b}^{*}$ & $83,2 \mathrm{~b}$ & $104,2 \mathrm{~b}$ & $124,2 \mathrm{~b}$ & $178,2 \mathrm{abc}$ \\
2 & $65,8 \mathrm{a}$ & $74,5 \mathrm{a}$ & $93,0 \mathrm{a}$ & $111,7 \mathrm{a}$ & $181,9 \mathrm{bc}$ \\
3 & $76,0 \mathrm{~b}$ & $86,9 \mathrm{~b}$ & $107,4 \mathrm{~b}$ & $127,3 \mathrm{~b}$ & $182,9 \mathrm{c}$ \\
4 & $74,7 \mathrm{~b}$ & $85,6 \mathrm{~b}$ & $104,3 \mathrm{~b}$ & $125,5 \mathrm{~b}$ & $187,7 \mathrm{c}$ \\
5 & $59,6 \mathrm{a}$ & $67,5 \mathrm{a}$ & $85,5 \mathrm{a}$ & $104,2 \mathrm{a}$ & $163,5 \mathrm{ab}$ \\
6 & $59,7 \mathrm{a}$ & $67,6 \mathrm{a}$ & $85,4 \mathrm{a}$ & $105,1 \mathrm{a}$ & $162,4 \mathrm{a}$ \\
$\mathrm{CV} \%$ & 4,8 & 4,9 & 5,0 & 4,8 & 4,7 \\
\hline
\end{tabular}

\footnotetext{
* Comparação de médias dentro de cada coluna (teste de Tukey a 5\% de probabilidade).
} 
Tabela 8. Cultivar Aurora: condutividade elétrica - embebição de 50 sementes em $50 \mathrm{~mL}$ de água destilada, a $20^{\circ} \mathrm{C}$ (Ano I).

\begin{tabular}{|c|c|c|c|c|c|}
\hline & \multicolumn{5}{|c|}{ Períodos de embebição } \\
\hline & $1 \mathrm{~h}$ & $2 \mathrm{~h}$ & $4 \mathrm{~h}$ & $8 \mathrm{~h}$ & $24 h$ \\
\hline Lotes & ............ & 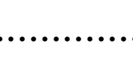 & $\mathrm{lmho} / \mathrm{cm}$ & & \\
\hline 1 & $61,7 b^{*}$ & $73,9 \mathrm{~b}$ & $93,1 \mathrm{~b}$ & $112,7 \mathrm{c}$ & $163,4 \mathrm{c}$ \\
\hline 2 & $55,8 \mathrm{ab}$ & $67,0 \mathrm{~b}$ & $87,8 \mathrm{~b}$ & $104,7 \mathrm{bc}$ & $152,9 \mathrm{bc}$ \\
\hline 3 & $59,8 \mathrm{~b}$ & $70,3 \mathrm{~b}$ & $91,6 \mathrm{~b}$ & $109,1 \mathrm{c}$ & $146,5 \mathrm{~b}$ \\
\hline 4 & $59,4 \mathrm{~b}$ & $68,4 \mathrm{~b}$ & $89,3 \mathrm{~b}$ & $106,8 \mathrm{bc}$ & $154,5 \mathrm{bc}$ \\
\hline 5 & $46,7 \mathrm{a}$ & $53,4 \mathrm{a}$ & $70,9 \mathrm{a}$ & $88,3 \mathrm{a}$ & $130,2 \mathrm{a}$ \\
\hline 6 & $47,7 \mathrm{a}$ & $55,3 \mathrm{a}$ & $73,8 \mathrm{a}$ & $92,8 \mathrm{ab}$ & $130,9 \mathrm{a}$ \\
\hline $\mathrm{CV} \%$ & 8,0 & 7,3 & 6,7 & 6,3 & 3,3 \\
\hline
\end{tabular}

* Comparação de médias dentro de cada coluna (teste de Tukey a 5\% de probabilidade).

Tabela 9. Cultivar Aurora: condutividade elétrica - embebição de 25 sementes em $75 \mathrm{~mL}$ de água destilada, a $20^{\circ} \mathrm{C}$ (Ano I).

\begin{tabular}{|c|c|c|c|c|c|}
\hline & \multicolumn{5}{|c|}{ Períodos de embebição } \\
\hline & $1 \mathrm{~h}$ & $2 \mathrm{~h}$ & $4 h$ & $8 h$ & $24 h$ \\
\hline Lotes & & & $\mathrm{mho} / \mathrm{cm} /$ & & \\
\hline 1 & $61,3 c^{*}$ & $68,9 \mathrm{c}$ & $81,3 \mathrm{~b}$ & $95,6 \mathrm{~b}$ & $141,9 \mathrm{bc}$ \\
\hline 2 & $55,8 \mathrm{bc}$ & $62,8 \mathrm{bc}$ & $74,1 \mathrm{ab}$ & $88,7 \mathrm{ab}$ & $136,5 \mathrm{abc}$ \\
\hline 3 & $60,2 \mathrm{c}$ & $69,5 \mathrm{c}$ & $81,6 \mathrm{~b}$ & $96,6 \mathrm{~b}$ & $142,1 \mathrm{bc}$ \\
\hline 4 & $62,1 \mathrm{c}$ & $68,7 \mathrm{c}$ & $82,7 \mathrm{~b}$ & $98,9 \mathrm{~b}$ & $146,9 \mathrm{c}$ \\
\hline 5 & $47,9 \mathrm{a}$ & $52,8 \mathrm{a}$ & $65,0 \mathrm{a}$ & $78,3 \mathrm{a}$ & $124,7 \mathrm{ab}$ \\
\hline 6 & $50,0 \mathrm{ab}$ & $56,2 \mathrm{ab}$ & $67,9 \mathrm{a}$ & 83,2 a & $121,6 \mathrm{a}$ \\
\hline $\mathrm{CV} \%$ & 5,9 & 5,8 & 5,6 & 5,2 & 6,5 \\
\hline
\end{tabular}

\footnotetext{
* Comparação de médias dentro de cada coluna (teste de Tukey a 5\% de probabilidade).
} 
Tabela 10. Cultivar Aurora: condutividade elétrica - embebição de 50 sementes em $75 \mathrm{~mL}$ de água destilada, a $20^{\circ} \mathrm{C}$ (Ano I).

\begin{tabular}{|c|c|c|c|c|c|}
\hline & \multicolumn{5}{|c|}{ Períodos de embebição } \\
\hline & $1 \mathrm{~h}$ & $2 \mathrm{~h}$ & $4 \mathrm{~h}$ & $8 \mathrm{~h}$ & $24 \mathrm{~h}$ \\
\hline Lotes & \multicolumn{5}{|c|}{ 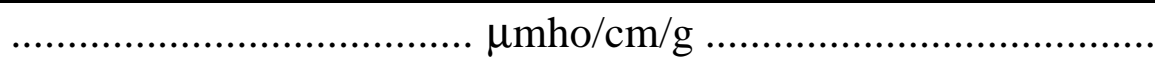 } \\
\hline 1 & $46,0 \mathrm{~cd}^{*}$ & $54,2 \mathrm{~cd}$ & $67,0 \mathrm{~cd}$ & $78,9 \mathrm{bc}$ & $121,3 \mathrm{~b}$ \\
\hline 2 & $41,5 \mathrm{bc}$ & $48,8 \mathrm{bc}$ & $60,1 \mathrm{bc}$ & $74,2 \mathrm{abc}$ & $113,7 \mathrm{~b}$ \\
\hline 3 & $45,2 \mathrm{~cd}$ & $54,1 \mathrm{~cd}$ & $65,8 \mathrm{~cd}$ & $80,3 \mathrm{c}$ & $116,7 \mathrm{~b}$ \\
\hline 4 & $49,5 \mathrm{~d}$ & $57,7 \mathrm{~d}$ & $69,5 \mathrm{~d}$ & $85,4 \mathrm{c}$ & $118,1 \mathrm{~b}$ \\
\hline 5 & $34,0 \mathrm{a}$ & $40,5 \mathrm{a}$ & $50,7 \mathrm{a}$ & $64,8 \mathrm{a}$ & $98,6 \mathrm{a}$ \\
\hline 6 & $34,7 \mathrm{ab}$ & $41,4 \mathrm{ab}$ & $52,8 \mathrm{ab}$ & $66,6 \mathrm{ab}$ & $104,2 \mathrm{a}$ \\
\hline CV\% & 7,8 & 7,2 & 6,7 & 7,4 & 3,7 \\
\hline
\end{tabular}

* Comparação de médias dentro de cada coluna (teste de Tukey a 5\% de probabilidade).

Também, verificou-se que o teste de condutividade elétrica proporcionou informações completamente distintas das originadas dos testes de classificação do vigor de plântulas e de emergência de plântulas em campo, apresentados na Tabela 3, os quais indicaram o lote 4 como o de melhor qualidade e o lote 2 como de qualidade inferior. Em alguns procedimentos, houve inclusive, inversão no ranqueamento de lotes, indicando o lote 4 como o de menor potencial (Tabelas 9 e 10, por exemplo). Assim, não foi possível indicar, de maneira confiável, um dos procedimentos realizados para este teste como o mais adequado para identificação do potencial fisiológico de lotes deste cultivar.

Da mesma forma, Lima (1993), trabalhando com sementes de cebola, não obteve resultados promissores para o teste de condutividade elétrica, em avaliações efetuadas após quatro e 24 horas de embebição.

Os resultados do teste de condutividade elétrica, para o cultivar Petroline, são observados nas Tabelas 11 a 16. 
Tabela 11. Cultivar Petroline: condutividade elétrica - embebição de 25 sementes em $25 \mathrm{~mL}$ de água destilada, a $20^{\circ} \mathrm{C}$ (Ano I).

\begin{tabular}{cccccc}
\hline & \multicolumn{5}{c}{ Períodos de embebição } \\
\cline { 2 - 6 } & \multicolumn{1}{c}{$1 \mathrm{~h}$} & $\mathrm{~h}$ & $4 \mathrm{~h}$ & $8 \mathrm{~h}$ & $24 \mathrm{~h}$ \\
\hline Lotes & $\ldots \ldots \ldots \ldots \ldots \ldots \ldots \ldots \ldots \ldots \ldots \ldots \ldots \ldots \ldots \ldots \ldots \ldots \ldots \ldots \ldots \ldots \ldots \ldots \ldots \ldots \ldots \ldots \ldots \ldots \ldots \ldots \ldots \ldots \ldots \ldots \ldots \ldots \ldots$ \\
10 & $147,9 \mathrm{bcd}^{*}$ & $187,5 \mathrm{bcd}$ & $224,4 \mathrm{ab}$ & $296,0 \mathrm{bc}$ & $394,5 \mathrm{~b}$ \\
11 & $143,8 \mathrm{abc}$ & $183,9 \mathrm{bc}$ & $233,8 \mathrm{abc}$ & $293,8 \mathrm{bc}$ & $397,1 \mathrm{~b}$ \\
12 & $140,2 \mathrm{ab}$ & $174,9 \mathrm{ab}$ & $218,0 \mathrm{ab}$ & $266,8 \mathrm{ab}$ & $406,4 \mathrm{~b}$ \\
13 & $179,3 \mathrm{~d}$ & $226,8 \mathrm{~d}$ & $287,1 \mathrm{c}$ & $341,7 \mathrm{c}$ & $454,9 \mathrm{~b}$ \\
14 & $110,5 \mathrm{a}$ & $139,1 \mathrm{a}$ & $176,2 \mathrm{a}$ & $208,8 \mathrm{a}$ & $282,4 \mathrm{a}$ \\
15 & $177,1 \mathrm{~cd}$ & $218,5 \mathrm{~cd}$ & $268,9 \mathrm{bc}$ & $310,2 \mathrm{bc}$ & $432,1 \mathrm{~b}$ \\
$\mathrm{CV} \%$ & 10,3 & 10,1 & 11,0 & 11,0 & 10,2 \\
\hline
\end{tabular}

* Comparação de médias dentro de cada coluna (teste de Tukey a 5\% de probabilidade).

Tabela 12. Cultivar Petroline: condutividade elétrica - embebição de 50 sementes em $25 \mathrm{~mL}$ de água destilada, a $20^{\circ} \mathrm{C}$ (Ano I).

\begin{tabular}{cccccc}
\hline & \multicolumn{5}{c}{ Períodos de embebição } \\
\cline { 2 - 6 } & $1 \mathrm{~h}$ & $2 \mathrm{~h}$ & $4 \mathrm{~h}$ & $8 \mathrm{~h}$ & $24 \mathrm{~h}$ \\
\hline Lotes & $\ldots \ldots \ldots \ldots \ldots \ldots \ldots \ldots \ldots \ldots \ldots \ldots \ldots \ldots \ldots \ldots \ldots \ldots \ldots \ldots \ldots \ldots \ldots \ldots \ldots \ldots \ldots \ldots \ldots \ldots \ldots \ldots \ldots \ldots \ldots \ldots \ldots \ldots \ldots \ldots$ \\
10 & $140,1 \mathrm{a}^{*}$ & $175,4 \mathrm{ab}$ & $215,5 \mathrm{ab}$ & $262,2 \mathrm{ab}$ & $400,5 \mathrm{~b}$ \\
11 & $136,6 \mathrm{a}$ & $178,8 \mathrm{ab}$ & $223,6 \mathrm{~b}$ & $266,2 \mathrm{ab}$ & $444,3 \mathrm{~b}$ \\
12 & $148,8 \mathrm{ab}$ & $176,8 \mathrm{ab}$ & $215,1 \mathrm{ab}$ & $266,2 \mathrm{ab}$ & $370,7 \mathrm{ab}$ \\
13 & $191,3 \mathrm{c}$ & $237,9 \mathrm{c}$ & $292,3 \mathrm{c}$ & $351,9 \mathrm{c}$ & $397,6 \mathrm{~b}$ \\
14 & $128,5 \mathrm{a}$ & $156,3 \mathrm{a}$ & $191,5 \mathrm{a}$ & $231,5 \mathrm{a}$ & $286,7 \mathrm{a}$ \\
15 & $171,9 \mathrm{bc}$ & $204,6 \mathrm{~b}$ & $242,1 \mathrm{~b}$ & $282,5 \mathrm{~b}$ & $391,4 \mathrm{~b}$ \\
CV\% & 7,7 & 7,0 & 5,9 & 6,3 & 11,4 \\
\hline
\end{tabular}

\footnotetext{
* Comparação de médias dentro de cada coluna (teste de Tukey a 5\% de probabilidade).
} 
Tabela 13. Cultivar Petroline: condutividade elétrica - embebição de 25 sementes em $50 \mathrm{~mL}$ de água destilada, a $20^{\circ} \mathrm{C}$ (Ano I).

\begin{tabular}{cccccc}
\hline & \multicolumn{5}{c}{ Períodos de embebição } \\
\cline { 2 - 6 } & $1 \mathrm{~h}$ & $2 \mathrm{~h}$ & $4 \mathrm{~h}$ & $8 \mathrm{~h}$ & $24 \mathrm{~h}$ \\
\hline Lotes & $\ldots \ldots \ldots \ldots \ldots \ldots \ldots \ldots \ldots \ldots \ldots \ldots \ldots \ldots \ldots \ldots \ldots \ldots \ldots \ldots \ldots \ldots \ldots \ldots \ldots \ldots \ldots \ldots \ldots \ldots \ldots \ldots \ldots \ldots$ \\
10 & $86,3 \mathrm{~b} *$ & $103,7 \mathrm{ab}$ & $131,6 \mathrm{ab}$ & $173,5 \mathrm{~b}$ & $180,6 \mathrm{ab}$ \\
11 & $74,5 \mathrm{ab}$ & $95,3 \mathrm{ab}$ & $120,2 \mathrm{ab}$ & $151,2 \mathrm{ab}$ & $225,7 \mathrm{~b}$ \\
12 & $76,2 \mathrm{ab}$ & $96,1 \mathrm{ab}$ & $114,5 \mathrm{ab}$ & $142,3 \mathrm{ab}$ & $207,1 \mathrm{ab}$ \\
13 & $94,9 \mathrm{~b}$ & $123,4 \mathrm{~b}$ & $153,3 \mathrm{~b}$ & $190,9 \mathrm{~b}$ & $218,2 \mathrm{ab}$ \\
14 & $52,0 \mathrm{a}$ & $66,5 \mathrm{a}$ & $86,3 \mathrm{a}$ & $105,6 \mathrm{a}$ & $149,5 \mathrm{a}$ \\
15 & $77,7 \mathrm{ab}$ & $101,2 \mathrm{ab}$ & $118,4 \mathrm{ab}$ & $151,5 \mathrm{ab}$ & $190,8 \mathrm{ab}$ \\
CV\% & 15,4 & 16,9 & 17,1 & 17,1 & 19,4 \\
\hline
\end{tabular}

* Comparação de médias dentro de cada coluna (teste de Tukey a 5\% de probabilidade).

Tabela 14. Cultivar Petroline: condutividade elétrica - embebição de 50 sementes em $50 \mathrm{~mL}$ de água destilada, a $20^{\circ} \mathrm{C}$ (Ano I).

\begin{tabular}{cccccc}
\hline & \multicolumn{5}{c}{ Períodos de embebição } \\
\cline { 2 - 7 } & $1 \mathrm{~h}$ & $2 \mathrm{~h}$ & $4 \mathrm{~h}$ & $8 \mathrm{~h}$ & $24 \mathrm{~h}$ \\
\hline Lotes & $\ldots \ldots \ldots \ldots \ldots \ldots \ldots \ldots \ldots \ldots \ldots \ldots \ldots \ldots \ldots \ldots \ldots \ldots \ldots \ldots \ldots \ldots \ldots \ldots \ldots \ldots \ldots \ldots \ldots \ldots \ldots \ldots$ \\
10 & $69,7 \mathrm{ab}^{*}$ & $89,8 \mathrm{~b}$ & $102,3 \mathrm{ab}$ & $127,8 \mathrm{~b}$ & $177,2 \mathrm{~b}$ \\
11 & $71,8 \mathrm{bc}$ & $91,5 \mathrm{bc}$ & $101,6 \mathrm{ab}$ & $128,4 \mathrm{~b}$ & $196,0 \mathrm{bc}$ \\
12 & $75,1 \mathrm{bc}$ & $91,7 \mathrm{bc}$ & $110,1 \mathrm{ab}$ & $128,8 \mathrm{~b}$ & $182,6 \mathrm{~b}$ \\
13 & $104,4 \mathrm{~d}$ & $128,6 \mathrm{~d}$ & $142,0 \mathrm{c}$ & $179,9 \mathrm{~d}$ & $229,2 \mathrm{c}$ \\
14 & $58,2 \mathrm{a}$ & $72,9 \mathrm{a}$ & $91,3 \mathrm{a}$ & $104,9 \mathrm{a}$ & $133,8 \mathrm{a}$ \\
15 & $83,8 \mathrm{c}$ & $105,1 \mathrm{c}$ & $120,9 \mathrm{bc}$ & $150,2 \mathrm{c}$ & $201,2 \mathrm{bc}$ \\
CV\% & 7,1 & 6,9 & 10,6 & 6,9 & 8,9 \\
\hline
\end{tabular}

* Comparação de médias dentro de cada coluna (teste de Tukey a 5\% de probabilidade). 
Tabela 15. Cultivar Petroline: condutividade elétrica - embebição de 25 sementes em $75 \mathrm{~mL}$ de água destilada, a $20^{\circ} \mathrm{C}$ (Ano I).

\begin{tabular}{cccccc}
\hline & \multicolumn{5}{c}{ Períodos de embebição } \\
\cline { 2 - 6 } & $1 \mathrm{~h}$ & $2 \mathrm{~h}$ & $4 \mathrm{~h}$ & $8 \mathrm{~h}$ & $24 \mathrm{~h}$ \\
\hline Lotes & $\ldots \ldots \ldots \ldots \ldots \ldots \ldots \ldots \ldots \ldots \ldots \ldots \ldots \ldots \ldots \ldots \ldots \ldots \ldots \ldots \ldots \ldots \ldots \ldots \ldots \ldots \ldots \ldots \ldots \ldots \ldots \ldots \ldots \ldots \ldots \ldots \ldots \ldots \ldots$ \\
10 & $60,3 \mathrm{bc} *$ & $74,2 \mathrm{bc}$ & $90,8 \mathrm{~b}$ & $110,7 \mathrm{~b}$ & $146,1 \mathrm{~b}$ \\
11 & $56,8 \mathrm{ab}$ & $72,0 \mathrm{~b}$ & $91,2 \mathrm{~b}$ & $106,5 \mathrm{~b}$ & $139,3 \mathrm{~b}$ \\
12 & $75,1 \mathrm{~d}$ & $87,3 \mathrm{c}$ & $111,9 \mathrm{c}$ & $126,0 \mathrm{~b}$ & $140,1 \mathrm{~b}$ \\
13 & $71,2 \mathrm{~cd}$ & $85,0 \mathrm{bc}$ & $102,2 \mathrm{bc}$ & $124,8 \mathrm{~b}$ & $169,7 \mathrm{~b}$ \\
14 & $43,6 \mathrm{a}$ & $51,6 \mathrm{a}$ & $64,4 \mathrm{a}$ & $77,7 \mathrm{a}$ & $101,8 \mathrm{a}$ \\
15 & $60,2 \mathrm{bc}$ & $70,9 \mathrm{~b}$ & $89,6 \mathrm{~b}$ & $101,7 \mathrm{ab}$ & $154,4 \mathrm{~b}$ \\
$\mathrm{CV} \%$ & 10,3 & 8,5 & 9,6 & 10,0 & 10,6 \\
\hline
\end{tabular}

* Comparação de médias dentro de cada coluna (teste de Tukey a 5\% de probabilidade).

Tabela 16. Cultivar Petroline: condutividade elétrica - embebição de 50 sementes em $75 \mathrm{~mL}$ de água destilada, a $20^{\circ} \mathrm{C}$ (Ano I).

\begin{tabular}{cccccc}
\hline & \multicolumn{5}{c}{ Períodos de embebição } \\
\cline { 2 - 6 } & $1 \mathrm{~h}$ & $2 \mathrm{~h}$ & $4 \mathrm{~h}$ & $8 \mathrm{~h}$ & $24 \mathrm{~h}$ \\
\hline Lotes & $\ldots \ldots \ldots \ldots \ldots \ldots \ldots \ldots \ldots \ldots \ldots \ldots \ldots \ldots \ldots \ldots \ldots \ldots \ldots \ldots \ldots \ldots \ldots \ldots \ldots \ldots \ldots \ldots \ldots \ldots \ldots \ldots \ldots \ldots \ldots \ldots \ldots \ldots \ldots \ldots$ \\
10 & $55,6 \mathrm{bc} *$ & $68,2 \mathrm{bc}$ & $86,8 \mathrm{bc}$ & $104,4 \mathrm{bc}$ & $121,5 \mathrm{ab}$ \\
11 & $50,8 \mathrm{~b}$ & $61,5 \mathrm{~b}$ & $77,6 \mathrm{~b}$ & $97,1 \mathrm{~b}$ & $145,9 \mathrm{bc}$ \\
12 & $55,8 \mathrm{bc}$ & $64,2 \mathrm{~b}$ & $80,8 \mathrm{~b}$ & $98,9 \mathrm{~b}$ & $127,8 \mathrm{~b}$ \\
13 & $65,3 \mathrm{c}$ & $77,8 \mathrm{c}$ & $98,7 \mathrm{c}$ & $120,9 \mathrm{c}$ & $163,9 \mathrm{c}$ \\
14 & $38,5 \mathrm{a}$ & $44,6 \mathrm{a}$ & $59,0 \mathrm{a}$ & $76,1 \mathrm{a}$ & $97,6 \mathrm{a}$ \\
15 & $56,3 \mathrm{bc}$ & $68,3 \mathrm{bc}$ & $83,7 \mathrm{~b}$ & $102,1 \mathrm{~b}$ & $135,0 \mathrm{~b}$ \\
$\mathrm{CV} \%$ & 8,7 & 9,3 & 8,1 & 7,8 & 9,7 \\
\hline
\end{tabular}

\footnotetext{
* Comparação de médias dentro de cada coluna (teste de Tukey a 5\% de probabilidade).
} 
Para esse cultivar, constatou-se que, com exceção do procedimento em que se utilizaram 25 sementes embebidas em $75 \mathrm{~mL}$ de água destilada, cujos resultados estão apresentados na Tabela 15, os quais indicaram o lote 12 como de potencial inferior, em todos os demais, o lote 14 apresentou maior potencial fisiológico e, o lote 13, qualidade inferior.

Estes resultados concordam com os testes de germinação, de classificação do vigor de plântulas e de frio, apresentados na Tabela 4, ao apontar o lote 14 como o de maior vigor e, com os testes de emergência de plântulas em casa de vegetação e em campo, os quais além de também terem detectado o melhor desempenho do lote 14, indicaram o potencial inferior do lote 13.

Pode-se verificar, contudo que, para este cultivar, houve uniformidade das informações proporcionadas pelo teste, em todos os procedimentos e períodos avaliados, ocorrendo significativa liberação de eletrólitos durante as primeiras horas de embebição.

Essa constatação está de acordo com as observações de Vieira \& Krzyzanowski (1999), os quais afirmam que, para espécies de sementes consideradas pequenas, como a maioria das hortaliças, o período de embebição durante a condução do teste, pode ser reduzido. Porém, embora não sejam relatados estudos que comprovem a eficiência do teste de condutividade elétrica em sementes de cebola, a partir de leituras efetuadas em poucas horas de embebição, pesquisas realizadas com outras espécies de sementes pequenas como alface (Guimarães et al., 1993), cenoura (Andrade et al., 1995), maxixe (Torres et al., 1998) e tomate (Rodo et al., 1998), revelaram que resultados promissores foram obtidos em avaliações após quatro horas de embebição.

É importante salientar, também, que embora todos os procedimentos avaliados tenham destacado os lotes de melhor e pior desempenho, comparáveis inclusive com o teste de emergência de plântulas em campo, verificou-se que o uso de 50 sementes (Tabelas 12, 14 e 16), conduziu à maior sensibilidade do 
teste, em comparação ao uso de 25 sementes (Tabelas 11, 13 e 15). Assim, o uso de quatro repetições de 50 sementes, conforme recomendado por Loeffler (1988), seria o mais indicado.

Outro fato a ser considerado é de que, para o cultivar Petroline, o teste de condutividade elétrica proporcionou diferenças mais nítidas entre os lotes, em relação ao cultivar Aurora. Esta diferença entre resposta de cultivares pode estar associada a diferenças mais estreitas detectadas na qualidade inicial dos lotes do cultivar Aurora, a partir dos resultados dos testes de germinação, de frio e de emergência de plântulas em casa de vegetação, apresentados na Tabela 3 ou, ainda, a características genéticas, próprias de cada cultivar.

Na Tabela 17 são apresentados, para o cultivar Aurora, os resultados dos testes de envelhecimento acelerado e de deterioração controlada.

Verificou-se que os procedimentos dos testes de envelhecimento acelerado tradicional (72 horas), de envelhecimento acelerado com solução salina (72 horas) e de deterioração controlada ( $24 \%$ de água), indicaram, através de diferenças estatisticamente significativas, o lote 4 como o de melhor qualidade; o procedimento do teste com solução salina, ainda, indicou o lote 2 como de qualidade inferior, de maneira semelhante aos testes de classificação do vigor de plântulas e de emergência de plântulas em campo, apresentados na Tabela 3, embora discordando dos resultados obtidos nos vários procedimentos avaliados para o teste de condutividade elétrica (Tabelas 5 a 10), os quais, de uma maneira geral, apontaram os lotes 5 e 6 como de maior potencial.

Para os procedimentos dos testes de envelhecimento acelerado tradicional (48 horas) e de deterioração controlada (19\% de água), observou-se que, apesar de ocorrerem algumas diferenças estatísticas, os resultados evidenciaram somente a qualidade inferior do lote 2 , enquanto no envelhecimento acelerado com solução salina (48 horas), não foram verificadas diferenças significativas entre os lotes. 
Tabela 17. Cultivar Aurora: resultados dos testes de envelhecimento acelerado tradicional (EAT), envelhecimento acelerado com solução salina (EASS) e deterioração controlada (DC), em seis lotes de sementes de cebola (Ano I).

\begin{tabular}{|c|c|c|c|c|c|c|}
\hline & \multicolumn{2}{|c|}{ EAT } & \multicolumn{2}{|c|}{ EASS } & \multicolumn{2}{|c|}{$\mathrm{DC}$} \\
\hline & $48 \mathrm{~h}$ & $72 \mathrm{~h}$ & $48 \mathrm{~h}$ & $72 \mathrm{~h}$ & $19 \%$ & $24 \%$ \\
\hline Lotes & ....... & ...... & $\cdots$ & & . & $\ldots \ldots \ldots$ \\
\hline 1 & $91 \mathrm{a}^{*}$ & $89 \mathrm{~b}$ & $77 \mathrm{a}$ & $67 \mathrm{bc}$ & $75 a b$ & $70 \mathrm{~b}$ \\
\hline 2 & $81 \mathrm{~b}$ & $89 \mathrm{~b}$ & $72 \mathrm{a}$ & $54 \mathrm{c}$ & $67 \mathrm{~b}$ & $73 \mathrm{ab}$ \\
\hline 3 & $87 \mathrm{ab}$ & $95 \mathrm{ab}$ & $81 \mathrm{a}$ & $78 \mathrm{ab}$ & $87 \mathrm{a}$ & $83 \mathrm{ab}$ \\
\hline 4 & $86 a b$ & $99 \mathrm{a}$ & $80 \mathrm{a}$ & $81 \mathrm{a}$ & $75 \mathrm{ab}$ & $86 \mathrm{a}$ \\
\hline 5 & $87 \mathrm{ab}$ & $97 \mathrm{ab}$ & $80 \mathrm{a}$ & $72 a b$ & $73 \mathrm{ab}$ & $75 a b$ \\
\hline 6 & $90 \mathrm{ab}$ & $98 \mathrm{a}$ & $80 \mathrm{a}$ & $66 \mathrm{bc}$ & $79 \mathrm{ab}$ & $76 \mathrm{ab}$ \\
\hline CV\% & 4,9 & 5,7 & 6,4 & 6,5 & 7,8 & 7,1 \\
\hline
\end{tabular}

* Comparação de médias dentro de cada coluna (teste de Tukey a 5\% de probabilidade).

Dessa forma, os resultados obtidos para o teste de envelhecimento acelerado, indicaram que o período de 72 horas separou os lotes em diferentes níveis de qualidade de maneira mais eficiente que o de 48 horas, bem como a metodologia com o uso de solução salina.

Cabe ressaltar que o período de 72 horas é sugerido pela ISTA (1995) para a condução deste teste na avaliação do vigor de sementes de cebola. Também, em relação às condições em que os testes foram conduzidos, constatouse que o grau de umidade inicial apresentou uniformidade entre os lotes avaliados, com variação de no máximo $1,1 \%$ (5,6 a 6,7\%) entre os mesmos. 
Os resultados dos procedimentos estudados para o teste de envelhecimento acelerado tradicional indicaram que o grau de umidade das sementes apresentou variações de 3,9 (33,6 a 37,5\%) e 2,5\% (37,2 a 39,7\%) entre os lotes, respectivamente, para os períodos de 48 e 72 horas, estando estas dentro do limite considerado tolerável para condução de teste, ou seja, 3 a 4\%, segundo Marcos Filho (1999b).

No entanto, o grau de umidade das sementes, verificado após o teste de envelhecimento acelerado com solução salina, foi menor e mais uniforme, após os períodos avaliados, do que os observados para as envelhecidas pelo método tradicional, ou seja, variações de 0,3 (11,9 a 12,2\%) e 0,5\% (11,7 a 12,2\%) foram registradas para os períodos de 48 e 72 horas, respectivamente, revelando que o método retardou e reduziu a absorção de água das sementes.

Para o teste de deterioração controlada, verificou-se que foi atingida a uniformidade esperada para os lotes avaliados, sendo observados valores de 18,5 a $19,0 \%$ e 23,7 a $24,2 \%$, respectivamente, para os procedimentos em que se ajustou o teor de água para 19 e 24\%. Entretanto, observa-se na Tabela 17, que o procedimento, no qual as sementes foram umedecidas a $24 \%$ de água, provocou maiores diferenças na intensidade de deterioração das mesmas, revelando a alta qualidade do lote 4, o que não foi observado para o outro procedimento (sementes com $19 \%$ de água).

Para o cultivar Petroline, observam-se na Tabela 18, os resultados dos testes de envelhecimento acelerado e de deterioração controlada.

Em relação aos procedimentos estudados para o teste de envelhecimento acelerado, observou-se que, para o envelhecimento tradicional (48 horas), os lotes 11, 12 e 14 foram identificados como de alta qualidade e os lotes 10, 13 e 15 como de baixa qualidade. 
Tabela 18. Cultivar Petroline: resultados dos testes de envelhecimento acelerado tradicional (EAT), envelhecimento acelerado com solução salina (EASS) e deterioração controlada (DC), em seis lotes de sementes de cebola (Ano I).

\begin{tabular}{|c|c|c|c|c|c|c|}
\hline & \multicolumn{2}{|c|}{ EAT } & \multicolumn{2}{|c|}{ EASS } & \multicolumn{2}{|c|}{$\overline{\mathrm{DC}}$} \\
\hline & $48 \mathrm{~h}$ & $72 \mathrm{~h}$ & $48 \mathrm{~h}$ & $72 \mathrm{~h}$ & $19 \%$ & $24 \%$ \\
\hline Lotes & $\ldots . .$. & $\ldots \ldots \ldots$ & ……........ & ........... & ... & $\ldots \ldots . . . . .$. \\
\hline 10 & $74 b^{*}$ & $77 \mathrm{~b}$ & $68 \mathrm{bc}$ & $64 c$ & $64 \mathrm{bc}$ & $52 \mathrm{~d}$ \\
\hline 11 & $86 \mathrm{a}$ & $91 \mathrm{ab}$ & $85 \mathrm{a}$ & $79 a b$ & $83 \mathrm{a}$ & $68 a b c$ \\
\hline 12 & $87 \mathrm{a}$ & $85 \mathrm{ab}$ & $77 \mathrm{abc}$ & $66 \mathrm{c}$ & $80 a b$ & $62 \mathrm{bcd}$ \\
\hline 13 & $71 \mathrm{~b}$ & $80 \mathrm{~b}$ & $66 \mathrm{c}$ & $57 \mathrm{c}$ & $56 \mathrm{c}$ & $58 \mathrm{~cd}$ \\
\hline 14 & $89 \mathrm{a}$ & $94 \mathrm{a}$ & $87 \mathrm{a}$ & $80 \mathrm{a}$ & $79 \mathrm{ab}$ & $78 \mathrm{a}$ \\
\hline 15 & $74 \mathrm{~b}$ & $87 \mathrm{ab}$ & $79 \mathrm{ab}$ & $67 \mathrm{bc}$ & $76 \mathrm{ab}$ & $70 \mathrm{ab}$ \\
\hline CV\% & 5,2 & 5,8 & 7,6 & 6,5 & 7,5 & 5,8 \\
\hline
\end{tabular}

* Comparação de médias dentro de cada coluna (teste de Tukey a 5\% de probabilidade).

Por outro lado, para os testes de envelhecimento acelerado tradicional (72 horas), de envelhecimento acelerado com solução salina (48 e 72 horas) e de deterioração controlada ( $24 \%$ de água), foram detectadas diferenças mais evidentes no potencial fisiológico dos lotes; estes testes, além de apontarem o maior vigor do lote 14 e o pior desempenho do lote 13 , de maneira semelhante aos testes de emergência de plântulas em casa de vegetação e em campo, apresentados na Tabela 4, e aos procedimentos do teste de condutividade elétrica, apresentados nas Tabelas 11 a 16, ainda indicaram desempenho inferior para o lote 10 , como constatado nos testes de classificação do vigor de plântulas e de emergência de plântulas em casa de vegetação (Tabela 4). 
No entanto, os procedimentos dos testes de envelhecimento acelerado com solução salina (48 horas) e de deterioração controlada (19\% de água), detectaram o lote 11 como de alta qualidade, não diferindo estatisticamente do 14 , fato também observado para o teste de emergência de plântulas em casa de vegetação, apresentado na Tabela 4.

Analisando-se os resultados dos procedimentos estudados para o teste de deterioração controlada, verificou-se que o mesmo foi realizado com lotes de sementes em condições uniformes quanto ao conteúdo de água, segundo proposto por Matthews (1980), ou seja, foram alcançados valores de 18,8 a 19,2\% e 23,6 a $24,0 \%$ para os ajustes de 19 e $24 \%$ de água, respectivamente. Para este teste, observou-se ainda que, no procedimento em que as sementes foram umedecidas até atingirem $24 \%$ de água, as diferenças entre os lotes foram mais evidentes, em relação ao tratamento em que as sementes foram umedecidas até $19 \%$ de água, como também observado para o cultivar Aurora.

Quanto ao grau de umidade inicial, os lotes apresentaram uniformidade entre si, variando apenas $0,4 \%$ (4,8 a 5,2\%); entretanto, após a exposição das sementes ao teste de envelhecimento acelerado tradicional, houve variações mais acentuadas, verificando-se diferenças de 4,4\% (37,0 a 41,4\%) para o período de 48 horas e de $6 \%$ (38,1 a 44,1\%) para o período de 72 horas; estes valores extrapolaram o limite de 3 a $4 \%$ nas variações do grau de umidade após a condução do teste, indicado por Marcos Filho (1999b).

Assim, certifica-se de que o de teste envelhecimento acelerado tradicional não foi conduzido em condições uniformes, havendo maior insegurança em relação às informações proporcionadas pelo mesmo.

Porém, para o período de 72 horas, apesar de verificarem-se variações acentuadas no grau de umidade determinado após a condução do teste, este indicou diferenças entre os lotes de maneira semelhante aos testes de emergência 
de plântulas em casa de vegetação e em campo (Tabela 4), acusando o maior potencial do lote 14 e o pior desempenho dos lotes 10 e 13 .

Também, é interessante observar que os lotes que atingiram, respectivamente, maior e menor conteúdo de água, foram aqueles com melhor e pior desempenho, respectivamente.

Portanto, como verificado em pesquisa realizada com sementes de cebola (Powell, 1995), após 24 horas de envelhecimento acelerado (100\% de umidade relativa a $45^{\circ} \mathrm{C}$ ) houve variação acentuada no grau de umidade, de 11,8 a $24,0 \%$, sendo que a germinação após este período foi inversamente proporcional ao grau de umidade alcançado, isto é, lotes que absorveram água mais rapidamente, atingindo grau de umidade elevado, após 24 horas de exposição às condições do teste, apresentaram germinação inferior, indicando maior grau de deterioração, em relação aos lotes que absorveram água mais lentamente. Isto também foi revelado na presente pesquisa para sementes do cultivar Petroline, não havendo desta forma, segurança em indicar um dos procedimentos avaliados para detectar diferenças de vigor entre lotes deste cultivar, mesmo tendo o período de 72 horas identificado os lotes de maior e menor desempenho.

Por outro lado, o envelhecimento acelerado com solução salina promoveu a redução da intensidade de captação de água pelas sementes durante o período de envelhecimento, de modo que, ao final dos períodos estudados, as mesmas atingiram graus de umidade uniformes e sensivelmente inferiores aos verificados com o uso do método tradicional; as variações obtidas entre os lotes foram de $0,9 \%$, para ambos períodos avaliados, ou seja, 12,0 a 12,9\% (48 horas) e 12,4 a 13,3 (72 horas).

Diante disto, foi constatada a viabilidade do uso da solução salina, proposta por Jianhua \& McDonald (1996), no controle da absorção de água pelas sementes e na avaliação do vigor; vale salientar que este fato foi observado para os dois cultivares em estudo, porém, apesar de não haver nenhum trabalho 
relatando o uso deste procedimento para sementes de cebola, foram constatados resultados consistentes para sementes de pimentão (Panobianco \& Marcos Filho, 1999), cenoura (Rodo et al., 2000), pepino (Bhering et al., 2000) e tomate (Panobianco \& Marcos Filho, 2001).

\subsubsection{Considerações gerais}

Diante dos resultados obtidos na avaliação do potencial fisiológico das sementes do cultivar Aurora, ficou evidenciado o melhor desempenho do lote 4, a partir dos testes de primeira contagem do teste de germinação, de classificação do vigor de plântulas, de envelhecimento acelerado tradicional e com solução salina (72 horas) e de deterioração controlada ( $24 \%$ de água); ainda, os testes de classificação do vigor de plântulas e de envelhecimento acelerado com solução salina (72 horas), detectaram o menor potencial do lote 2, de maneira semelhante ao teste de emergência de plântulas em campo.

Para o cultivar Petroline, verificou-se que os testes de germinação e de frio apontaram o lote 14 como o de maior qualidade, enquanto que, os testes de classificação do vigor de plântulas e de condutividade elétrica, além de também indicarem elevado potencial para este lote, detectaram o menor vigor do lote 10, assim como os testes de envelhecimento acelerado tradicional e com uso de solução salina (72 horas) e de deterioração controlada (24\% de água); estes ainda, acusaram o pior desempenho do 13, de maneira compatível aos testes de emergência de plântulas em casa de vegetação e em campo.

Portanto, considerando-se ambos cultivares, constatou-se, durante o primeiro ano experimental, que o teste de envelhecimento acelerado com uso de solução salina (72 horas), foi considerado o mais eficiente na identificação de diferenças entre os lotes, apresentando relação mais estreita com o teste de emergência de plântulas em campo. 
No entanto, constataram-se diferenças mais evidentes entre os lotes de sementes do cultivar Petroline, em relação ao cultivar Aurora; assim, para o segundo ano experimental, optou-se pela realização de envelhecimento artificial dos lotes deste cultivar, buscando-se maior diferenciação entre os mesmos e, consequentemente, maior sensibilidade dos métodos na avaliação do potencial fisiológico das sementes, a fim de se alcançar os objetivos propostos neste estudo.

\subsubsection{Avaliação do desempenho das plantas}

Os resultados apresentados e discutidos a seguir, referentes à avaliação do desempenho das plantas, foram obtidos para os sistemas de semeadura direta e de transplante de mudas.

\subsubsection{Sistema de semeadura direta}

Para este sistema, encontram-se, respectivamente, nas Tabelas 19, 20 e 21, os resultados de altura de plantas, diâmetro na região do colo e massa de matéria seca, para o cultivar Aurora; não houve, porém, diferenças significativas entre os lotes, para todos os parâmetros, em todas as épocas de avaliação.

Esta semelhança constatada entre os lotes deste cultivar, resultou das diferenças estreitas no potencial fisiológico das sementes, detectadas nos testes de germinação, de frio e de emergência de plântulas em casa de vegetação. Assim, para o cultivar Aurora, não foi possível verificarem-se relações entre o vigor das sementes e o desempenho das plantas em campo, no sistema de semeadura direta. 
Tabela 19. Cultivar Aurora: resultados de altura de plantas, no sistema de semeadura direta, em seis lotes de sementes de cebola (Ano I).

\begin{tabular}{|c|c|c|c|c|c|}
\hline & \multicolumn{5}{|c|}{ Épocas de avaliação } \\
\hline & $28 \mathrm{~d}$ & $56 \mathrm{~d}$ & $84 d$ & $98 \mathrm{~d}$ & $112 d$ \\
\hline Lotes & 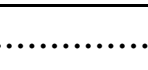 & ㄴ..… & $\ldots \mathrm{cm} \mathrm{...}$ & . & $\ldots$ \\
\hline 1 & $9,3 \mathrm{a}^{*}$ & $39,9 \mathrm{a}$ & $53,3 \mathrm{a}$ & $53,5 \mathrm{a}$ & $59,0 \mathrm{a}$ \\
\hline 2 & $8,8 \mathrm{a}$ & $37,0 \mathrm{a}$ & $50,7 \mathrm{a}$ & 56,9 a & $62,3 \mathrm{a}$ \\
\hline 3 & $9,1 \mathrm{a}$ & $40,2 \mathrm{a}$ & $54,6 \mathrm{a}$ & $58,5 \mathrm{a}$ & $62,3 \mathrm{a}$ \\
\hline 4 & $8,8 \mathrm{a}$ & $40,6 \mathrm{a}$ & $47,7 \mathrm{a}$ & $56,8 \mathrm{a}$ & $59,0 \mathrm{a}$ \\
\hline 5 & $8,8 \mathrm{a}$ & $37,4 \mathrm{a}$ & $52,4 \mathrm{a}$ & $58,3 \mathrm{a}$ & $64,5 \mathrm{a}$ \\
\hline 6 & $8,4 \mathrm{a}$ & $36,8 \mathrm{a}$ & $49,2 \mathrm{a}$ & $52,2 \mathrm{a}$ & $61,4 \mathrm{a}$ \\
\hline CV\% & 5,9 & 7,1 & 7,9 & 8,8 & 6,3 \\
\hline
\end{tabular}

* Comparação de médias dentro de cada coluna (teste de Tukey a 5\% de probabilidade).

Tabela 20. Cultivar Aurora: resultados de diâmetro na região do colo, no sistema de semeadura direta, em seis lotes de sementes de cebola (Ano I).

\begin{tabular}{cccccc}
\hline & \multicolumn{5}{c}{ Épocas de avaliação } \\
\cline { 2 - 6 } & $28 \mathrm{~d}$ & $56 \mathrm{~d}$ & $84 \mathrm{~d}$ & $98 \mathrm{~d}$ & $112 \mathrm{~d}$ \\
\hline Lotes & $\ldots \ldots \ldots \ldots \ldots \ldots \ldots \ldots \ldots \ldots \ldots \ldots \ldots \ldots \ldots \ldots \ldots \ldots \ldots \ldots \ldots \ldots \ldots \ldots \ldots \ldots \ldots \ldots \ldots \ldots \ldots \ldots \ldots \ldots \ldots \ldots \ldots \ldots \ldots \ldots \ldots \ldots \ldots \ldots \ldots \ldots$ \\
1 & $0,18 \mathrm{~cm} \ldots \ldots \ldots \ldots \ldots$ & $0,63 \mathrm{a}$ & $1,52 \mathrm{a}$ & $1,94 \mathrm{a}$ & $3,26 \mathrm{a}$ \\
2 & $0,17 \mathrm{a}$ & $0,66 \mathrm{a}$ & $1,54 \mathrm{a}$ & $2,17 \mathrm{a}$ & $3,20 \mathrm{a}$ \\
3 & $0,18 \mathrm{a}$ & $0,68 \mathrm{a}$ & $1,67 \mathrm{a}$ & $1,99 \mathrm{a}$ & $2,97 \mathrm{a}$ \\
4 & $0,17 \mathrm{a}$ & $0,68 \mathrm{a}$ & $1,60 \mathrm{a}$ & $1,98 \mathrm{a}$ & $2,86 \mathrm{a}$ \\
5 & $0,19 \mathrm{a}$ & $0,63 \mathrm{a}$ & $1,58 \mathrm{a}$ & $2,04 \mathrm{a}$ & $2,86 \mathrm{a}$ \\
6 & $0,19 \mathrm{a}$ & $0,68 \mathrm{a}$ & $1,54 \mathrm{a}$ & $1,84 \mathrm{a}$ & $3,31 \mathrm{a}$ \\
$\mathrm{CV} \%$ & 8,2 & 7,0 & 8,4 & 10,1 & 13,4 \\
\hline
\end{tabular}

* Comparação de médias dentro de cada coluna (teste de Tukey a 5\% de probabilidade). 
Tabela 21. Cultivar Aurora: resultados de massa de matéria seca, no sistema de semeadura direta, em seis lotes de sementes de cebola (Ano I).

\begin{tabular}{cccccc}
\hline & \multicolumn{5}{c}{ Épocas de avaliação } \\
\cline { 2 - 6 } & $28 \mathrm{~d}$ & $56 \mathrm{~d}$ & $84 \mathrm{~d}$ & $98 \mathrm{~d}$ & $112 \mathrm{~d}$ \\
\hline Lotes & $\ldots \ldots \ldots \ldots \ldots \ldots \ldots \ldots \ldots \ldots \ldots \ldots \ldots \ldots \ldots \ldots \ldots \ldots \ldots \ldots \ldots \ldots \ldots \ldots \ldots \ldots \ldots \ldots \ldots \ldots \ldots \ldots \ldots \ldots \ldots \ldots \ldots \ldots \ldots \ldots \ldots \ldots \ldots \ldots \ldots \ldots \ldots \ldots \ldots$ \\
1 & $0,013 \mathrm{a}^{*}$ & $0,389 \mathrm{a}$ & $2,938 \mathrm{a}$ & $4,339 \mathrm{a}$ & $7,232 \mathrm{a}$ \\
2 & $0,012 \mathrm{a}$ & $0,384 \mathrm{a}$ & $2,660 \mathrm{a}$ & $5,145 \mathrm{a}$ & $7,868 \mathrm{a}$ \\
3 & $0,013 \mathrm{a}$ & $0,385 \mathrm{a}$ & $3,101 \mathrm{a}$ & $4,816 \mathrm{a}$ & $6,950 \mathrm{a}$ \\
4 & $0,012 \mathrm{a}$ & $0,396 \mathrm{a}$ & $2,383 \mathrm{a}$ & $4,376 \mathrm{a}$ & $6,444 \mathrm{a}$ \\
5 & $0,012 \mathrm{a}$ & $0,334 \mathrm{a}$ & $2,921 \mathrm{a}$ & $4,735 \mathrm{a}$ & $7,221 \mathrm{a}$ \\
6 & $0,012 \mathrm{a}$ & $0,388 \mathrm{a}$ & $2,497 \mathrm{a}$ & $3,808 \mathrm{a}$ & $7,868 \mathrm{a}$ \\
CV\% & 6,6 & 13,6 & 18,1 & 21,6 & 22,3 \\
\hline
\end{tabular}

* Comparação de médias dentro de cada coluna (teste de Tukey a 5\% de probabilidade).

Entretanto, é interessante verificar, além dos resultados apresentados nas Tabelas, as informações nas Figuras 1, 2 e 3, referentes ao primeiro ano experimental, as quais podem auxiliar a melhor compreensão da evolução do desenvolvimento da cultura, em todos os parâmetros avaliados; porém, como foi observada semelhança entre ambos cultivares e sistemas de cultivo em estudo, serão destacadas somente as Figuras correspondentes ao cultivar Aurora para o sistema de semeadura direta.

Para a altura de plantas (Tabela 19 e Figura 1), observou-se que, ao longo das épocas de avaliação, houve crescimento inicial lento a partir da emergência das plântulas, verificado aos 28 dias após a semeadura. Aos 56 dias, este parâmetro aumentou de maneira considerável, estabilizando-se aos 84 dias, em função do início do processo de bulbificação, constatado pelo aumento do diâmetro na região do colo, nesta mesma época (Tabela 20 e Figura 2). 


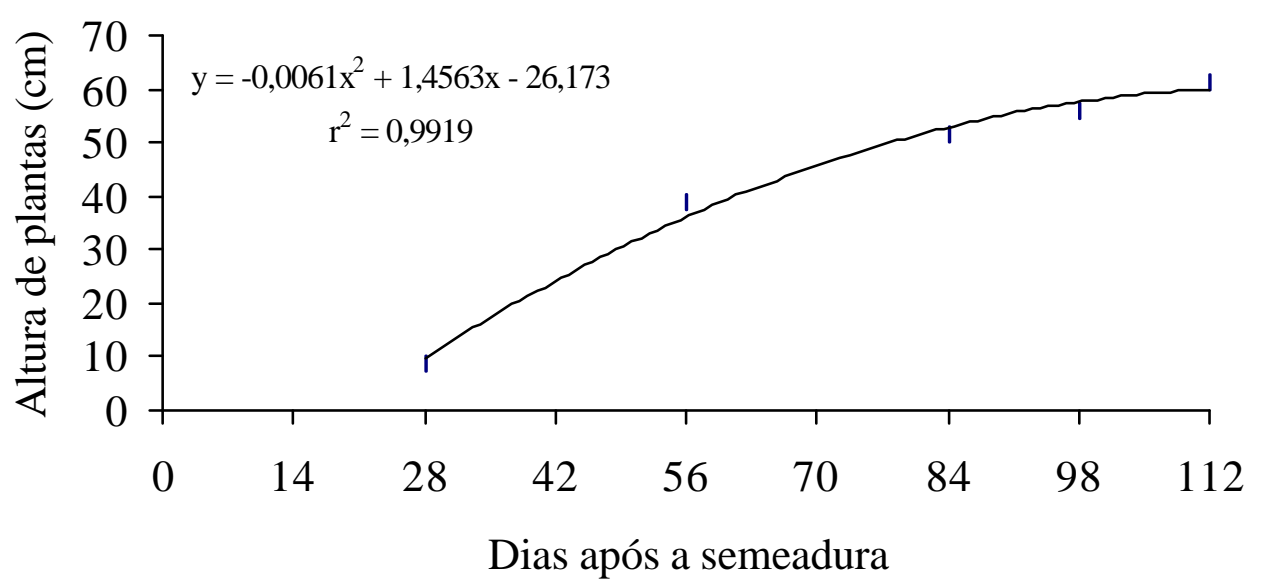

Figura 1 - Cultivar Aurora: análise de regressão polinomial para altura de plantas, no sistema de semeadura direta (Ano I).

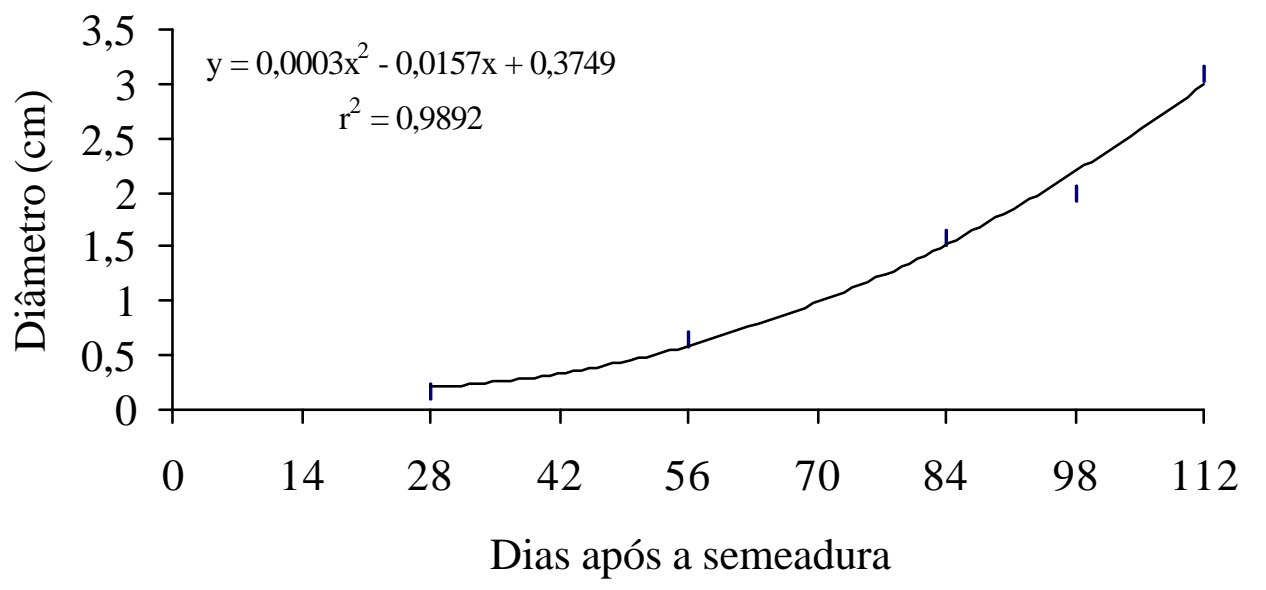

Figura 2 - Cultivar Aurora: análise de regressão polinomial para diâmetro na região do colo, no sistema de semeadura direta (Ano I). 
Vale salientar que, a partir dos 84 dias após a semeadura, foram registradas temperaturas em torno de $21^{\circ} \mathrm{C}$ e fotoperíodo de 12,5 horas de luz; estas seriam as condições climáticas favoráveis para o inicio da diferenciação dos bulbos. De acordo com Fontes (1998), a primeira etapa do desenvolvimento das plantas de cebola é caracterizada pelo crescimento relativamente lento, seguido pelo rápido incremento da parte aérea, o qual culmina com o início do estádio de bulbificação; isto foi revelado neste estudo, para este cultivar.

Em relação ao acúmulo de matéria seca, pelos resultados apresentados na Tabela 21 e Figura 3, verificou-se que não houve acréscimo até aos 56 dias após a semeadura, ocorrendo maior aumento deste parâmetro a partir dos 84 dias, coincidindo também, com o início do processo de formação dos bulbos.

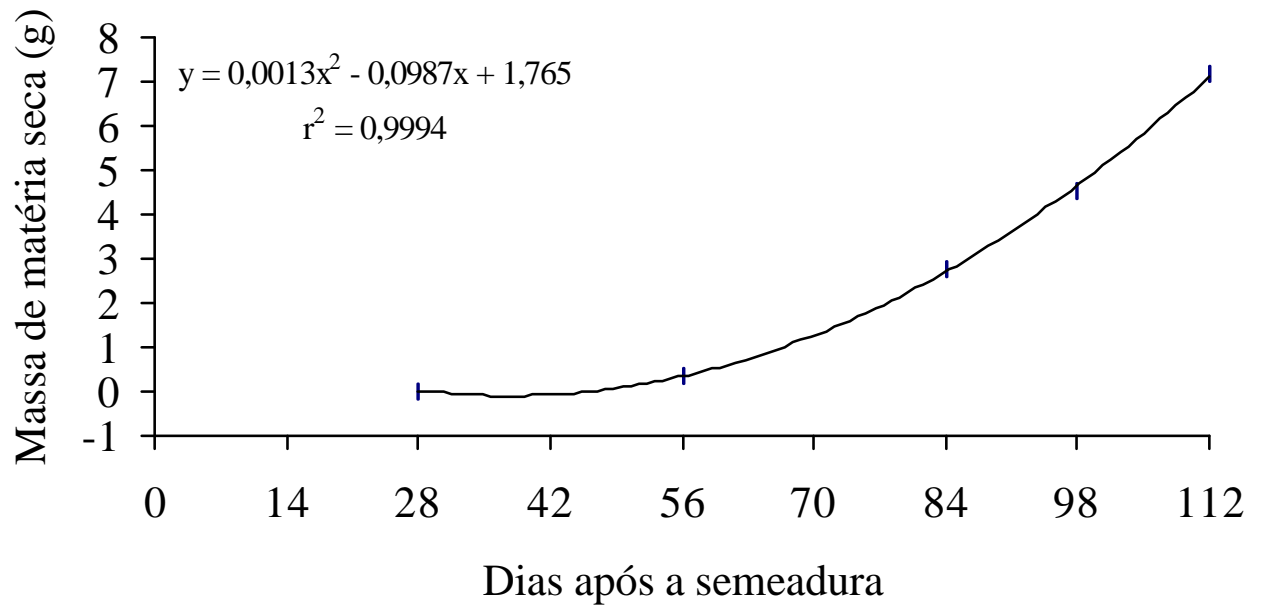

Figura 3 - Cultivar Aurora: análise de regressão polinomial para massa de matéria seca, no sistema de semeadura direta (Ano I). 
Para o cultivar Petroline, as determinações de altura de plantas não acusaram diferenças significativas entre os lotes de sementes (Tabela 22), da mesma maneira como verificado para o cultivar Aurora.

Observou-se, ainda, menor crescimento inicial na altura de plantas, até aos 56 após a semeadura, porém, a partir dos 84 dias houve maior impulso no crescimento, o qual prolongou-se até aos 112 dias; como destacado para o cultivar Aurora, provavelmente este seria o início do processo de bulbificação.

Tabela 22. Cultivar Petroline: resultados de altura de plantas, no sistema de semeadura direta, em seis lotes de sementes de cebola (Ano I).

\begin{tabular}{cccccc}
\hline & \multicolumn{5}{c}{ Épocas de avaliação } \\
\cline { 2 - 7 } & $28 \mathrm{~d}$ & $56 \mathrm{~d}$ & $84 \mathrm{~d}$ & $98 \mathrm{~d}$ & $112 \mathrm{~d}$ \\
\hline Lotes & $\ldots \ldots \ldots \ldots \ldots \ldots \ldots \ldots \ldots \ldots \ldots \ldots \ldots \ldots \ldots \ldots \ldots \ldots \ldots \ldots \ldots \ldots \ldots \ldots \ldots \ldots \ldots \ldots \ldots \ldots \ldots \ldots \ldots \ldots \ldots \ldots \ldots \ldots \ldots \ldots \ldots \ldots$ \\
10 & $8,1 \mathrm{a}^{*}$ & $35,5 \mathrm{a}$ & $52,1 \mathrm{a}$ & $56,2 \mathrm{a}$ & $62,3 \mathrm{a}$ \\
11 & $8,8 \mathrm{a}$ & $37,1 \mathrm{a}$ & $56,5 \mathrm{a}$ & $58,6 \mathrm{a}$ & $66,8 \mathrm{a}$ \\
12 & $8,6 \mathrm{a}$ & $36,3 \mathrm{a}$ & $54,9 \mathrm{a}$ & $55,7 \mathrm{a}$ & $62,5 \mathrm{a}$ \\
13 & $7,8 \mathrm{a}$ & $33,7 \mathrm{a}$ & $53,3 \mathrm{a}$ & $61,8 \mathrm{a}$ & $68,5 \mathrm{a}$ \\
14 & $8,8 \mathrm{a}$ & $37,7 \mathrm{a}$ & $55,8 \mathrm{a}$ & $57,3 \mathrm{a}$ & $65,8 \mathrm{a}$ \\
15 & $8,4 \mathrm{a}$ & $36,7 \mathrm{a}$ & $52,4 \mathrm{a}$ & $58,2 \mathrm{a}$ & $68,0 \mathrm{a}$ \\
CV\% & 7,6 & 7,2 & 6,6 & 8,5 & 7,2 \\
\hline * Comparação de médias dentro de cada coluna (teste de Tukey a $5 \%$ de probabilidade).
\end{tabular}

$\mathrm{Na}$ Tabela 23, para os resultados de diâmetro na região do colo, verificaram-se diferenças significativas entre os lotes aos 84 dias após a semeadura, as quais apontaram maior diâmetro para as plantas provenientes do lote 14 e diâmetro inferior, para as do lote 10; no entanto, estas diferenças não se mantiveram até o final do ciclo da cultura. 
Tabela 23. Cultivar Petroline: resultados de diâmetro na região do colo, no sistema de semeadura direta, em seis lotes de sementes de cebola (Ano I).

\begin{tabular}{cccccc}
\hline & \multicolumn{5}{c}{ Épocas de avaliação } \\
\cline { 2 - 6 } & $28 \mathrm{~d}$ & $56 \mathrm{~d}$ & $84 \mathrm{~d}$ & $98 \mathrm{~d}$ & $112 \mathrm{~d}$ \\
\hline Lotes & $\ldots \ldots \ldots \ldots \ldots \ldots \ldots \ldots \ldots \ldots \ldots \ldots \ldots \ldots \ldots \ldots \ldots \ldots \ldots \ldots \ldots \ldots \ldots \ldots \ldots \ldots \ldots \ldots \ldots \ldots \ldots \ldots \ldots \ldots \ldots \ldots \ldots \ldots \ldots \ldots \ldots \ldots \ldots \ldots \ldots \ldots \ldots \ldots \ldots$ \\
10 & $0,18 \mathrm{a}^{*}$ & $0,58 \mathrm{a}$ & $1,48 \mathrm{~b}$ & $1,80 \mathrm{a}$ & $2,66 \mathrm{a}$ \\
11 & $0,19 \mathrm{a}$ & $0,64 \mathrm{a}$ & $1,71 \mathrm{ab}$ & $2,04 \mathrm{a}$ & $2,98 \mathrm{a}$ \\
12 & $0,18 \mathrm{a}$ & $0,62 \mathrm{a}$ & $1,61 \mathrm{ab}$ & $1,92 \mathrm{a}$ & $3,04 \mathrm{a}$ \\
13 & $0,17 \mathrm{a}$ & $0,60 \mathrm{a}$ & $1,64 \mathrm{ab}$ & $2,06 \mathrm{a}$ & $3,10 \mathrm{a}$ \\
14 & $0,19 \mathrm{a}$ & $0,65 \mathrm{a}$ & $1,81 \mathrm{a}$ & $2,03 \mathrm{a}$ & $2,78 \mathrm{a}$ \\
15 & $0,19 \mathrm{a}$ & $0,62 \mathrm{a}$ & $1,61 \mathrm{ab}$ & $1,95 \mathrm{a}$ & $2,91 \mathrm{a}$ \\
$\mathrm{CV} \%$ & 7,0 & 7,2 & 8,9 & 10,6 & 11,6 \\
\hline
\end{tabular}

É importante salientar, que estas informações estão de acordo com os resultados obtidos nos testes de envelhecimento acelerado tradicional e com solução salina ( 72 horas), de deterioração controlada ( $24 \%$ de água) e de emergência de plântulas em casa de vegetação, na avaliação do potencial fisiológico das sementes, os quais indicaram, de maneira confiável, o maior vigor do lote 14 e desempenho inferior para o lote 10.

Complementando, observou-se ainda, na Tabela 23 que, a partir desta mesma época de avaliação (84 dias após a semeadura), foi verificado aumento significativo do diâmetro na região do colo, revelando o início da diferenciação dos bulbos, da mesma forma que no cultivar Aurora.

Em relação à massa de matéria seca, constataram-se aos 28 dias após a semeadura, diferenças estatísticas entre os lotes de sementes, nas quais as plantas oriundas do lote 13 foram identificadas como as que apresentaram menor valor 
em relação a este parâmetro (Tabela 24); o menor potencial fisiológico deste lote foi evidenciado pelos testes de condutividade elétrica, de envelhecimento acelerado tradicional e com solução salina (72 horas), de deterioração controlada (24\% de água) e de emergência de plântulas em casa de vegetação e em campo.

Por outro lado, observou-se a partir destes resultados, que as plantas produziram maior quantidade de fotoassimilados somente a partir dos 84 dias após a semeadura, ou seja, no início da formação dos bulbos, de maneira similar ao verificado para o cultivar Aurora.

Tabela 24. Cultivar Petroline: resultados de massa de matéria seca, no sistema de semeadura direta, em seis lotes de sementes de cebola (Ano I).

\begin{tabular}{|c|c|c|c|c|c|}
\hline & \multicolumn{5}{|c|}{ Épocas de avaliação } \\
\hline & $28 \mathrm{~d}$ & $56 \mathrm{~d}$ & $84 \mathrm{~d}$ & $98 \mathrm{~d}$ & $112 \mathrm{~d}$ \\
\hline Lotes & \multicolumn{5}{|c|}{ 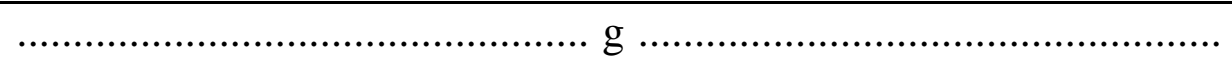 } \\
\hline 10 & $0,011 a b^{*}$ & $0,265 \mathrm{a}$ & $2,359 \mathrm{a}$ & $3,743 \mathrm{~b}$ & $6,014 b$ \\
\hline 11 & $0,013 \mathrm{a}$ & $0,323 \mathrm{a}$ & $3,298 \mathrm{a}$ & $4,989 \mathrm{ab}$ & 8,506 a \\
\hline 12 & $0,013 \mathrm{a}$ & $0,292 \mathrm{a}$ & $2,777 \mathrm{a}$ & $3,975 \mathrm{ab}$ & $7,536 \mathrm{ab}$ \\
\hline 13 & $0,009 \mathrm{~b}$ & $0,267 \mathrm{a}$ & $2,998 \mathrm{a}$ & $5,733 \mathrm{a}$ & 8,993 a \\
\hline 14 & $0,012 \mathrm{a}$ & $0,326 \mathrm{a}$ & $3,328 \mathrm{a}$ & $4,838 \mathrm{ab}$ & $7,620 \mathrm{ab}$ \\
\hline 15 & $0,011 \mathrm{ab}$ & $0,284 \mathrm{a}$ & $2,655 \mathrm{a}$ & $4,515 \mathrm{ab}$ & $7,188 a b$ \\
\hline CV\% & 10,0 & 15,0 & 20,0 & 19,0 & 14,3 \\
\hline
\end{tabular}

* Comparação de médias dentro de cada coluna (teste de Tukey a 5\% de probabilidade).

Diante disto, constatou-se que as plantas de cebola apresentaram capacidade fotossintética limitada no estádio inicial de desenvolvimento, conforme relataram Shadbolt \& Holm (1956) e Wicks (1973). 
Assim, conforme destacaram Ellis (1992) e TeKrony \& Egli (1991), as estruturas da planta presentes na semente são aparentemente importantes apenas para o crescimento inicial da plântula, durante período relativamente curto após a emergência e que a maioria dos tecidos vegetais envolvidos na produção de matéria seca é formada somente após este período; no entanto, foram verificadas diferenças significativas entre os lotes aos 28 dias após a semeadura, de maneira compatível aos resultados de testes que detectaram o potencial fisiológico das sementes, indicando que é possível que o vigor tenha afetado a capacidade da planta em acumular matéria seca neste período.

Porém, aos 98 e 112 dias após a semeadura, também foram encontradas diferenças significativas entre os lotes; entretanto, ao contrário das observações verificadas aos 28 dias, aos 98 e 112 dias evidenciou-se a maior produção de matéria seca para plantas provenientes do lote 13, o qual foi identificado como de menor qualidade pelos testes de avaliação do potencial fisiológico, em laboratório. Contudo, foi apontado menor acúmulo para plantas originadas do lote 10, o qual foi considerado como de menor qualidade nos testes de envelhecimento acelerado tradicional e com solução salina (72 horas), de deterioração controlada (24\% de água) e de emergência de plântulas em casa de vegetação.

Diante disto, constataram-se relações entre o potencial fisiológico dos lotes e o desempenho inicial das plantas do cultivar Petroline, ao contrário do verificado para o cultivar Aurora, conforme relatado anteriormente.

$\mathrm{Na}$ Tabela 25, encontram-se os resultados de avaliação comercial, produção média de bulbos e valor da produção para o cultivar Aurora, onde não foram reveladas diferenças significativas entre os lotes; entretanto, quanto ao valor prático das comparações entre as médias, observaram-se tendências nos resultados de número de bulbos, os quais indicaram o lote 4 como aquele que proporcionou a produção de maior quantidade de bulbos $/ \mathrm{m}^{2}$, corroborando, desta forma, os resultados dos testes de primeira contagem, de classificação do vigor de 
plântulas, de envelhecimento acelerado tradicional e com solução salina (72 horas), de deterioração controlada ( $24 \%$ de água) e de emergência de plântulas em campo, os quais indicaram o maior potencial fisiológico deste lote.

Tabela 25. Cultivar Aurora: resultados de produção e avaliação comercial de bulbos, no sistema de semeadura direta, em seis lotes de sementes de cebola (Ano I).

\begin{tabular}{|c|c|c|c|c|c|}
\hline & Número & Avaliaçã & bulbos & Produção & Valor de \\
\hline & de bulbos & Diâmetro & Massa & média & produção** \\
\hline Lotes & (bulbos $/ \mathrm{m}^{2}$ ) & $(\mathrm{cm})$ & $(\mathrm{g})$ & (t/ha) & (US\$/ha) \\
\hline 1 & $63,00 a^{*}$ & $48,50 \mathrm{a}$ & $66,50 \mathrm{a}$ & $44,10 \mathrm{a}$ & $8820,00 \mathrm{a}$ \\
\hline 2 & $61,69 \mathrm{a}$ & $49,13 \mathrm{a}$ & $68,53 \mathrm{a}$ & $43,70 \mathrm{a}$ & $8740,00 \mathrm{a}$ \\
\hline 3 & $59,50 \mathrm{a}$ & $48,43 \mathrm{a}$ & $65,92 \mathrm{a}$ & $40,20 \mathrm{a}$ & $8040,00 \mathrm{a}$ \\
\hline 4 & 69,13 a & $49,64 \mathrm{a}$ & $67,15 \mathrm{a}$ & $46,30 \mathrm{a}$ & $9260,00 \mathrm{a}$ \\
\hline 5 & $66,94 \mathrm{a}$ & $46,84 \mathrm{a}$ & $59,46 \mathrm{a}$ & $40,80 \mathrm{a}$ & $8160,00 \mathrm{a}$ \\
\hline 6 & $64,75 \mathrm{a}$ & $51,02 \mathrm{a}$ & $74,12 \mathrm{a}$ & $48,40 \mathrm{a}$ & $9680,00 \mathrm{a}$ \\
\hline $\mathrm{CV} \%$ & 24,9 & 7,1 & 20,3 & 37,8 & 37,8 \\
\hline
\end{tabular}

Entretanto, é importante considerar a população de plantas observada após a correção do número de sementes utilizadas para o estabelecimento do estande, em função dos resultados obtidos no teste de germinação.

Assim, neste cultivar, foram verificadas 8 a 10 plantas $/ \mathrm{m}$, para os lotes avaliados, comprovando que o experimento foi conduzido em condições relativamente uniformes quanto à densidade das plantas, embora o lote 4 tenha originado o maior número de plantas. Provavelmente, isto explique o fato deste 
lote ter produzido maior número de bulbos em relação aos demais, pois, segundo Ellis (1992), efeitos indiretos na produtividade final podem ocorrer devido à emergência mais precoce e uniforme de lotes considerados mais vigorosos, além da produção de plântulas com maior crescimento inicial que, conseqüentemente, provocariam diferenças iniciais entre plantas; estas diferenças poderiam manterse ao longo do desenvolvimento da cultura, refletindo-se em diferenças na estatura de plantas e produção de matéria seca.

Diante disso, essas informações são importantes para a obtenção de constatações seguras a respeito da influência do vigor das sementes no desempenho das plantas, especialmente para o sistema de semeadura direta.

Para o cultivar Petroline, foram obtidas 7 a 9 plantas $/ \mathrm{m}$, para os lotes em estudo, durante o estabelecimento do estande e, assim como para o cultivar Aurora, verificou-se uniformidade relativa na população de plantas.

Os resultados das avaliações referentes à produção de bulbos, para o cultivar Petroline, são apresentados na Tabela 26, onde se observou que também não houve diferenças significativas, mas apenas tendências em indicar o lote 14 como o que proporcionou maior número de bulbos, maior diâmetro e massa médios, maior produção média e maior valor de produção, indicando maior rendimento final neste sistema; da mesma maneira, obtiveram-se os menores rendimentos em número de bulbos, produção média e valor da produção para os lotes 10 e 13 .

Estes resultados, embora apenas sob tendências nos valores médios, corresponderam diretamente aos resultados dos testes de envelhecimento acelerado tradicional e com solução salina (72 horas), de deterioração controlada (24\% de água) e de emergência de plântulas em casa de vegetação, os quais indicaram o maior potencial do lote 14 e o menor desempenho dos lotes 10 e 13 . 
Tabela 26. Cultivar Petroline: resultados de produção e avaliação comercial de bulbos, no sistema de semeadura direta, em seis lotes de sementes de cebola (Ano I).

\begin{tabular}{|c|c|c|c|c|c|}
\hline & \multirow{2}{*}{$\begin{array}{l}\text { Número } \\
\text { de bulbos }\end{array}$} & \multicolumn{2}{|c|}{ Avaliação de bulbos } & \multirow{2}{*}{$\begin{array}{c}\text { Produção } \\
\text { média }\end{array}$} & \multirow{2}{*}{$\begin{array}{c}\text { Valor de } \\
\text { produção*** }\end{array}$} \\
\hline & & Diâmetro & Massa & & \\
\hline Lotes & (bulbos $/ \mathrm{m}^{2}$ ) & $(\mathrm{cm})$ & $(\mathrm{g})$ & (t/ha) & (US\$/ha) \\
\hline 10 & $45,94 a^{*}$ & $51,95 \mathrm{a}$ & $75,41 \mathrm{a}$ & $35,90 \mathrm{a}$ & $7180,00 \mathrm{a}$ \\
\hline 11 & $64,75 \mathrm{a}$ & $55,96 \mathrm{a}$ & $91,92 \mathrm{a}$ & $60,20 \mathrm{a}$ & $12040,00 \mathrm{a}$ \\
\hline 12 & $47,69 \mathrm{a}$ & $55,41 \mathrm{a}$ & $89,45 \mathrm{a}$ & $43,90 \mathrm{a}$ & $8780,00 \mathrm{a}$ \\
\hline 13 & $46,38 \mathrm{a}$ & $55,09 \mathrm{a}$ & $80,49 \mathrm{a}$ & $37,10 \mathrm{a}$ & $7420,00 \mathrm{a}$ \\
\hline 14 & $65,63 \mathrm{a}$ & $58,47 \mathrm{a}$ & $98,63 \mathrm{a}$ & $67,30 \mathrm{a}$ & $13460,00 \mathrm{a}$ \\
\hline 15 & $57,31 \mathrm{a}$ & $52,40 \mathrm{a}$ & $73,60 \mathrm{a}$ & $42,70 \mathrm{a}$ & $8540,00 \mathrm{a}$ \\
\hline CV\% & 26,0 & 7,3 & 20,5 & 42,5 & 42,5 \\
\hline
\end{tabular}

Assim, no sistema de semeadura direta, não foram constatadas relações entre o vigor de sementes e o desempenho de plantas, bem como reflexos na produção dos bulbos, para o cultivar Aurora.

No entanto, para o cultivar Petroline, foram detectadas algumas diferenças entre os lotes de sementes em relação ao diâmetro na região colo, apontadas no início do estádio de bulbificação e ao acúmulo de matéria seca, identificadas logo após a emergência, de maneira compatível com os testes de envelhecimento acelerado tradicional e com solução salina (72 horas), de deterioração controlada ( $24 \%$ de água) e de emergência de plântulas em casa de vegetação e em campo; porém, estas diferenças não persistiram até o final do ciclo da cultura, não sendo obtidas diferenças significativas na produção. 


\subsubsection{Sistema de transplante de mudas}

$\mathrm{Na}$ Tabela 27, encontram-se os resultados da avaliação de altura de plantas, para o cultivar Aurora, os quais indicaram diferenças significativas apenas aos 28 dias após a semeadura, onde se observaram plantas de maior altura oriundas dos lotes 2 e 4 e, menor, do lote 3; entretanto, estas diferenças apoiaram as informações dos testes de primeira contagem, de classificação do vigor de plântulas, de envelhecimento acelerado tradicional e com solução salina (72 horas), de deterioração controlada ( $24 \%$ de água) e de emergência de plântulas em campo, realizados para avaliação do potencial fisiológico dos lotes, somente na identificação da maior altura de plantas provenientes do lote 4 .

Tabela 27. Cultivar Aurora: resultados de altura de plantas, no sistema de transplante de mudas, em seis lotes de sementes de cebola (Ano I).

\begin{tabular}{ccccccccc}
\hline & \multicolumn{7}{c}{ Épocas de avaliação } \\
\cline { 2 - 8 } & $28 \mathrm{~d}$ & $42 \mathrm{~d}$ & $84 \mathrm{~d}$ & $98 \mathrm{~d}$ & $112 \mathrm{~d}$ & $126 \mathrm{~d}$ & $140 \mathrm{~d}$ & $154 \mathrm{~d}$ \\
\hline Lotes & $\ldots \ldots \ldots \ldots \ldots \ldots \ldots \ldots \ldots \ldots \ldots \ldots \ldots \ldots \ldots \ldots \ldots \ldots \ldots \ldots \ldots \ldots \ldots \ldots \ldots \ldots \ldots \ldots \ldots \ldots \ldots \ldots \ldots \ldots \ldots \ldots \ldots \ldots \ldots \ldots \ldots \ldots \ldots \ldots \ldots \ldots \ldots \ldots \ldots \ldots \ldots \ldots \ldots \ldots$ \\
1 & $15,3 \mathrm{ab} *$ & $16,3 \mathrm{a}$ & $31,6 \mathrm{a}$ & $54,0 \mathrm{a}$ & $57,9 \mathrm{a}$ & $63,7 \mathrm{a}$ & $61,9 \mathrm{a}$ & $59,3 \mathrm{a}$ \\
2 & $15,4 \mathrm{a}$ & $16,4 \mathrm{a}$ & $30,4 \mathrm{a}$ & $52,5 \mathrm{a}$ & $62,2 \mathrm{a}$ & $63,4 \mathrm{a}$ & $61,6 \mathrm{a}$ & $61,2 \mathrm{a}$ \\
3 & $14,3 \mathrm{~b}$ & $16,2 \mathrm{a}$ & $28,0 \mathrm{a}$ & $47,1 \mathrm{a}$ & $62,9 \mathrm{a}$ & $62,8 \mathrm{a}$ & $63,9 \mathrm{a}$ & $65,5 \mathrm{a}$ \\
4 & $15,4 \mathrm{a}$ & $15,7 \mathrm{a}$ & $28,5 \mathrm{a}$ & $48,4 \mathrm{a}$ & $62,9 \mathrm{a}$ & $66,8 \mathrm{a}$ & $63,8 \mathrm{a}$ & $65,6 \mathrm{a}$ \\
5 & $14,7 \mathrm{ab}$ & $15,6 \mathrm{a}$ & $28,1 \mathrm{a}$ & $51,6 \mathrm{a}$ & $61,1 \mathrm{a}$ & $62,2 \mathrm{a}$ & $57,2 \mathrm{a}$ & $59,5 \mathrm{a}$ \\
6 & $14,5 \mathrm{ab}$ & $16,5 \mathrm{a}$ & $28,8 \mathrm{a}$ & $49,4 \mathrm{a}$ & $62,6 \mathrm{a}$ & $64,8 \mathrm{a}$ & $62,1 \mathrm{a}$ & $66,7 \mathrm{a}$ \\
CV\% & 3,3 & 5,3 & 13,1 & 9,5 & 10,3 & 9,9 & 11,1 & 11,0 \\
\hline * Comparação de médias dentro de cada coluna (teste de Tukey a $5 \%$ de probabilidade).
\end{tabular}


Além disso, verificou-se que houve aumento significativo no crescimento das plantas dos 84 aos 112 dias após a semeadura, permanecendo estável até aos 154 dias. Cabe ressaltar ainda que, neste período, foram registradas temperaturas na faixa $\operatorname{dos} 21^{\circ} \mathrm{C}$ e fotoperíodo de 12,5 horas de luz, indicando condições climáticas adequadas para o inicio da bulbificação; este fato foi também constatado para o sistema de semeadura direta, no entanto, aos 84 dias, sendo importante lembrar que, neste sistema, a semeadura foi realizada aproximadamente um mês antes do que no sistema de transplante de mudas.

Quanto aos resultados das determinações do diâmetro na região do colo, apresentados na Tabela 28, observaram-se diferenças significativas somente aos 140 e 154 dias após a semeadura.

Tabela 28. Cultivar Aurora: resultados de diâmetro na região do colo, no sistema de transplante de mudas, em seis lotes de sementes de cebola (Ano I).

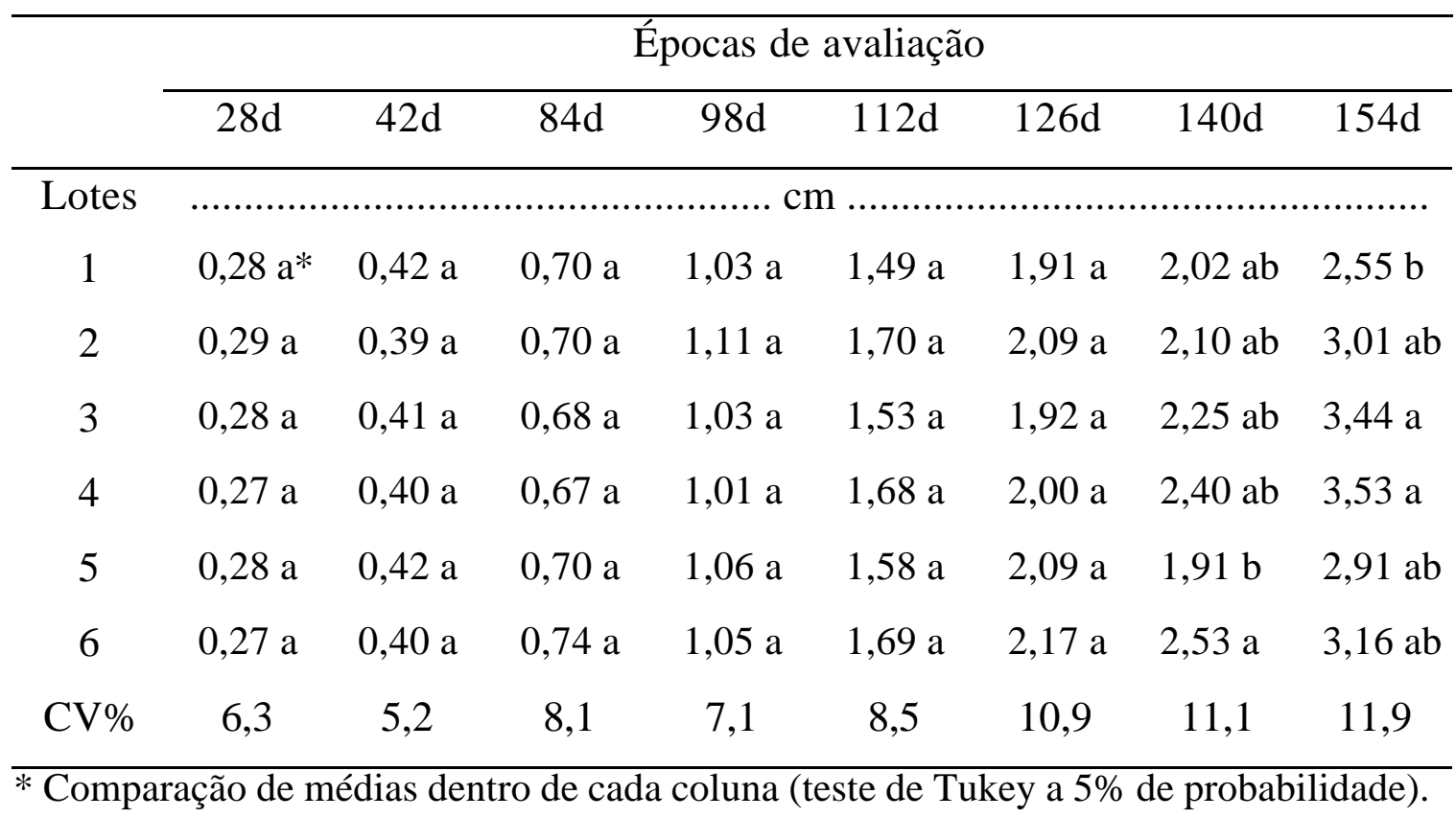


Porém, houve relação entre estas diferenças e os resultados dos testes de avaliação do potencial fisiológico das sementes apenas na identificação do maior diâmetro para as plantas originadas de sementes do lote 4, aos 154 dias, o qual foi acusado como o de maior vigor pelos testes de classificação do vigor de plântulas, de envelhecimento acelerado tradicional e com solução salina (72 horas), de deterioração controlada ( $24 \%$ de água) e de emergência de plântulas em campo.

Em relação à evolução do crescimento, constatou-se que o incremento do diâmetro na região do colo foi evidenciado a partir dos 98 dias após a semeadura, período no qual também foi observado aumento na altura de plantas e condições climáticas propícias para o início da formação dos bulbos.

No entanto, conforme os resultados apresentados na Tabela 29, para massa de matéria seca, não foram detectadas diferenças significativas, assim como também verificado no sistema de semeadura direta para este mesmo parâmetro e cultivar. Ainda, observou-se que houve acréscimo no acúmulo de matéria seca a partir dos 98 dias após a semeadura, indicando maior capacidade das plantas na produção de fotoassimilados para o início da bulbificação, corroborando as informações destacadas para altura de plantas e diâmetro na região do colo, neste mesmo período de avaliação.

Portanto, da mesma forma verificada no sistema de semeadura direta, não foram obtidos resultados suficientes para se detectarem relações evidentes entre o potencial fisiológico dos lotes de sementes e o desempenho das plantas do cultivar Aurora.

Para o cultivar Petroline, observam-se na Tabela 30 os resultados referentes à altura de plantas, nos quais não foram detectadas diferenças significativas. Também, constatou-se que, a partir dos 84 dias, houve maior impulso ao crescimento das plantas, o qual prosseguiu até aos 112 dias, estabilizando o crescimento até aos 154 após a semeadura. 
Tabela 29. Cultivar Aurora: resultados de massa de matéria seca, no sistema de transplante de mudas, em seis lotes de sementes de cebola (Ano I).

\begin{tabular}{|c|c|c|c|c|c|c|c|c|}
\hline & \multicolumn{8}{|c|}{ Épocas de avaliação } \\
\hline & $28 \mathrm{~d}$ & $42 d$ & $84 d$ & $98 \mathrm{~d}$ & $112 d$ & $126 \mathrm{~d}$ & $140 d$ & $154 d$ \\
\hline Lotes & & & & ......... & ......... & & 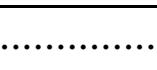 & ............. \\
\hline 1 & $0,031 a^{*}$ & $0,072 \mathrm{a}$ & $0,452 \mathrm{a}$ & $1,923 \mathrm{a}$ & $3,637 \mathrm{a}$ & $5,855 \mathrm{a}$ & $6,591 \mathrm{a}$ & $6,261 \mathrm{a}$ \\
\hline 2 & $0,031 \mathrm{a}$ & $0,070 \mathrm{a}$ & $0,455 \mathrm{a}$ & $1,949 \mathrm{a}$ & $4,632 \mathrm{a}$ & $5,928 \mathrm{a}$ & $6,752 \mathrm{a}$ & $8,077 \mathrm{a}$ \\
\hline 3 & $0,031 \mathrm{a}$ & $0,068 \mathrm{a}$ & $0,373 \mathrm{a}$ & $1,455 \mathrm{a}$ & $4,005 \mathrm{a}$ & $5,417 \mathrm{a}$ & $7,150 \mathrm{a}$ & $8,880 \mathrm{a}$ \\
\hline 4 & $0,031 \mathrm{a}$ & $0,065 \mathrm{a}$ & $0,357 \mathrm{a}$ & $1,488 \mathrm{a}$ & $4,427 \mathrm{a}$ & $6,261 \mathrm{a}$ & $7,340 \mathrm{a}$ & 8,658 \\
\hline 5 & $0,030 \mathrm{a}$ & $0,066 \mathrm{a}$ & $0,373 \mathrm{a}$ & $1,781 \mathrm{a}$ & $4,016 \mathrm{a}$ & $6,255 \mathrm{a}$ & $5,409 \mathrm{a}$ & $6,977 \mathrm{a}$ \\
\hline 6 & $0,028 \mathrm{a}$ & $0,071 \mathrm{a}$ & $0,401 \mathrm{a}$ & $1,608 \mathrm{a}$ & $4,488 \mathrm{a}$ & $6,443 \mathrm{a}$ & $8,412 \mathrm{a}$ & 8,735 \\
\hline $\mathrm{CV} \%$ & 8,0 & 9,5 & 21,7 & 21,2 & 27,0 & 19,1 & 26,1 & 20,2 \\
\hline
\end{tabular}

* Comparação de médias dentro de cada coluna (teste de Tukey a 5\% de probabilidade).

Tabela 30. Cultivar Petroline: resultados de altura de plantas, no sistema de transplante de mudas, em seis lotes de sementes de cebola (Ano I).

\begin{tabular}{ccccccccc}
\hline & \multicolumn{7}{c}{ Épocas de avaliação } \\
\cline { 2 - 9 } & $28 \mathrm{~d}$ & $42 \mathrm{~d}$ & $84 \mathrm{~d}$ & $98 \mathrm{~d}$ & $112 \mathrm{~d}$ & $126 \mathrm{~d}$ & $140 \mathrm{~d}$ & $154 \mathrm{~d}$ \\
\hline Lotes & $\ldots \ldots \ldots \ldots \ldots \ldots \ldots \ldots \ldots \ldots \ldots \ldots \ldots \ldots \ldots \ldots \ldots \ldots \ldots \ldots \ldots \ldots \ldots \ldots \ldots \ldots \ldots \ldots \ldots \ldots \ldots \ldots \ldots \ldots \ldots \ldots \ldots \ldots \ldots \ldots \ldots \ldots \ldots \ldots \ldots \ldots \ldots \ldots \ldots \ldots \ldots \ldots \ldots \ldots \ldots \ldots \ldots$ \\
10 & 13,6 a* & $14,2 \mathrm{a}$ & $29,0 \mathrm{a}$ & $48,0 \mathrm{a}$ & $60,5 \mathrm{a}$ & $67,5 \mathrm{a}$ & $70,1 \mathrm{a}$ & $70,0 \mathrm{a}$ \\
11 & $14,8 \mathrm{a}$ & $15,8 \mathrm{a}$ & $28,0 \mathrm{a}$ & $49,4 \mathrm{a}$ & $62,0 \mathrm{a}$ & $64,6 \mathrm{a}$ & $63,3 \mathrm{a}$ & $69,4 \mathrm{a}$ \\
12 & $13,7 \mathrm{a}$ & $14,5 \mathrm{a}$ & $29,0 \mathrm{a}$ & $52,7 \mathrm{a}$ & $61,7 \mathrm{a}$ & $71,3 \mathrm{a}$ & $69,4 \mathrm{a}$ & $67,8 \mathrm{a}$ \\
13 & $13,3 \mathrm{a}$ & $14,3 \mathrm{a}$ & $29,0 \mathrm{a}$ & $48,2 \mathrm{a}$ & $63,0 \mathrm{a}$ & $68,7 \mathrm{a}$ & $70,4 \mathrm{a}$ & $69,0 \mathrm{a}$ \\
14 & $13,4 \mathrm{a}$ & $15,1 \mathrm{a}$ & $29,0 \mathrm{a}$ & $50,8 \mathrm{a}$ & $62,2 \mathrm{a}$ & $68,0 \mathrm{a}$ & $73,5 \mathrm{a}$ & $69,7 \mathrm{a}$ \\
15 & $14,1 \mathrm{a}$ & $15,5 \mathrm{a}$ & $28,0 \mathrm{a}$ & $48,6 \mathrm{a}$ & $62,6 \mathrm{a}$ & $70,0 \mathrm{a}$ & $70,1 \mathrm{a}$ & $69,3 \mathrm{a}$ \\
$\mathrm{CV} \%$ & 7,6 & 4,9 & 6,7 & 7,8 & 6,7 & 6,1 & 9,3 & 10,4 \\
\hline
\end{tabular}

* Comparação de médias dentro de cada coluna (teste de Tukey a 5\% de probabilidade). 
Para as avaliações de diâmetro na região do colo e de massa de matéria seca (Tabelas 31 e 32, respectivamente), os maiores aumentos destes parâmetros foram observados somente a partir dos 98 dias após a semeadura, ou seja, no início do processo de bulbificação, como também verificado para o cultivar Aurora; no entanto, em relação a essas mesmas determinações, foram acusadas diferenças significativas aos 42 dias após a semeadura, época em que foi realizado o transplante das mudas para o campo.

Tabela 31. Cultivar Petroline: resultados de diâmetro na região do colo, no sistema de transplante de mudas, em seis lotes de sementes de cebola (Ano I).

\begin{tabular}{|c|c|c|c|c|c|c|c|c|}
\hline & \multicolumn{8}{|c|}{ Épocas de avaliação } \\
\hline & $28 \mathrm{~d}$ & $42 \mathrm{~d}$ & $84 \mathrm{~d}$ & $98 \mathrm{~d}$ & $112 \mathrm{~d}$ & $126 \mathrm{~d}$ & 140d & $154 d$ \\
\hline Lotes & \multicolumn{8}{|c|}{ 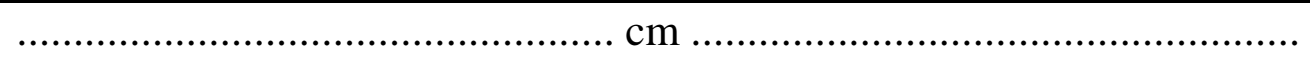 } \\
\hline 10 & $0,21 b^{*}$ & $0,37 \mathrm{ab}$ & $0,69 \mathrm{a}$ & $0,89 \mathrm{a}$ & $1,43 \mathrm{a}$ & $1,94 \mathrm{a}$ & $2,01 \mathrm{a}$ & $2,83 \mathrm{ab}$ \\
\hline 11 & $0,29 \mathrm{a}$ & $0,39 \mathrm{ab}$ & $0,69 \mathrm{a}$ & $1,08 \mathrm{a}$ & $1,52 \mathrm{a}$ & $2,03 \mathrm{a}$ & $1,99 \mathrm{a}$ & $3,30 \mathrm{ab}$ \\
\hline 12 & $0,28 \mathrm{a}$ & $0,40 \mathrm{ab}$ & $0,72 \mathrm{a}$ & $1,03 \mathrm{a}$ & $1,42 \mathrm{a}$ & $1,84 \mathrm{a}$ & $1,98 \mathrm{a}$ & $3,43 \mathrm{a}$ \\
\hline 13 & $0,28 \mathrm{a}$ & $0,36 \mathrm{~b}$ & $0,69 \mathrm{a}$ & $0,98 \mathrm{a}$ & $1,37 \mathrm{a}$ & $1,67 \mathrm{a}$ & $2,17 \mathrm{a}$ & $2,79 a b$ \\
\hline 14 & $0,28 \mathrm{a}$ & $0,42 \mathrm{a}$ & $0,68 \mathrm{a}$ & $1,05 \mathrm{a}$ & $1,63 \mathrm{a}$ & $1,76 \mathrm{a}$ & $2,14 \mathrm{a}$ & $3,08 \mathrm{ab}$ \\
\hline 15 & $0,28 \mathrm{a}$ & $0,42 \mathrm{a}$ & $0,65 \mathrm{a}$ & $1,02 \mathrm{a}$ & $1,48 \mathrm{a}$ & $1,89 \mathrm{a}$ & $1,96 \mathrm{a}$ & $2,49 \mathrm{~b}$ \\
\hline CV\% & 6,2 & 6,0 & 6,2 & 8,0 & 10,0 & 10,4 & 14,2 & 13,9 \\
\hline
\end{tabular}

* Comparação de médias dentro de cada coluna (teste de Tukey a 5\% de probabilidade). 
Tabela 32. Cultivar Petroline: resultados de massa de matéria seca, no sistema de transplante de mudas, em seis lotes de sementes de cebola (Ano I).

\begin{tabular}{|c|c|c|c|c|c|c|c|c|}
\hline & \multicolumn{8}{|c|}{ Épocas de avaliação } \\
\hline & $28 d$ & $42 d$ & $84 d$ & $98 d$ & $112 d$ & $126 \mathrm{~d}$ & $140 d$ & $154 d$ \\
\hline Lotes & & & & ........... & & & & \\
\hline 10 & $0,026 \mathrm{a}^{*}$ & $0,056 \mathrm{bc}$ & $0,355 \mathrm{a}$ & $1,257 \mathrm{a}$ & 2,944 a & $5,749 \mathrm{a}$ & $7,511 \mathrm{a}$ & $8,341 \mathrm{a}$ \\
\hline 11 & $0,029 \mathrm{a}$ & $0,072 \mathrm{a}$ & $0,370 \mathrm{a}$ & $1,666 \mathrm{a}$ & $3,800 \mathrm{a}$ & $6,159 \mathrm{a}$ & $6,995 \mathrm{a}$ & $9,441 \mathrm{a}$ \\
\hline 12 & $0,029 \mathrm{a}$ & $0,066 \mathrm{ab}$ & $0,381 \mathrm{a}$ & $1,647 \mathrm{a}$ & $2,982 \mathrm{a}$ & $5,860 \mathrm{a}$ & 7,091 a & $10,246 \mathrm{a}$ \\
\hline 13 & $0,026 \mathrm{a}$ & $0,052 \mathrm{c}$ & $0,370 \mathrm{a}$ & $1,317 \mathrm{a}$ & $3,124 \mathrm{a}$ & $4,568 \mathrm{a}$ & $7,088 \mathrm{a}$ & $8,027 \mathrm{a}$ \\
\hline 14 & $0,028 \mathrm{a}$ & $0,069 \mathrm{a}$ & $0,399 a$ & $1,594 \mathrm{a}$ & $3,647 \mathrm{a}$ & $5,008 \mathrm{a}$ & $7,648 \mathrm{a}$ & $9,451 \mathrm{a}$ \\
\hline 15 & $0,028 \mathrm{a}$ & $0,068 \mathrm{a}$ & $0,340 \mathrm{a}$ & $1,487 \mathrm{a}$ & $3,522 \mathrm{a}$ & $5,732 \mathrm{a}$ & $7,065 \mathrm{a}$ & $7,666 \mathrm{a}$ \\
\hline $\mathrm{CV} \%$ & 8,4 & 8,9 & 15,4 & 18,0 & 20,0 & 17,4 & 25,6 & 21,8 \\
\hline
\end{tabular}

* Comparação de médias dentro de cada coluna (teste de Tukey a 5\% de probabilidade).

Assim, foi detectado o menor diâmetro de plantas provenientes do lote 13, bem como o baixo acúmulo de matéria seca de plantas oriundas dos lotes 10 e 13 e, ainda, os maiores valores destas determinações para as plantas originadas do lote 14, embora não diferindo estatisticamente do lote 15 quanto ao diâmetro e do lote 12 em relação à massa de matéria seca; estas diferenças corresponderam os resultados obtidos nos testes de envelhecimento acelerado tradicional e com solução salina ( 72 horas), de deterioração controlada ( $24 \%$ de água) e de emergência de plântulas em casa de vegetação e em campo, os quais identificaram a maior qualidade do lote 14 e o menor vigor para os lotes 10 e 13 .

A partir destas informações, considerou-se que, para este cultivar, cujas diferenças iniciais no potencial fisiológico dos lotes eram mais evidentes em relação ao cultivar Aurora, houve influência do vigor das sementes na produção das mudas, visto que diferenças significativas foram constatadas neste estádio de 
desenvolvimento das plantas. Estes resultados confirmam os encontrados por Stradioto Neto et al. (1992) e Piana et al. (1995), os quais observaram relação direta entre o potencial fisiológico das sementes de cebola, a emergência de plântulas em campo e o desempenho de mudas.

Porém, é importante observar que esta relação foi indicada somente aos 42 dias após a semeadura, não persistindo até o final do ciclo da cultura e, assim, não afetando a produção dos bulbos, como pode ser constatado para os cultivares Aurora e Petroline, respectivamente nas Tabelas 33 e 34.

Tabela 33. Cultivar Aurora: resultados de produção e avaliação comercial de bulbos, no sistema de transplante de mudas, em seis lotes de sementes de cebola (Ano I).

\begin{tabular}{|c|c|c|c|c|c|}
\hline & \multirow{2}{*}{$\begin{array}{l}\text { Número } \\
\text { de bulbos }\end{array}$} & \multicolumn{2}{|c|}{ Avaliação de bulbos } & \multirow{2}{*}{$\begin{array}{l}\text { Produção } \\
\text { média }\end{array}$} & \multirow{2}{*}{$\begin{array}{c}\text { Valor de } \\
\text { produção** }\end{array}$} \\
\hline & & Diâmetro & Massa & & \\
\hline Lotes & (bulbos $/ \mathrm{m}^{2}$ ) & $(\mathrm{cm})$ & (g) & (t/ha) & (US\$/ha) \\
\hline 10 & $66,57 \mathrm{ab}^{*}$ & $44,72 \mathrm{a}$ & $60,60 \mathrm{a}$ & $40,10 \mathrm{a}$ & $6004,50 \mathrm{a}$ \\
\hline 11 & $71,25 \mathrm{a}$ & $46,84 \mathrm{a}$ & $62,41 \mathrm{a}$ & $44,30 \mathrm{a}$ & 6636,25 a \\
\hline 12 & $60,47 \mathrm{~b}$ & $46,71 \mathrm{a}$ & $62,18 \mathrm{a}$ & $37,70 \mathrm{a}$ & $5645,25 \mathrm{a}$ \\
\hline 13 & $61,88 \mathrm{ab}$ & $46,52 \mathrm{a}$ & $62,10 \mathrm{a}$ & $38,90 \mathrm{a}$ & $5828,50 \mathrm{a}$ \\
\hline 14 & $69,38 \mathrm{ab}$ & $46,75 \mathrm{a}$ & $63,07 \mathrm{a}$ & $43,50 \mathrm{a}$ & $6525,50 \mathrm{a}$ \\
\hline 15 & $65,62 \mathrm{ab}$ & $47,64 \mathrm{a}$ & $66,61 \mathrm{a}$ & $43,40 \mathrm{a}$ & $6502,75 \mathrm{a}$ \\
\hline $\mathrm{CV} \%$ & 9,4 & 6,4 & 16,8 & 17,2 & 17,2 \\
\hline
\end{tabular}

* Comparação de médias dentro de cada coluna (teste de Tukey a 5\% de probabilidade). ** Valor médio de produção: US\$ 200,00/t (FNP - Agrianual, 2001). 
Tabela 34. Cultivar Petroline: resultados de produção e avaliação comercial de bulbos, no sistema de transplante de mudas, em seis lotes de sementes de cebola (Ano I).

\begin{tabular}{|c|c|c|c|c|c|}
\hline & \multirow{2}{*}{$\begin{array}{l}\text { Número } \\
\text { de bulbos }\end{array}$} & \multicolumn{2}{|c|}{ Avaliação de bulbos } & \multirow{2}{*}{$\begin{array}{c}\text { Produção } \\
\text { média }\end{array}$} & \multirow{2}{*}{$\begin{array}{c}\text { Valor de } \\
\text { produção*** }\end{array}$} \\
\hline & & Diâmetro & Massa & & \\
\hline Lotes & (bulbos $/ \mathrm{m}^{2}$ ) & $(\mathrm{cm})$ & (g) & (t/ha) & (US\$/ha) \\
\hline 10 & $71,25 \mathrm{a}^{*}$ & 49,67 a & $69,32 \mathrm{a}$ & 49,40 a & $7413,00 \mathrm{a}$ \\
\hline 11 & $66,57 \mathrm{a}$ & $50,43 \mathrm{a}$ & $72,33 \mathrm{a}$ & $48,50 \mathrm{a}$ & $7278,00 \mathrm{a}$ \\
\hline 12 & 66,56 a & 49,78 a & $68,62 \mathrm{a}$ & $45,40 \mathrm{a}$ & $6807,50 \mathrm{a}$ \\
\hline 13 & $61,88 \mathrm{a}$ & $49,61 \mathrm{a}$ & $69,62 \mathrm{a}$ & $43,00 \mathrm{a}$ & $6446,75 \mathrm{a}$ \\
\hline 14 & $71,72 \mathrm{a}$ & $52,82 \mathrm{a}$ & $80,03 \mathrm{a}$ & $57,30 \mathrm{a}$ & $8594,00 \mathrm{a}$ \\
\hline 15 & $64,69 \mathrm{a}$ & $50,31 \mathrm{a}$ & $72,40 \mathrm{a}$ & $46,60 \mathrm{a}$ & $6983,50 \mathrm{a}$ \\
\hline CV\% & 9,8 & 6,1 & 15,2 & 17,2 & 17,2 \\
\hline
\end{tabular}

* Comparação de médias dentro de cada coluna (teste de Tukey a 5\% de probabilidade). ** Valor médio de produção: US\$200,00/t (FNP - Agrianual, 2001).

Nos resultados de produção e avaliação comercial de bulbos, para o cultivar Aurora, houve diferenças significativas entre os lotes somente em relação à quantidade de bulbos produzidos, ou seja, verificou-se que os lotes 2 e 3 produziram, respectivamente, maior e menor número de bulbos $/ \mathrm{m}^{2}$; estas diferenças entre os lotes não concordam com aquelas verificadas nos testes de classificação do vigor de plântulas, de envelhecimento acelerado tradicional e com solução salina (72 horas) e de emergência de plântulas em casa de vegetação, os quais apontaram o menor vigor para o lote 2 .

Para o cultivar Petroline, não foram detectadas diferenças significativas entre os lotes em relação à produção final, apesar do lote 14 ter apresentado os maiores valores observados, além das plantas provenientes do lote 13 terem produzido o menor número de bulbos e, conseqüentemente, menor produção e 
retorno econômico; os lotes 13 e 14 foram identificados como os de menor e maior vigor nos testes de condutividade elétrica, de envelhecimento acelerado tradicional e com solução salina (72 horas), de deterioração controlada (24\% de água) e de emergência de plântulas em casa de vegetação e em campo.

Além disso, no sistema de transplante de mudas, assim como no sistema de semeadura direta, é importante salientar a população de plantas alcançada após o estabelecimento das plantas em campo.

Diante disso, para este sistema, foram transplantadas 14 plantas/m, para ambos cultivares, proporcionando desta forma, estande altamente uniforme. Porém, convém ressaltar que, embora a produção de mudas de cebola seja tradicionalmente realizada em canteiros, neste experimento optou-se em produzilas em bandejas, em casa de vegetação, para o maior controle das condições de desenvolvimento das plantas.

Entretanto, na ocasião do transplante, adotou-se o critério de seleção de mudas com altura superior a $14 \mathrm{~cm}$ e diâmetro na região do colo de 0,3 a $0,4 \mathrm{~cm}$, embora estas características não estivessem diretamente de acordo com as geralmente recomendadas para o desenvolvimento das mudas em canteiros, ou seja, 18 a 20cm de altura e 0,5 a 0,7cm de diâmetro (Ferreira \& Castellane, 1988), pois não foram encontradas referências para a produção de mudas em bandeja, em casa de vegetação, para estes mesmos parâmetros.

No entanto, para o cultivar Aurora, de maneira similar aos resultados obtidos no sistema de semeadura direta, com exceção das diferenças em altura de plantas observadas aos 28 dias após a semeadura, não foram detectadas diferenças significativas que indicassem relações evidentes entre as informações proporcionadas em laboratório e o desempenho das plantas, com reflexos na produção de bulbos, no sistema de transplante de mudas. 
Por outro lado, para o cultivar Petroline, evidenciaram-se diferenças estatísticas na produção de mudas, de maneira semelhante às verificadas para os testes de envelhecimento acelerado tradicional e com solução salina (72 horas), de deterioração controlada (24 de água) e de emergência de plântulas em casa de vegetação e em campo, embora estes resultados não tenham persistido de maneira significativa até a produção final.

\subsubsection{Considerações gerais}

Através destes resultados observados para ambos cultivares em estudo e para os dois sistemas de cultivo de cebola, pode-se considerar que o vigor das sementes exerceu influência na fase tipicamente vegetativa da cultura, ou seja, na fase inicial do desenvolvimento das plantas, enquanto estas ainda apresentavam baixo potencial competitivo pelos recursos do meio ambiente, devido ao lento crescimento após e emergência das plântulas, além de possuírem capacidade fotossintética limitada, acumulando assim, baixo conteúdo de matéria seca (Shadbolt \& Holm,1956; Wicks, 1973).

Este fato foi claramente detectado para o cultivar Petroline, pelas diferenças significativas entre as plantas em relação ao diâmetro na região do colo e massa de matéria seca, aos 42 dias após a semeadura, isto é, no estádio da formação de mudas. Vale salientar que nesta etapa do desenvolvimento, o vegetal já havia ultrapassado o estádio de plântula, ou seja, não era mais totalmente dependente das reservas da semente; porém, mesmo assim, ainda apresentou relação direta entre o seu desempenho e o vigor dos lotes. Isto indica que as

mudas formadas ainda apresentavam resíduos do potencial fisiológico das sementes que lhes deram origem. 
No entanto, estas diferenças detectadas no início do desenvolvimento das plantas, não foram mais significativas ao longo do ciclo da cultura, desaparecendo ao início do estádio de bulbificação, quando as plantas atingiram maior estatura e massa de matéria seca, ocorrendo assim, maior competição entre as mesmas, além da intensificação da ação dos fatores temperatura e fotoperíodo em função das exigências do cultivar; estas constatações apóiam Carvalho (1986) e TeKrony \& Egli (1991), os quais relataram que o efeito do vigor da semente sobre o vegetal é atenuado com o decorrer do desenvolvimento da planta, havendo predomínio da influência da interação entre genótipo e ambiente.

As diferenças entre plantas, provenientes de lotes com potencial fisiológico distinto, não afetaram, portanto, de forma significativa, a produção final; assim, da mesma forma discutida por Burris (1976) e Roberts (1986), em condições de alta competitividade entre plantas, o vigor das sementes teria pouca influência no desenvolvimento das plantas e na produtividade.

Porém, neste primeiro ano experimental, estas informações foram baseadas somente nos resultados obtidos para o cultivar Petroline, devido à qualidade inicial mais uniforme dos lotes do cultivar Aurora.

Assim, após o envelhecimento artificial dos lotes do cultivar Aurora, buscando-se diferenças mais acentuadas em relação ao potencial fisiológico dos mesmos, poderiam ser alcançados resultados mais evidentes no relacionamento entre o vigor das sementes e o desempenho das plantas para este cultivar, no segundo ano experimental. 


\subsection{Ano II}

Neste ano experimental, foram obtidos os resultados da avaliação do potencial fisiológico das sementes, em laboratório, e do desempenho das plantas, em casa de vegetação e em campo, para os cultivares Aurora e Petroline, após o envelhecimento artificial dos lotes do cultivar Aurora.

\subsubsection{Avaliação do potencial fisiológico}

Para ambos cultivares, embora tenham sido efetuadas todas as avaliações propostas, não serão considerados os resultados dos procedimentos dos testes de condutividade elétrica, com o uso de 25 sementes, de envelhecimento acelerado tradicional e com uso de solução salina, por 48 horas e, de deterioração controlada, com sementes umedecidas a $19 \%$ de água; estes, assim como no primeiro ano, não foram eficientes em revelar diferenças de potencial fisiológico entre os lotes, de maneira compatível à emergência de plântulas em casa de vegetação e em campo e demais testes avaliados.

Portanto, serão apresentados e discutidos, além dos resultados dos testes de germinação, de primeira contagem, de classificação do vigor de plântulas, de frio e de emergência de plântulas em casa de vegetação e em campo, somente os resultados dos procedimentos dos testes de condutividade elétrica, com o uso de 50 sementes, após quatro e 24 horas de embebição, de envelhecimento acelerado tradicional e com uso de solução salina, por 72 horas e, de deterioração controlada, com sementes umedecidas a $24 \%$ de água.

Na Tabela 35, encontram-se os resultados obtidos para o cultivar Aurora nos testes de germinação, de primeira contagem, de classificação do vigor de plântulas, de frio e de emergência de plântulas em casa de vegetação e em campo, os quais detectaram, estatisticamente, o pior desempenho do lote 3. 
Tabela 35. Cultivar Aurora: resultados dos testes de germinação (G), primeira contagem do teste de germinação (PCG), classificação do vigor de plântulas (CVP), frio sem terra (TF), emergência de plântulas em casa de vegetação (ECV) e emergência de plântulas em campo (EC), em seis lotes de sementes de cebola (Ano II).

\begin{tabular}{ccccccc}
\hline & $\mathrm{G}$ & PCG & CVP & TF & ECV & EC \\
\hline Lotes & $\ldots \ldots \ldots \ldots \ldots \ldots \ldots \ldots \ldots \ldots \ldots \ldots \ldots \ldots \ldots \ldots \ldots \ldots \ldots \ldots \ldots \ldots \ldots \ldots \ldots \ldots \ldots \ldots \ldots \ldots \ldots \ldots \ldots \ldots \ldots \ldots \ldots \ldots \ldots \ldots \ldots \ldots \ldots \ldots \ldots \ldots \ldots \ldots \ldots \ldots \ldots \ldots \ldots \ldots$ \\
1 & $89 \mathrm{ab}^{*}$ & $75 \mathrm{~b}$ & $52 \mathrm{c}$ & $72 \mathrm{~cd}$ & $84 \mathrm{bc}$ & $62 \mathrm{~b}$ \\
2 & $80 \mathrm{bc}$ & $67 \mathrm{bc}$ & $51 \mathrm{~cd}$ & $68 \mathrm{~d}$ & $76 \mathrm{~cd}$ & $58 \mathrm{~b}$ \\
3 & $76 \mathrm{c}$ & $57 \mathrm{c}$ & $42 \mathrm{~d}$ & $53 \mathrm{e}$ & $69 \mathrm{~d}$ & $40 \mathrm{c}$ \\
4 & $93 \mathrm{a}$ & $90 \mathrm{a}$ & $85 \mathrm{a}$ & $85 \mathrm{a}$ & $92 \mathrm{a}$ & $73 \mathrm{a}$ \\
5 & $91 \mathrm{a}$ & $85 \mathrm{a}$ & $70 \mathrm{~b}$ & $78 \mathrm{bc}$ & $90 \mathrm{ab}$ & $71 \mathrm{a}$ \\
6 & $95 \mathrm{a}$ & $91 \mathrm{a}$ & $75 \mathrm{~b}$ & $82 \mathrm{ab}$ & $91 \mathrm{ab}$ & $70 \mathrm{a}$ \\
CV\% & 5,3 & 4,3 & 4,8 & 3,3 & 4,4 & 3,6 \\
\hline * Comparação de médias dentro de cada coluna (teste de Tukey a 5\% de probabilidade).
\end{tabular}

Os testes de classificação do vigor de plântulas, de frio e de emergência de plântulas em casa de vegetação, destacaram, ainda, o maior potencial do lote 4; este também foi identificado como o lote de melhor qualidade, no primeiro ano de experimento, para este cultivar.

Diante desses resultados, cabe ressaltar que o envelhecimento artificial realizado para o cultivar Aurora, durante o segundo ano experimental, provocou maior diferenciação no potencial fisiológico das sementes e, consequentemente, maior sensibilidade dos testes em indicar os lotes de melhor e pior desempenho. 
Para o cultivar Petroline observa-se, na Tabela 36, que os resultados desses mesmos testes, apontaram diferenças estatisticamente significativas entre os lotes; assim, o lote 14 foi considerado como de alto potencial, seguido pelo lote 11 e, os lotes 10 e 13 , como de menor qualidade.

A eficiência desses testes na classificação dos lotes em maior ou menor vigor, com exceção do teste de primeira contagem, confirmou observação efetuada no primeiro ano de realização do experimento.

Tabela 36. Cultivar Petroline: resultados dos testes de germinação $(G)$, primeira contagem do teste de germinação (PCG), classificação do vigor de plântulas (CVP), frio sem terra (TF), emergência de plântulas em casa de vegetação (ECV) e emergência de plântulas em campo (EC), em seis lotes de sementes de cebola (Ano II).

\begin{tabular}{|c|c|c|c|c|c|c|}
\hline & $\bar{G}$ & PCG & CVP & $\mathrm{TF}$ & ECV & $\overline{E C}$ \\
\hline Lotes & $\ldots .$. & .......... & .. & $\ldots$ & ...... & $\ldots \ldots$ \\
\hline 10 & $82 b^{*}$ & $71 \mathrm{c}$ & $59 \mathrm{~b}$ & $73 \mathrm{c}$ & $70 \mathrm{~d}$ & $54 \mathrm{c}$ \\
\hline 11 & $94 \mathrm{a}$ & $91 \mathrm{a}$ & $74 \mathrm{a}$ & $86 \mathrm{~b}$ & $92 \mathrm{ab}$ & $79 \mathrm{a}$ \\
\hline 12 & $91 \mathrm{a}$ & $83 a b$ & $60 \mathrm{~b}$ & $82 \mathrm{~b}$ & $85 \mathrm{abc}$ & $66 \mathrm{~b}$ \\
\hline 13 & $79 \mathrm{~b}$ & $70 \mathrm{c}$ & $51 \mathrm{~b}$ & $75 c$ & $77 \mathrm{~cd}$ & $57 \mathrm{c}$ \\
\hline 14 & $94 \mathrm{a}$ & $91 \mathrm{a}$ & $77 \mathrm{a}$ & $91 \mathrm{a}$ & $93 a$ & $80 \mathrm{a}$ \\
\hline 15 & $85 \mathrm{~b}$ & 79 bc & $61 \mathrm{~b}$ & $84 \mathrm{~b}$ & $83 \mathrm{bc}$ & $65 \mathrm{~b}$ \\
\hline CV\% & 3,5 & 4,7 & 6,1 & 3,1 & 5,8 & 2,8 \\
\hline
\end{tabular}

Nas Tabelas 37 e 38, observam-se os resultados do teste de condutividade elétrica, respectivamente, para os cultivares Aurora e Petroline. 
Tabela 37. Cultivar Aurora: condutividade elétrica - embebição de 50 sementes em 25,50 e $75 \mathrm{~mL}$ de água destilada, a $20^{\circ} \mathrm{C}$, Ano II.

\begin{tabular}{|c|c|c|c|c|c|c|}
\hline & \multicolumn{2}{|c|}{$25 \mathrm{~mL}$} & \multicolumn{2}{|c|}{$50 \mathrm{~mL}$} & \multicolumn{2}{|c|}{$75 \mathrm{~mL}$} \\
\hline & $4 \mathrm{~h}$ & $24 \mathrm{~h}$ & $4 \mathrm{~h}$ & $24 \mathrm{~h}$ & $4 \mathrm{~h}$ & $24 \mathrm{~h}$ \\
\hline Lotes & .. & $\ldots \ldots \ldots \ldots \ldots . .$. & $\ldots \mu \mathrm{mho}$ & $\mathrm{m} / \mathrm{g} \ldots \ldots .$. & wa & 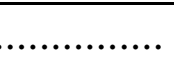 \\
\hline 1 & $172,9 \mathrm{a}^{*}$ & $321,5 \mathrm{a}$ & $85,6 \mathrm{ab}$ & $166,6 \mathrm{ab}$ & $65,9 \mathrm{ab}$ & $120,5 \mathrm{ab}$ \\
\hline 2 & $166,8 \mathrm{a}$ & $333,2 \mathrm{a}$ & $78,8 \mathrm{a}$ & $157,6 \mathrm{a}$ & 58,6 a & $117,2 \mathrm{a}$ \\
\hline 3 & $183,3 \mathrm{ab}$ & $373,8 \mathrm{~b}$ & $85,3 a b$ & $170,9 \mathrm{ab}$ & $68,0 \mathrm{ab}$ & $133,2 \mathrm{~b}$ \\
\hline 4 & $193,4 \mathrm{~b}$ & $337,4 \mathrm{ab}$ & $86,8 \mathrm{ab}$ & $162,3 \mathrm{ab}$ & $64,1 \mathrm{ab}$ & $118,0 \mathrm{a}$ \\
\hline 5 & $182,5 \mathrm{ab}$ & $327,7 \mathrm{a}$ & $84,2 \mathrm{ab}$ & $162,8 \mathrm{ab}$ & $59,9 \mathrm{ab}$ & $113,3 \mathrm{a}$ \\
\hline 6 & $179,8 a b$ & $337,1 \mathrm{ab}$ & $94,3 \mathrm{~b}$ & $179,5 \mathrm{~b}$ & $69,2 \mathrm{~b}$ & $127,4 \mathrm{ab}$ \\
\hline CV\% & 4,8 & 4,9 & 5,5 & 4,6 & 6,6 & 5,3 \\
\hline
\end{tabular}

* Comparação de médias dentro de cada coluna (teste de Tukey a 5\% de probabilidade).

Tabela 38. Cultivar Petroline: condutividade elétrica - embebição de 50 sementes em 25,50 e $75 \mathrm{~mL}$ de água destilada, a $20^{\circ} \mathrm{C}$, Ano II.

\begin{tabular}{|c|c|c|c|c|c|c|}
\hline & \multicolumn{2}{|c|}{$25 \mathrm{~mL}$} & \multicolumn{2}{|c|}{$50 \mathrm{~mL}$} & \multicolumn{2}{|c|}{$75 \mathrm{~mL}$} \\
\hline & $4 \mathrm{~h}$ & $24 \mathrm{~h}$ & $4 h$ & $24 \mathrm{~h}$ & $4 \mathrm{~h}$ & $24 \mathrm{~h}$ \\
\hline Lotes & .. & - & $\ldots \mu \mathrm{mho} / \mathrm{c}$ & $\lg \ldots . . . .$. & ........... & ............... \\
\hline 10 & $249,7 b^{*}$ & $419,9 \mathrm{bc}$ & $126,3 \mathrm{~b}$ & $228,9 \mathrm{~b}$ & $82,6 \mathrm{~b}$ & $154,8 \mathrm{~b}$ \\
\hline 11 & $236,6 \mathrm{~b}$ & $401,4 \mathrm{~b}$ & $121,2 \mathrm{ab}$ & $232,1 \mathrm{~b}$ & $78,9 \mathrm{~b}$ & $160,8 \mathrm{~b}$ \\
\hline 12 & $241,7 \mathrm{~b}$ & $393,9 \mathrm{ab}$ & $124,1 \mathrm{~b}$ & $227,3 \mathrm{~b}$ & $82,8 \mathrm{~b}$ & $155,3 \mathrm{~b}$ \\
\hline 13 & $301,2 \mathrm{c}$ & $489,9 \mathrm{c}$ & $160,5 \mathrm{c}$ & $286,0 \mathrm{c}$ & $102,7 \mathrm{c}$ & $200,7 \mathrm{c}$ \\
\hline 14 & $184,9 \mathrm{a}$ & $325,8 \mathrm{a}$ & $96,6 \mathrm{a}$ & $167,6 \mathrm{a}$ & 60,6 a & $117,7 \mathrm{a}$ \\
\hline 15 & $252,6 \mathrm{~b}$ & $451,5 \mathrm{bc}$ & $130,4 \mathrm{~b}$ & $220,3 \mathrm{~b}$ & $89,2 \mathrm{bc}$ & $166,8 \mathrm{~b}$ \\
\hline $\mathrm{CV} \%$ & 8,0 & 7,6 & 9,0 & 6,7 & 9,4 & 6,0 \\
\hline
\end{tabular}

* Comparação de médias dentro de cada coluna (teste de Tukey a 5\% de probabilidade). 
Para o cultivar Aurora, evidenciou-se, de uma maneira geral, que os procedimentos deste teste não apresentaram sensibilidade suficiente para detectar as diferenças no potencial fisiológico observadas nos testes de classificação do vigor de plântulas, de frio e de emergência de plântulas em casa de vegetação, apresentados na Tabela 35, os quais acusaram o maior vigor do lote 4 e o pior desempenho do lote 3 .

No entanto, os procedimentos em que se utilizaram 25 e $75 \mathrm{~mL}$ de água destilada, identificaram o menor potencial do lote 3, porém, somente após 24 horas de embebição; após quatro horas de embebição, não se observou este fato e, ainda, foi acusado pior desempenho para os lotes 4 e 6 , além de melhor qualidade para o lote 2. Isto também foi constatado com o uso de $50 \mathrm{~mL}$ de água destilada.

Ao mesmo tempo, para o cultivar Petroline, todos os procedimentos e períodos avaliados indicaram a alta qualidade do lote 14 e o desempenho inferior do lote 13. Esses resultados concordam com aqueles obtidos para o primeiro ano experimental e para os demais testes de vigor e de emergência de plântulas em casa de vegetação e em campo (Tabela 36).

Diante disto, verificou-se que há possibilidade de realização das leituras de condutividade após quatro horas de embebição; porém, estes resultados discordam de Lima (1993), que obteve, para sementes de cebola, respostas não confiáveis em leituras realizadas após quatro e 24 horas de embebição.

No entanto, estão de acordo com Vieira \& Krzyzanowski (1999), os quais afirmam que o período de embebição pode ser reduzido, quando realizado para espécies que produzem sementes relativamente pequenas, como a maioria das hortaliças. Portanto, diante dos resultados obtidos para este cultivar, constatou-se que, sementes de cebola, as quais são consideradas pequenas, liberam quantidades significativas de eletrólitos em poucas horas de embebição.

É importante salientar que, como também verificado para os resultados obtidos no primeiro ano de experimento, evidenciou-se que os procedimentos 
realizados na condução do teste de condutividade elétrica, para o cultivar Petroline, forneceram resultados mais confiáveis em relação aos observados para as sementes do cultivar Aurora, mesmo após o envelhecimento artificial dos lotes.

Esta diferença entre resposta de cultivares dentro de uma mesma espécie pode estar associada a efeitos do genótipo, o que, provavelmente, está relacionado a características do tegumento da semente (Thornton et al., 1990); a testa pode agir como barreira à entrada de água durante a embebição (McCormac \& Keefe, 1990). Em trabalhos recentes, Rech et al. (1999), verificaram diferenças nos resultados obtidos no teste de condutividade elétrica entre cultivares de ervilha; Panobianco et al. (2000), trabalhando com sementes de soja, constataram que a condutividade elétrica da solução de embebição é influenciada pelo teor de lignina do tegumento da semente, característica variável com o cultivar.

Portanto, o teste de condutividade elétrica não foi considerado eficiente para o cultivar Aurora, não possibilitando desta forma, a indicação deste teste para avaliação do potencial fisiológico das sementes.

Na Tabela 39 encontram-se os resultados dos testes de envelhecimento acelerado e de deterioração controlada para o cultivar Aurora.

Para os testes de envelhecimento acelerado com solução salina e de deterioração controlada, os resultados obtidos acusaram o lote 6 como de qualidade superior e o lote 3 como de potencial inferior, de maneira semelhante aos testes de classificação do vigor de plântulas, de frio e de emergência de plântulas em casa de vegetação (Tabela 35); o teste de envelhecimento acelerado tradicional indicou somente o pior desempenho do lote 3.

No entanto, vale ressaltar que os lotes avaliados apresentaram grau de umidade inicial uniforme entre si, ocorrendo diferença máxima de 0,5\% (6,8 a 7,3\%). Para o teste de deterioração controlada, após o umedecimento das sementes, constataram-se valores de 23,9 a $24,2 \%$ revelando assim, que as sementes atingiram o grau de umidade desejado, de maneira uniforme. 
Também, verificou-se variação de apenas 1,1\% (10,2 a 11,3\%), após a condução do teste de envelhecimento acelerado com uso de solução salina. Porém, para o envelhecimento acelerado tradicional, a variação observada após a execução do teste, foi de 5,8\% (33,5 a 39,3\%), ultrapassando o limite de 3 a 4\%, recomendado por Marcos Filho (1999b).

Tabela 39. Cultivar Aurora: resultados dos testes de envelhecimento acelerado tradicional (EAT), envelhecimento acelerado com solução salina (EASS) e deterioração controlada (DC), em seis lotes de sementes de cebola (Ano II).

\begin{tabular}{|c|c|c|c|}
\hline & EAT & $\overline{\text { EASS }}$ & DC \\
\hline & $72 h$ & $72 \mathrm{~h}$ & $24 \%$ \\
\hline Lotes & ….................. & $\ldots \%$ & ……............ \\
\hline 1 & $71 b^{*}$ & $66 \mathrm{~b}$ & $68 \mathrm{c}$ \\
\hline 2 & $69 \mathrm{~b}$ & $49 \mathrm{c}$ & $67 \mathrm{c}$ \\
\hline 3 & $56 \mathrm{c}$ & $39 \mathrm{~d}$ & $39 d$ \\
\hline 4 & $90 \mathrm{a}$ & $77 \mathrm{a}$ & $88 \mathrm{a}$ \\
\hline 5 & $86 \mathrm{a}$ & $65 \mathrm{~b}$ & $79 \mathrm{~b}$ \\
\hline 6 & $87 \mathrm{a}$ & $69 \mathrm{~b}$ & $81 \mathrm{~b}$ \\
\hline CV\% & 4,7 & 2,7 & 1,9 \\
\hline
\end{tabular}

* Comparação de médias dentro de cada coluna (teste de Tukey a 5\% de probabilidade).

Em relação ao cultivar Petroline (Tabela 40), observou-se que os testes de envelhecimento acelerado tradicional e com solução salina e deterioração controlada, indicaram os lotes 11 e 14 como de alta qualidade e os lotes 10 e 13 
como de qualidade inferior; isto também foi verificado para os testes de primeira contagem, de classificação do vigor de plântulas, de emergência de plântulas em casa de vegetação e em campo (Tabela 36) e para os procedimentos do teste de condutividade elétrica (Tabela 38); estes indicaram apenas o maior e o menor vigor dos lotes 14 e 13 .

Cabe destacar, porém, que os testes de envelhecimento acelerado com solução salina e de deterioração controlada, apresentaram maior compatibilidade com os resultados do teste de emergência de plântulas em campo.

Tabela 40. Cultivar Petroline: resultados dos testes de envelhecimento acelerado tradicional (EAT), envelhecimento acelerado com solução salina (EASS) e deterioração controlada (DC), em seis lotes de sementes de cebola (Ano II).

\begin{tabular}{|c|c|c|c|}
\hline & EAT & EASS & $\mathrm{DC}$ \\
\hline & $72 \mathrm{~h}$ & $72 \mathrm{~h}$ & $24 \%$ \\
\hline Lotes & \multicolumn{3}{|c|}{ 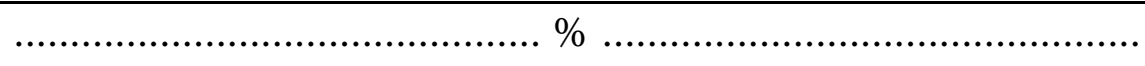 } \\
\hline 10 & $61 b^{*}$ & $64 \mathrm{~d}$ & $69 \mathrm{c}$ \\
\hline 11 & $85 \mathrm{a}$ & $86 \mathrm{ab}$ & $87 \mathrm{a}$ \\
\hline 12 & $61 \mathrm{~b}$ & $79 \mathrm{bc}$ & $80 \mathrm{~b}$ \\
\hline 13 & $40 \mathrm{c}$ & $61 \mathrm{~d}$ & $68 \mathrm{c}$ \\
\hline 14 & $83 \mathrm{a}$ & $87 \mathrm{a}$ & $89 \mathrm{a}$ \\
\hline 15 & $72 a b$ & $72 \mathrm{c}$ & $79 \mathrm{~b}$ \\
\hline $\mathrm{CV} \%$ & 7,8 & 3,8 & 2,5 \\
\hline
\end{tabular}

* Comparação de médias dentro de cada coluna (teste de Tukey a 5\% de probabilidade). 
O grau de umidade inicial dos lotes deste cultivar apresentou diferença máxima de $0,3 \%(6,2$ a 6,5\%), verificando-se assim, valores uniformes para a realização dos testes. No teste de deterioração controlada, observou-se uniformidade no grau de umidade ajustado, ou seja, foram obtidos resultados de 24,3 a 24,7\%, constatando-se a eficiência do procedimento adotado. Porém, para o teste de envelhecimento acelerado tradicional, registrou-se variação no grau de umidade entre os lotes de 9,6\% (31,0 a 40,6\%), após execução do teste; este valor ultrapassou o limite considerado tolerável (3 a 4\%), conforme Marcos Filho (1999b). Entretanto, para o teste de envelhecimento acelerado com o uso de solução salina, a variação máxima entre o grau de umidade alcançado após a condução deste foi de $0,9 \%(11,2$ a $12,1 \%)$.

Assim, confirmando as observações de Jianhua \& McDonald (1996), estes resultados, como no cultivar Aurora e no primeiro ano experimental, revelaram que no teste de envelhecimento acelerado com o uso alternativo de solução salina, as sementes captaram água com menor velocidade, resultando em menor variação no grau de umidade atingido após o teste.

Além disso, conforme estes mesmos autores, com a baixa umidade relativa no teste, há redução considerável do desenvolvimento de fungos, que podem constituir fontes de variação dos resultados; essa vantagem foi verificada na presente pesquisa, como observado para amostras de sementes de cebola do cultivar Petroline, na Figura 4, onde se nota a maior incidência de microorganismos no teste de envelhecimento acelerado tradicional, em relação ao teste de envelhecimento acelerado com solução salina.

Para o teste de deterioração controlada, assim como no primeiro ano de condução do experimento, o procedimento em que se ajustou o teor de água das sementes para $24 \%$, apresentou sensibilidade na avaliação do vigor das sementes, embora não estando de acordo com ISTA (1995), Lima (1993) e Powell (1984), os quais sugerem o uso de sementes de cebola umedecidas a 19\% de água. 

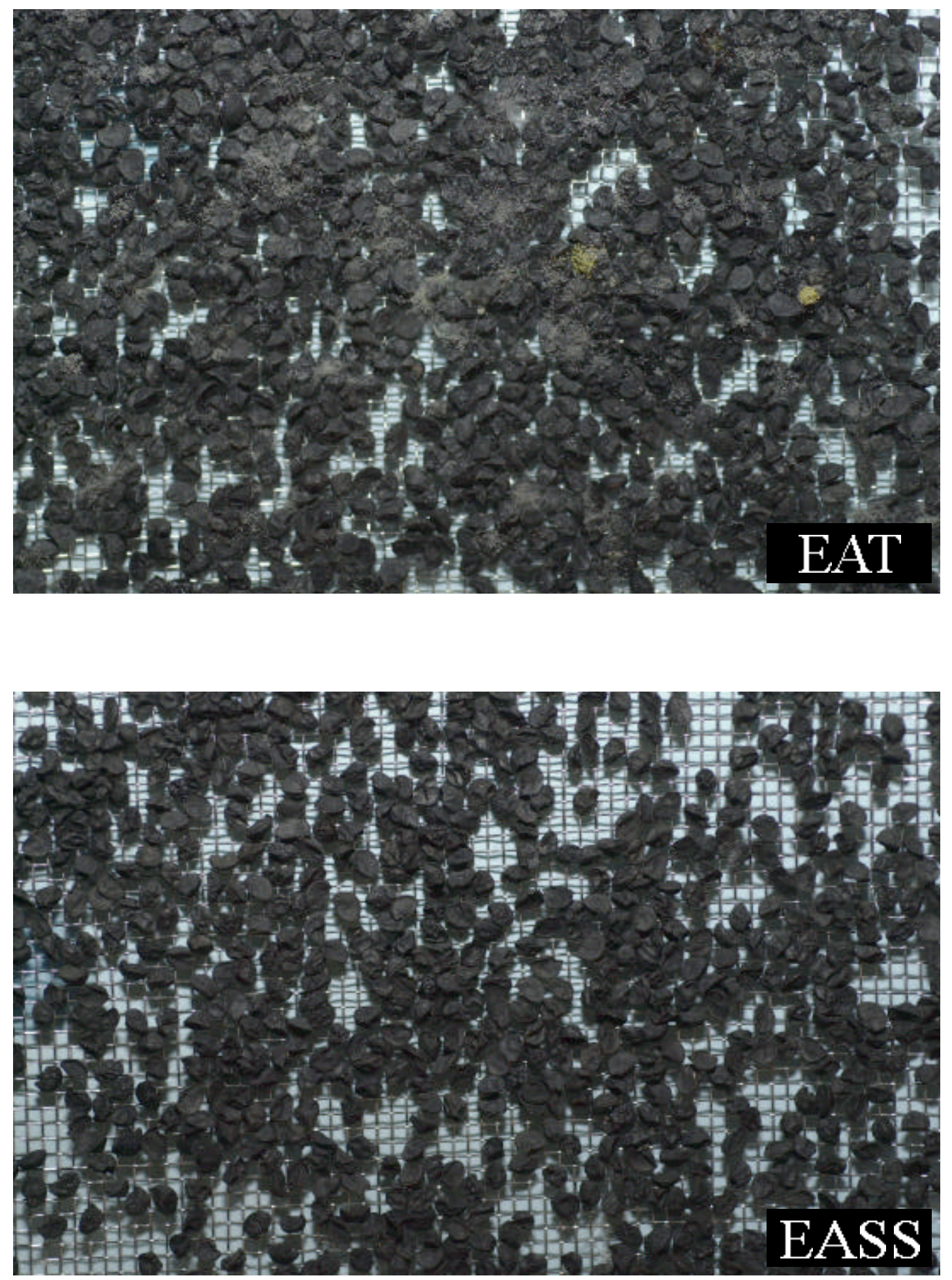

Figura 4 -Amostras de sementes de cebola, cultivar Petroline, submetidas aos testes de enw elhecimento acelerado tradicional ( $\mathrm{EAT}$ ) e enwelhecimento acelerado com solução salina (EASS), 72 horas. 


\subsubsection{Considerações gerais}

Através dos resultados obtidos neste segundo ano experimental, pode-se constatar que, com exceção do teste de condutividade elétrica, o envelhecimento artificial dos lotes do cultivar Aurora proporcionou a obtenção de diferenças mais nítidas na qualidade dos lotes de sementes e, consequentemente, resultados mais evidentes.

Verificou-se assim, para este cultivar, que o lote 3 foi destacado como o de pior desempenho, com igual eficiência por todos os testes avaliados. Os testes de classificação do vigor de plântulas, de frio, de envelhecimento acelerado com uso de solução salina (72 horas) e de deterioração controlada ( $24 \%$ de água), revelaram ainda, o maior potencial do lote 4 , de maneira semelhante ao teste de emergência de plântulas em casa de vegetação; este também foi considerado o lote de melhor qualidade no primeiro ano de execução do experimento, para o cultivar Aurora.

Para o cultivar Petroline, o lote 14 foi considerado como o de maior potencial, seguido pelo lote 11, nos testes de primeira contagem, de classificação do vigor de plântulas, de envelhecimento acelerado tradicional (72 horas) e de deterioração controlada ( $24 \%$ de água); os testes de frio, de condutividade elétrica (50 sementes em 25,50 ou $75 \mathrm{~mL}$ ) e de envelhecimento acelerado com solução salina (72 horas), identificaram somente o melhor desempenho do lote 14.

No entanto, ainda para o cultivar Petroline, os testes de classificação do vigor de plântulas, de condutividade elétrica e de envelhecimento acelerado tradicional (72 horas), acusaram o pior desempenho do lote 13, enquanto que, da mesma maneira que o teste de emergência de plântulas em campo, os testes de frio, de envelhecimento acelerado com solução salina (72 horas) e de deterioração controlada (24\% de água), detectaram, também, o menor vigor do lote 10. 
Assim, para ambos cultivares, como verificado no primeiro ano experimental, evidenciou-se novamente para este segundo ano a maior eficiência do teste de envelhecimento acelerado com solução salina (72 horas), na avaliação do potencial fisiológico de sementes de cebola, devido à relação deste com o teste de emergência de plântulas em campo. Da mesma forma, foram também eficientes os testes de deterioração controlada (24\% de água) e de classificação do vigor de plântulas, em comparação com os demais testes.

\subsubsection{Avaliação do desempenho das plantas}

Para este ano experimental, serão apresentados e discutidos a seguir, os resultados obtidos nos sistemas de semeadura direta e de transplante de mudas; no entanto, deve-se ressaltar que a condução do sistema de semeadura direta foi seriamente prejudicada, devido a problemas que surgiram por ocasião da instalação do experimento, em meados de junho.

Primeiramente, ocorreu entupimento de aspersores do sistema de irrigação, ocasionando desuniformidade da água distribuída nas parcelas, resultando assim, em baixa emergência e falhas no estande (3 a 5 plantas/m, para ambos cultivares). Vale salientar que esta seria a época mais adequada para a germinação das sementes, com temperaturas ao redor de $20^{\circ} \mathrm{C}$; entretanto, após a solução do problema com os aspersores, outra tentativa foi realizada em julho, mas, provavelmente pela ocorrência de baixas temperaturas no período $\left(16,0^{\circ} \mathrm{C}\right)$, houve redução acentuada na emergência das plântulas.

Assim, no mês de novembro, foi realizada nova tentativa de semeadura, a qual resultou em emergência de plântulas também deficiente (5 a 8 plantas/m), embora efetuando-se a primeira avaliação aos 28 dias após a semeadura; porém, em seguida, as plântulas foram seriamente afetadas pela incidência de 
temperatura e precipitação pluvial elevadas, ocorrendo ataque de queima das folhas (Alternaria porri) e, mais uma vez, perda do experimento. Diante disto, foi possível a realização de apenas uma coleta de dados, não sendo efetuada a avaliação da produção final para este sistema. Ao mesmo tempo, para o sistema de transplante de mudas, todas as etapas foram executadas conforme planejado.

\subsubsection{Sistema de semeadura direta}

Nas Tabelas 41 e 42, encontram-se os resultados de altura de plantas, diâmetro na região do colo e massa de matéria seca, obtidos aos 28 dias após a semeadura, respectivamente, para os cultivares Aurora e Petroline.

Tabela 41. Cultivar Aurora: resultados de altura de plantas, diâmetro na região do colo e massa de matéria seca, aos 28 dias após a semeadura, no sistema de semeadura direta, em seis lotes de sementes de cebola (Ano II).

\begin{tabular}{cccc}
\hline & $\begin{array}{c}\text { Altura de } \\
\text { plantas }\end{array}$ & $\begin{array}{c}\text { Diâmetro na } \\
\text { região do colo }\end{array}$ & $\begin{array}{c}\text { Massa de } \\
\text { matéria seca }\end{array}$ \\
\hline Lotes & $(\mathrm{cm})$ & $(\mathrm{cm})$ & $(\mathrm{g})$ \\
1 & $9,36 \mathrm{a}^{*}$ & $0,20 \mathrm{a}$ & $0,0143 \mathrm{a}$ \\
2 & $9,69 \mathrm{a}$ & $0,22 \mathrm{a}$ & $0,0142 \mathrm{a}$ \\
3 & $9,21 \mathrm{a}$ & $0,20 \mathrm{a}$ & $0,0122 \mathrm{a}$ \\
4 & $10,01 \mathrm{a}$ & $0,21 \mathrm{a}$ & $0,0144 \mathrm{a}$ \\
5 & $9,58 \mathrm{a}$ & $0,23 \mathrm{a}$ & $0,0146 \mathrm{a}$ \\
6 & $10,38 \mathrm{a}$ & $0,23 \mathrm{a}$ & $0,0174 \mathrm{a}$ \\
$\mathrm{CV} \%$ & 7,6 & 16,4 & 25,1 \\
\hline
\end{tabular}

* Comparação de médias dentro de cada coluna (teste de Tukey a 5\% de probabilidade). 
Tabela 42. Cultivar Petroline: resultados de altura de plantas, diâmetro na região do colo e massa de matéria seca, aos 28 dias após a semeadura, no sistema de semeadura direta, em seis lotes de sementes de cebola (Ano II).

\begin{tabular}{cccc}
\hline & $\begin{array}{c}\text { Altura de } \\
\text { plantas }\end{array}$ & $\begin{array}{c}\text { Diâmetro na } \\
\text { região do colo }\end{array}$ & $\begin{array}{c}\text { Massa de } \\
\text { matéria seca }\end{array}$ \\
\hline Lotes & $(\mathrm{cm})$ & $(\mathrm{cm})$ & $(\mathrm{g})$ \\
10 & $8,76 \mathrm{a}^{*}$ & $0,20 \mathrm{a}$ & $0,0110 \mathrm{ab}$ \\
11 & $9,65 \mathrm{a}$ & $0,21 \mathrm{a}$ & $0,0113 \mathrm{ab}$ \\
12 & $8,79 \mathrm{a}$ & $0,17 \mathrm{a}$ & $0,0094 \mathrm{ab}$ \\
13 & $8,31 \mathrm{a}$ & $0,18 \mathrm{a}$ & $0,0087 \mathrm{~b}$ \\
14 & $9,58 \mathrm{a}$ & $0,21 \mathrm{a}$ & $0,0140 \mathrm{a}$ \\
15 & $9,04 \mathrm{a}$ & $0,18 \mathrm{a}$ & $0,0120 \mathrm{ab}$ \\
$\mathrm{CV} \%$ & 8,1 & 13,9 & 19,3 \\
\hline
\end{tabular}

* Comparação de médias dentro de cada coluna (teste de Tukey a 5\% de probabilidade).

Em relação ao cultivar Aurora, não foram encontradas diferenças significativas, para nenhum dos parâmetros avaliados, mesmo após o envelhecimento artificial das sementes, o qual proporcionou diferenças mais nítidas entre os lotes, em testes para avaliação do potencial fisiológico, conduzidos em laboratório.

Para o cultivar Petroline, constataram-se diferenças significativas somente na determinação da massa de matéria seca, indicando relação direta com os resultados dos testes de classificação do vigor de plântulas, de frio, de condutividade elétrica (50 sementes em 25,50 ou $75 \mathrm{~mL}$ ), de envelhecimento acelerado tradicional e com solução salina (72 horas), de deterioração controlada (24\% de água) e de emergência de plântulas em campo, os quais acusaram a melhor qualidade do lote 14 e o pior desempenho do lote 13. 
Embora não houvesse condições para o prosseguimento do ensaio, foi possível notar que as informações obtidas para o cultivar Petroline confirmaram as verificadas no primeiro ano experimental, para este mesmo sistema, ao indicar diferenças significativas, quanto ao acúmulo de matéria seca pelas plantas, aos 28 dias após a semeadura, de maneira compatível aos resultados de laboratório.

\subsubsection{Sistema de transplante de mudas}

Neste sistema, não houve, de uma maneira geral, diferenças estatisticamente significativas para altura de plantas, diâmetro na região do colo e massa de matéria seca, ao longo do desenvolvimento das plantas do cultivar Aurora; entretanto, observaram-se diferenças de altura de plantas na fase inicial da formação das mudas, aos 28 dias após a semeadura e de diâmetro na região do colo, aos 84 dias (Tabelas 43, 44 e 45). Esses resultados se relacionaram às informações obtidas na avaliação do potencial fisiológico das sementes, ao indicar maior altura de plantas provenientes do lote 4 e menor altura e diâmetro na região do colo, em plantas desenvolvidas a partir do lote 3; nos testes realizados em laboratório, estes lotes foram caracterizados, respectivamente, como de maior e menor vigor.

Entretanto, constatou-se que, neste ano, as diferenças entre os lotes do cultivar Aurora eram mais amplas, em relação ao primeiro ano; no entanto, essas diferenças não se traduziram durante o desempenho das plantas.

Para o cultivar Petroline, verificaram-se diferenças significativas para altura de plantas (Tabela 46) e massa de matéria seca (Tabela 47) aos 42 dias após a semeadura, mas as mesmas não foram detectadas nas determinações de diâmetro na região do colo (Tabela 48) e nas demais épocas de avaliação. 
Tabela 43. Cultivar Aurora: resultados de altura de plantas, no sistema de transplante de mudas, em seis lotes de sementes de cebola (Ano II).

\begin{tabular}{ccccccc}
\hline & \multicolumn{5}{c}{ Épocas de avaliação } \\
\cline { 2 - 6 } & $28 \mathrm{~d}$ & $42 \mathrm{~d}$ & $84 \mathrm{~d}$ & $98 \mathrm{~d}$ & $112 \mathrm{~d}$ & $126 \mathrm{~d}$ \\
\hline Lotes & $\ldots \ldots \ldots \ldots \ldots \ldots \ldots \ldots \ldots \ldots \ldots \ldots \ldots \ldots \ldots \ldots \ldots \ldots \ldots \ldots \ldots \ldots \ldots \ldots \ldots \ldots \ldots \ldots \ldots \ldots \ldots \ldots \ldots \ldots \ldots \ldots \ldots \ldots \ldots \ldots \ldots \ldots \ldots \ldots \ldots \ldots \ldots \ldots \ldots \ldots \ldots \ldots \ldots$ \\
1 & $15,0 \mathrm{ab} *$ & $18,1 \mathrm{a}$ & $28,2 \mathrm{a}$ & $39,8 \mathrm{a}$ & $44,8 \mathrm{a}$ & $41,8 \mathrm{a}$ \\
2 & $13,5 \mathrm{~b}$ & $17,4 \mathrm{a}$ & $30,7 \mathrm{a}$ & $41,7 \mathrm{a}$ & $48,9 \mathrm{a}$ & $55,6 \mathrm{a}$ \\
3 & $13,3 \mathrm{~b}$ & $18,0 \mathrm{a}$ & $28,2 \mathrm{a}$ & $38,4 \mathrm{a}$ & $39,1 \mathrm{a}$ & $44,2 \mathrm{a}$ \\
4 & $17,2 \mathrm{a}$ & $19,9 \mathrm{a}$ & $29,3 \mathrm{a}$ & $40,1 \mathrm{a}$ & $43,6 \mathrm{a}$ & $43,6 \mathrm{a}$ \\
5 & $17,1 \mathrm{a}$ & $20,1 \mathrm{a}$ & $32,6 \mathrm{a}$ & $41,9 \mathrm{a}$ & $47,9 \mathrm{a}$ & $51,1 \mathrm{a}$ \\
6 & $16,3 \mathrm{ab}$ & $20,7 \mathrm{a}$ & $30,5 \mathrm{a}$ & $44,3 \mathrm{a}$ & $47,2 \mathrm{a}$ & $43,4 \mathrm{a}$ \\
$\mathrm{CV} \%$ & 8,8 & 9,5 & 17,6 & 13,5 & 16,0 & 9,1 \\
\hline
\end{tabular}

* Comparação de médias dentro de cada coluna (teste de Tukey a 5\% de probabilidade).

Tabela 44. Cultivar Aurora: resultados de diâmetro na região do colo, no sistema de transplante de mudas, em seis lotes de sementes de cebola (Ano II).

\begin{tabular}{ccccccc}
\hline & \multicolumn{5}{c}{ Épocas de avaliação } \\
\cline { 2 - 6 } & $28 \mathrm{~d}$ & $42 \mathrm{~d}$ & $84 \mathrm{~d}$ & $98 \mathrm{~d}$ & $112 \mathrm{~d}$ & $126 \mathrm{~d}$ \\
\hline Lotes & $\ldots \ldots \ldots \ldots \ldots \ldots \ldots \ldots \ldots \ldots \ldots \ldots \ldots \ldots \ldots \ldots \ldots \ldots \ldots \ldots \ldots \ldots \ldots \ldots \ldots \ldots \ldots \ldots \ldots \ldots \ldots \ldots \ldots \ldots \ldots \ldots \ldots \ldots \ldots \ldots \ldots \ldots \ldots \ldots \ldots \ldots \ldots \ldots \ldots \ldots \ldots \ldots$ \\
1 & $0,20 \mathrm{a}^{*}$ & $0,30 \mathrm{a}$ & $0,78 \mathrm{ab}$ & $1,18 \mathrm{a}$ & $1,93 \mathrm{a}$ & $2,70 \mathrm{a}$ \\
2 & $0,24 \mathrm{a}$ & $0,30 \mathrm{a}$ & $0,75 \mathrm{~b}$ & $1,23 \mathrm{a}$ & $1,90 \mathrm{a}$ & $3,10 \mathrm{a}$ \\
3 & $0,20 \mathrm{a}$ & $0,30 \mathrm{a}$ & $0,76 \mathrm{~b}$ & $1,09 \mathrm{a}$ & $1,64 \mathrm{a}$ & $3,55 \mathrm{a}$ \\
4 & $0,20 \mathrm{a}$ & $0,30 \mathrm{a}$ & $0,79 \mathrm{ab}$ & $1,34 \mathrm{a}$ & $1,90 \mathrm{a}$ & $3,18 \mathrm{a}$ \\
5 & $0,20 \mathrm{a}$ & $0,30 \mathrm{a}$ & $0,95 \mathrm{a}$ & $1,36 \mathrm{a}$ & $2,04 \mathrm{a}$ & $3,10 \mathrm{a}$ \\
6 & $0,20 \mathrm{a}$ & $0,30 \mathrm{a}$ & $0,77 \mathrm{ab}$ & $1,28 \mathrm{a}$ & $2,34 \mathrm{a}$ & $3,00 \mathrm{a}$ \\
$\mathrm{CV} \%$ & 2,1 & 1,0 & 9,1 & 13,4 & 26,0 & 33,4 \\
\hline
\end{tabular}

* Comparação de médias dentro de cada coluna (teste de Tukey a 5\% de probabilidade). 
Tabela 45. Cultivar Aurora: resultados de massa de matéria seca, no sistema de transplante de mudas, em seis lotes de sementes de cebola (Ano II).

\begin{tabular}{ccccccc}
\hline & \multicolumn{5}{c}{ Épocas de avaliação } \\
\cline { 2 - 7 } & $28 \mathrm{~d}$ & $42 \mathrm{~d}$ & $84 \mathrm{~d}$ & $98 \mathrm{~d}$ & $112 \mathrm{~d}$ & $126 \mathrm{~d}$ \\
\hline Lotes & $\ldots \ldots \ldots \ldots \ldots \ldots \ldots \ldots \ldots \ldots \ldots \ldots \ldots \ldots \ldots \ldots \ldots \ldots \ldots \ldots \ldots \ldots \ldots \ldots \ldots \ldots \ldots \ldots \ldots \ldots \ldots \ldots \ldots \ldots \ldots \ldots \ldots \ldots \ldots \ldots \ldots \ldots \ldots \ldots \ldots \ldots \ldots \ldots \ldots \ldots$ \\
1 & $0,015 \mathrm{a}^{*}$ & $0,040 \mathrm{a}$ & $0,605 \mathrm{a}$ & $1,539 \mathrm{a}$ & $3,505 \mathrm{a}$ & $4,486 \mathrm{a}$ \\
2 & $0,018 \mathrm{a}$ & $0,037 \mathrm{a}$ & $0,608 \mathrm{a}$ & $1,696 \mathrm{a}$ & $3,723 \mathrm{a}$ & $7,476 \mathrm{a}$ \\
3 & $0,013 \mathrm{a}$ & $0,040 \mathrm{a}$ & $0,558 \mathrm{a}$ & $1,260 \mathrm{a}$ & $2,548 \mathrm{a}$ & $7,042 \mathrm{a}$ \\
4 & $0,018 \mathrm{a}$ & $0,056 \mathrm{a}$ & $0,640 \mathrm{a}$ & $1,888 \mathrm{a}$ & $3,383 \mathrm{a}$ & $5,417 \mathrm{a}$ \\
5 & $0,019 \mathrm{a}$ & $0,054 \mathrm{a}$ & $0,894 \mathrm{a}$ & $1,897 \mathrm{a}$ & $4,214 \mathrm{a}$ & $6,779 \mathrm{a}$ \\
6 & $0,017 \mathrm{a}$ & $0,055 \mathrm{a}$ & $0,642 \mathrm{a}$ & $1,809 \mathrm{a}$ & $5,129 \mathrm{a}$ & $4,834 \mathrm{a}$ \\
$\mathrm{CV} \%$ & 21,0 & 24,0 & 26,7 & 31,4 & 43,3 & 50,7 \\
\hline
\end{tabular}

* Comparação de médias dentro de cada coluna (teste de Tukey a 5\% de probabilidade).

Tabela 46. Cultivar Petroline: resultados de altura de plantas, no sistema de transplante de mudas, em seis lotes de sementes de cebola (Ano II).

\begin{tabular}{ccccccc}
\hline & \multicolumn{5}{c}{ Épocas de avaliação } \\
\cline { 2 - 7 } & $28 \mathrm{~d}$ & $42 \mathrm{~d}$ & $84 \mathrm{~d}$ & $98 \mathrm{~d}$ & $112 \mathrm{~d}$ & $126 \mathrm{~d}$ \\
\hline Lotes & $\ldots \ldots \ldots \ldots \ldots \ldots \ldots \ldots \ldots \ldots \ldots \ldots \ldots \ldots \ldots \ldots \ldots \ldots \ldots \ldots \ldots \ldots \ldots \ldots \ldots \ldots \ldots \ldots \ldots \ldots \ldots \ldots \ldots \ldots \ldots \ldots \ldots \ldots \ldots \ldots \ldots \ldots \ldots \ldots \ldots \ldots \ldots \ldots \ldots \ldots$ \\
10 & $12,3 \mathrm{c}$ a* & $16,6 \mathrm{~b}$ & $26,8 \mathrm{a}$ & $38,9 \mathrm{a}$ & $42,7 \mathrm{a}$ & $46,9 \mathrm{a}$ \\
11 & $13,9 \mathrm{a}$ & $19,4 \mathrm{a}$ & $27,0 \mathrm{a}$ & $40,9 \mathrm{a}$ & $47,3 \mathrm{a}$ & $53,9 \mathrm{a}$ \\
12 & $13,9 \mathrm{a}$ & $18,2 \mathrm{ab}$ & $27,4 \mathrm{a}$ & $40,1 \mathrm{a}$ & $50,5 \mathrm{a}$ & $50,3 \mathrm{a}$ \\
13 & $12,5 \mathrm{a}$ & $17,6 \mathrm{ab}$ & $28,6 \mathrm{a}$ & $42,2 \mathrm{a}$ & $43,5 \mathrm{a}$ & $50,8 \mathrm{a}$ \\
14 & $12,9 \mathrm{a}$ & $18,8 \mathrm{ab}$ & $30,2 \mathrm{a}$ & $44,4 \mathrm{a}$ & $49,7 \mathrm{a}$ & $49,5 \mathrm{a}$ \\
15 & $12,4 \mathrm{a}$ & $16,5 \mathrm{~b}$ & $28,3 \mathrm{a}$ & $41,3 \mathrm{a}$ & $45,3 \mathrm{a}$ & $47,5 \mathrm{a}$ \\
$\mathrm{CV} \%$ & 10,7 & 6,8 & 13,6 & 12,7 & 11,7 & 13,1 \\
\hline
\end{tabular}

* Comparação de médias dentro de cada coluna (teste de Tukey a 5\% de probabilidade). 
Tabela 47. Cultivar Petroline: resultados de diâmetro na região do colo, no sistema de transplante de mudas, em seis lotes de sementes de cebola (Ano II).

\begin{tabular}{ccccccc}
\hline & \multicolumn{5}{c}{ Épocas de avaliação } \\
\cline { 2 - 7 } & $28 \mathrm{~d}$ & $42 \mathrm{~d}$ & $84 \mathrm{~d}$ & $98 \mathrm{~d}$ & $112 \mathrm{~d}$ & $126 \mathrm{~d}$ \\
\hline Lotes & $\ldots \ldots \ldots \ldots \ldots \ldots \ldots \ldots \ldots \ldots \ldots \ldots \ldots \ldots \ldots \ldots \ldots \ldots \ldots \ldots \ldots \ldots \ldots \ldots \ldots \ldots \ldots \ldots \ldots \ldots \ldots \ldots \ldots \ldots \ldots \ldots \ldots \ldots \ldots \ldots \ldots \ldots \ldots \ldots \ldots \ldots \ldots$ \\
10 & $0,19 \mathrm{a} *$ & $0,28 \mathrm{a}$ & $0,73 \mathrm{a}$ & $0,95 \mathrm{a}$ & $1,28 \mathrm{a}$ & $1,90 \mathrm{a}$ \\
11 & $0,20 \mathrm{a}$ & $0,30 \mathrm{a}$ & $0,78 \mathrm{a}$ & $1,05 \mathrm{a}$ & $1,74 \mathrm{a}$ & $3,00 \mathrm{a}$ \\
12 & $0,20 \mathrm{a}$ & $0,29 \mathrm{a}$ & $0,74 \mathrm{a}$ & $0,99 \mathrm{a}$ & $1,51 \mathrm{a}$ & $2,23 \mathrm{a}$ \\
13 & $0,19 \mathrm{a}$ & $0,28 \mathrm{a}$ & $0,74 \mathrm{a}$ & $1,08 \mathrm{a}$ & $1,34 \mathrm{a}$ & $2,65 \mathrm{a}$ \\
14 & $0,20 \mathrm{a}$ & $0,30 \mathrm{a}$ & $0,83 \mathrm{a}$ & $1,21 \mathrm{a}$ & $1,69 \mathrm{a}$ & $2,98 \mathrm{a}$ \\
15 & $0,20 \mathrm{a}$ & $0,30 \mathrm{a}$ & $0,73 \mathrm{a}$ & $1,10 \mathrm{a}$ & $1,65 \mathrm{a}$ & $2,98 \mathrm{a}$ \\
CV\% & 2,1 & 7,1 & 14,9 & 13,9 & 19,7 & 25,5 \\
\hline * Comparação de médias dentro de cada coluna (teste de Tukey a 5\% de probabilidade).
\end{tabular}

As diferenças detectadas para altura de plantas e massa de matéria seca, relacionaram-se com os resultados observados na avaliação do vigor das sementes, pelos testes de classificação do vigor de plântulas, de envelhecimento acelerado tradicional ( 72 horas), de deterioração controlada ( $24 \%$ de água) e de emergência de plântulas em campo, na identificação de menor e maior altura e acúmulo de matéria seca para plantas provenientes dos lotes 10 e 11, respectivamente. No entanto, ao contrário do sistema de semeadura direta, embora apenas com base em informações obtidas aos 28 dias após a semeadura, estas diferenças não refletiram o desempenho dos lotes 13 e 14, os quais foram considerados, em laboratório, respectivamente, como os lotes de maior e menor vigor, acompanhados pelos lotes 10 e 11 . 
Tabela 48. Cultivar Petroline: resultados de massa de matéria seca, no sistema de transplante de mudas, em seis lotes de sementes de cebola (Ano II).

\begin{tabular}{ccccccc}
\hline & \multicolumn{5}{c}{ Épocas de avaliação } \\
\cline { 2 - 7 } & $28 \mathrm{~d}$ & $42 \mathrm{~d}$ & $84 \mathrm{~d}$ & $98 \mathrm{~d}$ & $112 \mathrm{~d}$ & $126 \mathrm{~d}$ \\
\hline Lotes & $\ldots \ldots \ldots \ldots \ldots \ldots \ldots \ldots \ldots \ldots \ldots \ldots \ldots \ldots \ldots \ldots \ldots \ldots \ldots \ldots \ldots \ldots \ldots \ldots \ldots \ldots \ldots \ldots \ldots \ldots \ldots \ldots \ldots \ldots \ldots \ldots \ldots \ldots \ldots \ldots \ldots \ldots \ldots$ \\
10 & $0,013 \mathrm{a} *$ & $0,033 \mathrm{~b}$ & $0,421 \mathrm{a}$ & $0,994 \mathrm{a}$ & $1,852 \mathrm{a}$ & $2,837 \mathrm{a}$ \\
11 & $0,016 \mathrm{a}$ & $0,050 \mathrm{a}$ & $0,515 \mathrm{a}$ & $1,311 \mathrm{a}$ & $3,277 \mathrm{a}$ & $6,267 \mathrm{a}$ \\
12 & $0,016 \mathrm{a}$ & $0,042 \mathrm{ab}$ & $0,471 \mathrm{a}$ & $1,138 \mathrm{a}$ & $2,835 \mathrm{a}$ & $4,082 \mathrm{a}$ \\
13 & $0,012 \mathrm{a}$ & $0,040 \mathrm{ab}$ & $0,501 \mathrm{a}$ & $1,323 \mathrm{a}$ & $1,977 \mathrm{a}$ & $5,148 \mathrm{a}$ \\
14 & $0,012 \mathrm{a}$ & $0,039 \mathrm{ab}$ & $0,604 \mathrm{a}$ & $1,664 \mathrm{a}$ & $3,370 \mathrm{a}$ & $6,144 \mathrm{a}$ \\
15 & $0,012 \mathrm{a}$ & $0,037 \mathrm{ab}$ & $0,516 \mathrm{a}$ & $1,418 \mathrm{a}$ & $2,878 \mathrm{a}$ & $4,151 \mathrm{a}$ \\
$\mathrm{CV} \%$ & 18,4 & 17,8 & 30,5 & 32,5 & 36,4 & 37,2 \\
\hline
\end{tabular}

* Comparação de médias dentro de cada coluna (teste de Tukey a 5\% de probabilidade).

É importante considerar que, por ocasião do transplante, houve a ocorrência de temperaturas amenas $\left(20^{\circ} \mathrm{C}\right)$, apropriadas para este período de desenvolvimento da cultura. De acordo com Marcos Filho (1999a), o vigor das sementes responde diretamente à influência do meio ambiente, ou seja, em condições favoráveis para o desenvolvimento da cultura, a emergência das plântulas poderá corresponder aos resultados do teste de germinação e, assim, não seriam verificadas diferenças evidentes entre os lotes.

Provavelmente, estas condições ideais possam ter favorecido o desenvolvimento inicial das plantas, considerando que este sistema foi conduzido em casa de vegetação, até o momento do transplante; entretanto, convém ressaltar que, assim como no primeiro ano, mesmo as diferenças pouco acentuadas entre plantas foram observadas aos 42 dias após a semeadura (época do transplante das mudas). Houve, novamente, confirmação dos resultados obtidos por Stradioto 
Neto et al. (1992) e Piana et al. (1995), quanto à relação direta entre o desempenho de mudas e o potencial fisiológico de sementes de cebola.

Também, no estádio de bulbificação, houve elevação da temperatura e do fotoperíodo, sendo registrados valores de $25^{\circ} \mathrm{C}$ e 11,4 horas de luz, respectivamente, representando condições propícias para a formação dos bulbos. Diante disto, constatou-se que o experimento foi conduzido em condições favoráveis para o desenvolvimento da cultura. Assim, para os resultados referentes à avaliação comercial, produção média de bulbos e valor da produção, apresentados nas Tabelas 49 e 50, respectivamente para os cultivares Aurora e Petroline, também não observaram-se diferenças significativas entre os lotes e, desta maneira, influência direta do vigor das sementes na produção final. Isto significa que eventuais diferenças numéricas no valor da produção não puderam ser associadas à qualidade inicial das sementes.

Tabela 49. Cultivar Aurora: resultados de produção e avaliação comercial de bulbos, no sistema de transplante de mudas, em seis lotes de sementes de cebola (Ano II).

\begin{tabular}{|c|c|c|c|c|c|}
\hline & \multirow{2}{*}{$\begin{array}{l}\text { Número } \\
\text { de bulbos }\end{array}$} & \multicolumn{2}{|c|}{ Avaliação de bulbos } & \multirow{2}{*}{$\begin{array}{c}\text { Produção } \\
\text { média }\end{array}$} & \multirow{2}{*}{$\begin{array}{l}\text { Valor de } \\
\text { produção*** }\end{array}$} \\
\hline & & Diâmetro & Massa & & \\
\hline Lotes & (bulbos $/ \mathrm{m}^{2}$ ) & $(\mathrm{cm})$ & (g) & $(\mathrm{t} / \mathrm{ha})$ & (US\$/ha) \\
\hline 1 & $51,93 \mathrm{a}^{*}$ & $51,00 \mathrm{a}$ & $68,72 \mathrm{a}$ & $35,70 \mathrm{a}$ & $7140,00 \mathrm{a}$ \\
\hline 2 & $51,22 \mathrm{a}$ & 49,46 a & $64,70 \mathrm{a}$ & $33,50 \mathrm{a}$ & 6700,00 a \\
\hline 3 & 50,60 a & $47,41 \mathrm{a}$ & $58,40 \mathrm{a}$ & 29,40 a & 5880,00 a \\
\hline 4 & $55,25 \mathrm{a}$ & $48,15 \mathrm{a}$ & $59,00 \mathrm{a}$ & $32,70 \mathrm{a}$ & $6540,00 \mathrm{a}$ \\
\hline 5 & $53,25 \mathrm{a}$ & $49,24 \mathrm{a}$ & $63,55 \mathrm{a}$ & $33,90 \mathrm{a}$ & $6780,00 \mathrm{a}$ \\
\hline 6 & 53,93 a & $50,57 \mathrm{a}$ & $69,01 \mathrm{a}$ & $37,20 \mathrm{a}$ & 7440,00 a \\
\hline CV\% & 5,8 & 5,6 & 14,9 & 16,2 & 16,2 \\
\hline
\end{tabular}

* Comparação de médias dentro de cada coluna (teste de Tukey a 5\% de probabilidade).

** Valor médio de produção: US\$ 200,00/t (FNP - Agrianual, 2001). 
Tabela 50. Cultivar Petroline: resultados de produção e avaliação comercial de bulbos, no sistema de transplante de mudas, em seis lotes de sementes de cebola (Ano II).

\begin{tabular}{|c|c|c|c|c|c|}
\hline & \multirow{2}{*}{$\begin{array}{l}\text { Número } \\
\text { de bulbos }\end{array}$} & \multicolumn{2}{|c|}{ Avaliação de bulbos } & \multirow{2}{*}{$\begin{array}{c}\text { Produção } \\
\text { média }\end{array}$} & \multirow{2}{*}{$\begin{array}{l}\text { Valor de } \\
\text { produção** }\end{array}$} \\
\hline & & Diâmetro & Massa & & \\
\hline Lotes & (bulbos $/ \mathrm{m}^{2}$ ) & $(\mathrm{cm})$ & (g) & $(\mathrm{t} / \mathrm{ha})$ & (US\$/ha) \\
\hline 10 & $51,92 \mathrm{a}^{*}$ & $50,45 \mathrm{a}$ & $63,62 \mathrm{a}$ & $32,90 \mathrm{a}$ & $6580,00 \mathrm{a}$ \\
\hline 11 & $55,60 \mathrm{a}$ & $48,28 \mathrm{a}$ & $59,37 \mathrm{a}$ & $33,00 \mathrm{a}$ & $6600,00 \mathrm{a}$ \\
\hline 12 & $53,58 \mathrm{a}$ & $50,38 \mathrm{a}$ & $64,39 \mathrm{a}$ & $34,30 \mathrm{a}$ & $6860,00 \mathrm{a}$ \\
\hline 13 & $54,20 \mathrm{a}$ & $51,09 \mathrm{a}$ & $64,82 \mathrm{a}$ & $35,10 \mathrm{a}$ & $7020,00 \mathrm{a}$ \\
\hline 14 & $54,25 \mathrm{a}$ & $49,79 \mathrm{a}$ & $61,38 \mathrm{a}$ & $33,30 \mathrm{a}$ & $6660,00 \mathrm{a}$ \\
\hline 15 & 55,60 a & $49,77 \mathrm{a}$ & $62,50 \mathrm{a}$ & $34,80 \mathrm{a}$ & $6960,00 \mathrm{a}$ \\
\hline CV\% & 4,1 & 5,5 & 15,3 & 13,6 & 13,6 \\
\hline
\end{tabular}

* Comparação de médias dentro de cada coluna (teste de Tukey a 5\% de probabilidade). ** Valor médio de produção: US\$200,00/t (FNP - Agrianual, 2001).

\subsubsection{Considerações gerais}

Diante dos resultados obtidos durante o segundo ano experimental, considerou-se que não houve relações evidentes entre o vigor das sementes e o desempenho das plantas em campo, para ambos cultivares, mesmo após o envelhecimento artificial dos lotes do cultivar Aurora.

Entretanto, para o cultivar Petroline, no sistema de semeadura direta, constatou-se certa relação entre o acúmulo de matéria seca e a avaliação dos lotes em laboratório; porém, não foi possível a obtenção de informações mais detalhadas, devido aos problemas surgidos durante a execução do experimento. Assim, optou-se, para ambos sistemas de cultivo, pela repetição do experimento em campo, constituindo-se o terceiro ano experimental. 


\subsection{Ano III}

Para este ano experimental, serão apresentados e discutidos a seguir, os resultados referentes às avaliações do desempenho das plantas, nos sistemas de semeadura direta e de transplante de mudas, para os cultivares Aurora e Petroline.

\subsubsection{Sistema de semeadura direta}

Para o cultivar Aurora, observam-se nas Tabelas 51, 52 e 53, respectivamente, os resultados das avaliações de altura de plantas, diâmetro na região do colo e massa de matéria seca.

Em todos estes parâmetros determinados, constatou-se apenas diferença estatística entre os lotes 3 e 4, aos 56 dias após a semeadura. Esta diferença, aparentemente esporádica, apresentou relação direta com os resultados observados para os testes de laboratório e para o teste de emergência de plântulas em casa de vegetação.

No entanto, este fato foi detectado somente aos 56 dias após a semeadura, ou seja, na fase inicial do desenvolvimento da cultura, na qual havia baixa competitividade entre plantas. Convém salientar, ainda, que a diferença observada aos 56 dias após a semeadura, não se prolongou após este período. A partir dos 84 dias, houve incremento na altura de plantas, no diâmetro na região do colo e na massa de matéria seca; provavelmente, de acordo com Carvalho (1986), essa ocorrência seja devida a efeitos da interação entre genótipo e ambiente (temperatura e fotoperíodo de $21^{\circ} \mathrm{C}$ e 11,0 horas de luz, respectivamente). 
Tabela 51. Cultivar Aurora: resultados de altura de plantas, no sistema de semeadura direta, em seis lotes de sementes de cebola (Ano III).

\begin{tabular}{ccccccc}
\hline & \multicolumn{5}{c}{ Épocas de avaliação } \\
\cline { 2 - 7 } & $28 \mathrm{~d}$ & $56 \mathrm{~d}$ & $84 \mathrm{~d}$ & $98 \mathrm{~d}$ & $112 \mathrm{~d}$ & $126 \mathrm{~d}$ \\
\hline Lotes & $\ldots \ldots \ldots \ldots \ldots \ldots \ldots \ldots \ldots \ldots \ldots \ldots \ldots \ldots \ldots \ldots \ldots \ldots \ldots \ldots \ldots \ldots \ldots \ldots \ldots \ldots \ldots \ldots \ldots \ldots \ldots \ldots \ldots \ldots \ldots \ldots \ldots \ldots$ \\
1 & $6,24 \mathrm{a}^{*}$ & $22,0 \mathrm{ab}$ & $50,9 \mathrm{a}$ & $57,1 \mathrm{a}$ & $62,9 \mathrm{a}$ & $67,4 \mathrm{a}$ \\
2 & $6,23 \mathrm{a}$ & $21,3 \mathrm{ab}$ & $47,1 \mathrm{a}$ & $58,7 \mathrm{a}$ & $65,8 \mathrm{a}$ & $63,4 \mathrm{a}$ \\
3 & $6,41 \mathrm{a}$ & $19,6 \mathrm{~b}$ & $50,4 \mathrm{a}$ & $59,2 \mathrm{a}$ & $63,1 \mathrm{a}$ & $61,9 \mathrm{a}$ \\
4 & $7,40 \mathrm{a}$ & $25,4 \mathrm{a}$ & $50,6 \mathrm{a}$ & $61,8 \mathrm{a}$ & $65,1 \mathrm{a}$ & $71,0 \mathrm{a}$ \\
5 & $7,74 \mathrm{a}$ & $24,5 \mathrm{ab}$ & $53,6 \mathrm{a}$ & $65,3 \mathrm{a}$ & $70,5 \mathrm{a}$ & $69,3 \mathrm{a}$ \\
CV\% & $7,66 \mathrm{a}$ & $23,7 \mathrm{ab}$ & $47,5 \mathrm{a}$ & $56,3 \mathrm{a}$ & $63,8 \mathrm{a}$ & $63,5 \mathrm{a}$ \\
\hline
\end{tabular}

* Comparação de médias dentro de cada coluna (teste de Tukey a 5\% de probabilidade).

Tabela 52. Cultivar Aurora: resultados de diâmetro na região do colo, no sistema de semeadura direta, em seis lotes de sementes de cebola (Ano III).

\begin{tabular}{ccccccc}
\hline & \multicolumn{5}{c}{ Épocas de avaliação } \\
\cline { 2 - 7 } & $28 \mathrm{~d}$ & $56 \mathrm{~d}$ & $84 \mathrm{~d}$ & $98 \mathrm{~d}$ & $112 \mathrm{~d}$ & $126 \mathrm{~d}$ \\
\hline Lotes & $\ldots \ldots \ldots \ldots \ldots \ldots \ldots \ldots \ldots \ldots \ldots \ldots \ldots \ldots \ldots \ldots \ldots \ldots \ldots \ldots \ldots \ldots \ldots \ldots \ldots \ldots \ldots \ldots \ldots \ldots \ldots \ldots \ldots \ldots \ldots \ldots \ldots \ldots \ldots \ldots \ldots \ldots \ldots \ldots \ldots \ldots$ \\
2 & $0,2 \mathrm{a} *$ & $0,52 \mathrm{abc}$ & $1,27 \mathrm{a}$ & $1,83 \mathrm{a}$ & $2,48 \mathrm{a}$ & $3,30 \mathrm{a}$ \\
3 & $0,2 \mathrm{a}$ & $0,50 \mathrm{bc}$ & $1,20 \mathrm{a}$ & $1,83 \mathrm{a}$ & $2,25 \mathrm{a}$ & $3,18 \mathrm{a}$ \\
4 & $0,2 \mathrm{a}$ & $0,46 \mathrm{c}$ & $1,29 \mathrm{a}$ & $1,98 \mathrm{a}$ & $2,58 \mathrm{a}$ & $2,88 \mathrm{a}$ \\
5 & $0,2 \mathrm{a}$ & $0,60 \mathrm{a}$ & $1,25 \mathrm{a}$ & $1,98 \mathrm{a}$ & $2,55 \mathrm{a}$ & $3,23 \mathrm{a}$ \\
6 & $0,2 \mathrm{a}$ & $0,58 \mathrm{ab}$ & $1,32 \mathrm{a}$ & $2,20 \mathrm{a}$ & $2,75 \mathrm{a}$ & $3,10 \mathrm{a}$ \\
$\mathrm{CV} \%$ & 1,0 & $0,55 \mathrm{bc}$ & $1,22 \mathrm{a}$ & $2,15 \mathrm{a}$ & $2,38 \mathrm{a}$ & $2,85 \mathrm{a}$ \\
\hline
\end{tabular}

* Comparação de médias dentro de cada coluna (teste de Tukey a 5\% de probabilidade). 
Tabela 53. Cultivar Aurora: resultados de massa de matéria seca, no sistema de semeadura direta, em seis lotes de sementes de cebola (Ano III).

\begin{tabular}{ccccccc}
\hline & \multicolumn{5}{c}{ Épocas de avaliação } \\
\cline { 2 - 7 } & $28 \mathrm{~d}$ & $56 \mathrm{~d}$ & $84 \mathrm{~d}$ & $98 \mathrm{~d}$ & $112 \mathrm{~d}$ & $126 \mathrm{~d}$ \\
\hline Lotes & $\ldots \ldots \ldots \ldots \ldots \ldots \ldots \ldots \ldots \ldots \ldots \ldots \ldots \ldots \ldots \ldots \ldots \ldots \ldots \ldots \ldots \ldots \ldots \ldots \ldots \ldots \ldots \ldots \ldots \ldots \ldots \ldots \ldots \ldots \ldots \ldots \ldots \ldots \ldots \ldots \ldots \ldots \ldots \ldots \ldots \ldots \ldots \ldots \ldots \ldots$ \\
1 & $0,006 \mathrm{a}^{*}$ & $0,163 \mathrm{ab}$ & $1,815 \mathrm{a}$ & $3,685 \mathrm{a}$ & $7,118 \mathrm{a}$ & $10,255 \mathrm{a}$ \\
2 & $0,004 \mathrm{a}$ & $0,170 \mathrm{ab}$ & $1,556 \mathrm{a}$ & $3,795 \mathrm{a}$ & $6,178 \mathrm{a}$ & $8,498 \mathrm{a}$ \\
3 & $0,005 \mathrm{a}$ & $0,120 \mathrm{~b}$ & $1,953 \mathrm{a}$ & $4,175 \mathrm{a}$ & $6,728 \mathrm{a}$ & $6,833 \mathrm{a}$ \\
4 & $0,006 \mathrm{a}$ & $0,250 \mathrm{a}$ & $1,829 \mathrm{a}$ & $4,283 \mathrm{a}$ & $7,090 \mathrm{a}$ & $9,683 \mathrm{a}$ \\
5 & $0,006 \mathrm{a}$ & $0,243 \mathrm{a}$ & $2,067 \mathrm{a}$ & $5,480 \mathrm{a}$ & $8,488 \mathrm{a}$ & $9,013 \mathrm{a}$ \\
6 & $0,007 \mathrm{a}$ & $0,208 \mathrm{ab}$ & $1,733 \mathrm{a}$ & $4,493 \mathrm{a}$ & $6,978 \mathrm{a}$ & $7,033 \mathrm{a}$ \\
$\mathrm{CV} \%$ & 20,9 & 25,1 & 28,4 & 29,7 & 30,7 & 30,8 \\
\hline
\end{tabular}

* Comparação de médias dentro de cada coluna (teste de Tukey a 5\% de probabilidade).

Para o cultivar Petroline, encontram-se na Tabela 54, os resultados da avaliação de altura de plantas, podendo-se constatar, aos 28 e 56 dias após a semeadura, maiores valores deste parâmetro para as plantas provenientes dos lotes 11 e 14, bem como valores inferiores para as originadas dos lotes 10 e 13 . Houve, dessa maneira, proporcionalidade com os resultados referentes aos testes de laboratório e de emergência de plântulas, em casa de vegetação e em campo. 
Tabela 54. Cultivar Petroline: resultados de altura de plantas, no sistema de semeadura direta, em seis lotes de sementes de cebola (Ano III).

\begin{tabular}{ccccccc}
\hline & \multicolumn{5}{c}{ Épocas de avaliação } \\
\cline { 2 - 7 } & $28 \mathrm{~d}$ & $56 \mathrm{~d}$ & $84 \mathrm{~d}$ & $98 \mathrm{~d}$ & $112 \mathrm{~d}$ & $126 \mathrm{~d}$ \\
\hline Lotes & $\ldots \ldots \ldots \ldots \ldots \ldots \ldots \ldots \ldots \ldots \ldots \ldots \ldots \ldots \ldots \ldots \ldots \ldots \ldots \ldots \ldots \ldots \ldots \ldots \ldots \ldots \ldots \ldots \ldots \ldots \ldots \ldots \ldots \ldots \ldots \ldots \ldots \ldots \ldots \ldots \ldots \ldots \ldots \ldots \ldots \ldots \ldots \ldots \ldots \ldots \ldots \ldots \ldots$ \\
10 & $6,6 \mathrm{c} \mathrm{b}^{*}$ & $22,0 \mathrm{c}$ & $56,4 \mathrm{a}$ & $64,3 \mathrm{a}$ & $70,3 \mathrm{a}$ & $74,9 \mathrm{a}$ \\
11 & $9,3 \mathrm{a}$ & $29,2 \mathrm{a}$ & $58,7 \mathrm{a}$ & $66,4 \mathrm{a}$ & $73,8 \mathrm{a}$ & $75,3 \mathrm{a}$ \\
12 & $8,4 \mathrm{ab}$ & $25,5 \mathrm{abc}$ & $58,4 \mathrm{a}$ & $65,0 \mathrm{a}$ & $74,4 \mathrm{a}$ & $75,2 \mathrm{a}$ \\
13 & $6,6 \mathrm{~b}$ & $23,9 \mathrm{bc}$ & $54,5 \mathrm{a}$ & $60,6 \mathrm{a}$ & $66,9 \mathrm{a}$ & $73,0 \mathrm{a}$ \\
14 & $9,6 \mathrm{a}$ & $28,7 \mathrm{a}$ & $56,3 \mathrm{a}$ & $65,7 \mathrm{a}$ & $73,9 \mathrm{a}$ & $75,4 \mathrm{a}$ \\
15 & $8,6 \mathrm{ab}$ & $26,0 \mathrm{ab}$ & $55,8 \mathrm{a}$ & $64,6 \mathrm{a}$ & $73,0 \mathrm{a}$ & $70,9 \mathrm{a}$ \\
$\mathrm{CV} \%$ & 11,9 & 6,7 & 7,1 & 8,6 & 5,9 & 7,0 \\
\hline
\end{tabular}

* Comparação de médias dentro de cada coluna (teste de Tukey a 5\% de probabilidade).

Para a avaliação do diâmetro na região do colo (Tabela 55), assim como no cultivar Aurora, foram observadas diferenças significativas entre os lotes somente nas avaliações realizadas aos 56 dias após a semeadura; estas indicaram menor e maior diâmetro para plantas originadas, respectivamente, dos lotes $10 \mathrm{e}$ 14, de maneira compatível aos testes de envelhecimento acelerado com solução salina ( 72 horas) e de deterioração controlada ( $24 \%$ de água), os quais detectaram o maior potencial do lote 14 e o desempenho inferior do lote 10 .

$\mathrm{Na}$ Tabela 56, verificam-se os resultados de massa de matéria seca, onde se observaram diferenças significativas aos 28 e 56 dias após a semeadura, indicando maior acúmulo de matéria seca para as plantas desenvolvidas a partir dos lotes 11 e 14; para as plantas oriundas dos lotes 10 e 13, este acúmulo foi menor. Estes resultados corresponderam diretamente aos obtidos para os testes de laboratório e de emergência de plântulas, em casa de vegetação e em campo. 
Tabela 55. Cultivar Petroline: resultados de diâmetro na região do colo, no sistema de semeadura direta, em seis lotes de sementes de cebola (Ano III).

\begin{tabular}{|c|c|c|c|c|c|c|}
\hline & \multicolumn{6}{|c|}{ Épocas de avaliação } \\
\hline & $28 \mathrm{~d}$ & $56 \mathrm{~d}$ & $84 \mathrm{~d}$ & $98 \mathrm{~d}$ & $112 \mathrm{~d}$ & $126 \mathrm{~d}$ \\
\hline Lotes & $\cdots$ & ․․……… & .………. & ․․……... & ․․…….... & ․․……... \\
\hline 10 & $0,2 \mathrm{a}^{*}$ & $0,52 \mathrm{c}$ & $1,44 \mathrm{a}$ & $1,95 \mathrm{a}$ & $2,60 \mathrm{a}$ & $3,38 \mathrm{a}$ \\
\hline 11 & $0,2 \mathrm{a}$ & $0,65 \mathrm{ab}$ & $1,46 \mathrm{a}$ & $2,05 \mathrm{a}$ & $2,80 \mathrm{a}$ & $3,18 \mathrm{a}$ \\
\hline 12 & $0,2 \mathrm{a}$ & $0,61 \mathrm{abc}$ & $1,36 \mathrm{a}$ & $2,00 \mathrm{a}$ & $2,65 \mathrm{a}$ & $3,45 \mathrm{a}$ \\
\hline 13 & $0,2 \mathrm{a}$ & $0,56 \mathrm{bc}$ & $1,30 \mathrm{a}$ & $1,85 \mathrm{a}$ & $2,65 \mathrm{a}$ & $3,75 \mathrm{a}$ \\
\hline 14 & $0,3 \mathrm{a}$ & $0,68 \mathrm{a}$ & $1,39 \mathrm{a}$ & $1,98 \mathrm{a}$ & $2,55 \mathrm{a}$ & $3,43 \mathrm{a}$ \\
\hline 15 & $0,2 \mathrm{a}$ & $0,62 \mathrm{ab}$ & $1,36 \mathrm{a}$ & $1,98 \mathrm{a}$ & $2,60 \mathrm{a}$ & $3,30 \mathrm{a}$ \\
\hline CV\% & 2,0 & 7,3 & 10,6 & 12,0 & 10,3 & 10,5 \\
\hline
\end{tabular}

Diante destes resultados, de maneira mais evidente à constatada para o cultivar Aurora, considerou-se que o potencial fisiológico dos lotes influenciou diretamente o desenvolvimento inicial das plantas do cultivar Petroline, no sistema de semeadura direta.

No entanto, notou-se que, para este cultivar, as diferenças significativas no desenvolvimento inicial das plantas foram detectadas aos 28 e 56 dias após a semeadura (no cultivar Aurora foram verificadas apenas aos 56 dias); acredita-se que este fato tenha ocorrido devido à maior diferenciação entre os lotes do cultivar Petroline e ao progresso da deterioração das sementes, neste terceiro ano de execução do experimento. 
Tabela 56. Cultivar Petroline: resultados de massa de matéria seca, no sistema de semeadura direta, em seis lotes de sementes de cebola (Ano III).

\begin{tabular}{ccccccc}
\hline & \multicolumn{5}{c}{ Épocas de avaliação } \\
\cline { 2 - 7 } & $28 \mathrm{~d}$ & $56 \mathrm{~d}$ & $84 \mathrm{~d}$ & $98 \mathrm{~d}$ & $112 \mathrm{~d}$ & $126 \mathrm{~d}$ \\
\hline Lotes & $\ldots \ldots \ldots \ldots \ldots \ldots \ldots \ldots \ldots \ldots \ldots \ldots \ldots \ldots \ldots \ldots \ldots \ldots \ldots \ldots \ldots \ldots \ldots \ldots \ldots \ldots \ldots \ldots \ldots \ldots \ldots \ldots \ldots \ldots \ldots \ldots \ldots \ldots \ldots \ldots \ldots \ldots \ldots$ \\
10 & $0,005 \mathrm{c}^{*}$ & $0,153 \mathrm{~b}$ & $2,370 \mathrm{a}$ & $4,278 \mathrm{a}$ & $8,568 \mathrm{a}$ & $12,405 \mathrm{a}$ \\
11 & $0,009 \mathrm{a}$ & $0,315 \mathrm{a}$ & $2,513 \mathrm{a}$ & $5,398 \mathrm{a}$ & $9,578 \mathrm{a}$ & $11,008 \mathrm{a}$ \\
12 & $0,008 \mathrm{a}$ & $0,260 \mathrm{ab}$ & $2,230 \mathrm{a}$ & $4,805 \mathrm{a}$ & $9,308 \mathrm{a}$ & $11,973 \mathrm{a}$ \\
13 & $0,007 \mathrm{~b}$ & $0,190 \mathrm{~b}$ & $1,996 \mathrm{a}$ & $3,975 \mathrm{a}$ & $7,963 \mathrm{a}$ & $12,768 \mathrm{a}$ \\
14 & $0,009 \mathrm{a}$ & $0,338 \mathrm{a}$ & $2,158 \mathrm{a}$ & $4,765 \mathrm{a}$ & $7,890 \mathrm{a}$ & $12,282 \mathrm{a}$ \\
15 & $0,008 \mathrm{ab}$ & $0,245 \mathrm{ab}$ & $2,005 \mathrm{a}$ & $4,783 \mathrm{a}$ & $8,465 \mathrm{a}$ & $10,532 \mathrm{a}$ \\
CV\% & 8,6 & 19,9 & 22,1 & 24,4 & 19,5 & 14,5 \\
\hline * Comparação de médias dentro de cada coluna (teste de Tukey a 5\% de probabilidade).
\end{tabular}

Assim, a partir dos 84 dias após a semeadura não mais se verificaram diferenças estatisticamente significativas, não se observando, para ambos cultivares, reflexos do vigor das sementes na produção final; estes resultados encontram-se nas Tabelas 57 e 58, para os cultivares Aurora e Petroline, respectivamente.

É importante destacar que, neste ano de experimento, o número de plantas/m, obtidas no estabelecimento do estande, variou mais em relação aos anos anteriores, provavelmente devido ao avanço da deterioração dos lotes.

Para o cultivar Aurora foram registrados estandes de 4 a 8 plantas $/ \mathrm{m} \mathrm{e}$, para o cultivar Petroline, de 4 a 7 plantas $/ \mathrm{m}$; vale salientar que os valores inferiores, ou seja, de 4 plantas $/ \mathrm{m}$, foram encontrados somente para os lotes 3 e 13, caracterizados, respectivamente, para os cultivares Aurora e Petroline, como os lotes de menor potencial fisiológico. 
Tabela 57. Cultivar Aurora: resultados de produção e avaliação comercial de bulbos, no sistema de semeadura direta, em seis lotes de sementes de cebola (Ano III).

\begin{tabular}{|c|c|c|c|c|c|}
\hline & \multirow{2}{*}{$\begin{array}{l}\text { Número } \\
\text { de bulbos }\end{array}$} & \multicolumn{2}{|c|}{ Avaliação de bulbos } & \multirow{2}{*}{$\begin{array}{c}\text { Produção } \\
\text { média }\end{array}$} & \multirow{2}{*}{$\begin{array}{l}\text { Valor de } \\
\text { produção** }\end{array}$} \\
\hline & & Diâmetro & Massa & & \\
\hline Lotes & (bulbos $/ \mathrm{m}^{2}$ ) & $(\mathrm{cm})$ & (g) & (t/ha) & (US\$/ha) \\
\hline 1 & $40,00 a^{*}$ & $52,77 \mathrm{a}$ & 95,63 a & $38,30 \mathrm{a}$ & $7650,00 \mathrm{a}$ \\
\hline 2 & $32,08 \mathrm{a}$ & $59,58 \mathrm{a}$ & $121,00 \mathrm{a}$ & $38,80 \mathrm{a}$ & $7764,17 \mathrm{a}$ \\
\hline 3 & $33,33 \mathrm{a}$ & $54,33 \mathrm{a}$ & $97,72 \mathrm{a}$ & $32,60 \mathrm{a}$ & $6514,83 \mathrm{a}$ \\
\hline 4 & $34,58 \mathrm{a}$ & $58,63 \mathrm{a}$ & $114,13 \mathrm{a}$ & $39,50 \mathrm{a}$ & $7893,99 a$ \\
\hline 5 & $51,67 \mathrm{a}$ & 53,18 a & 96,66 a & 49,90 a & $9987,68 \mathrm{a}$ \\
\hline 6 & $35,83 \mathrm{a}$ & 52,86 a & 94,79 a & $34,00 \mathrm{a}$ & $6793,10 \mathrm{a}$ \\
\hline CV\% & 22,9 & 6,8 & 15,7 & 28,4 & 28,4 \\
\hline
\end{tabular}

* Comparação de médias dentro de cada coluna (teste de Tukey a 5\% de probabilidade). ** Valor médio de produção: US\$200,00/t (FNP - Agrianual, 2001).

Diante disto, considerou-se que esta diferença inicial no estabelecimento da cultura, em relação aos lotes de menor vigor, pode estar associada ao menor desempenho inicial das plantas, estando desta forma, de acordo com Ellis (1992); este relatou que sementes de menor vigor podem proporcionar falhas no estande e afetar o posterior desenvolvimento das plantas.

Entretanto, entre os demais lotes estudados, houve maior uniformidade no estabelecimento do estande, ou seja, variações de 6 a 8 plantas $/ \mathrm{m}$; mesmo assim, foram detectadas diferenças significativas no desempenho das plantas, para todos os parâmetros avaliados. Estas diferenças não influenciaram a produção final, ao contrário de Gamiely et al. (1990), que detectaram relação significativa entre o vigor das sementes e produtividade. 
Tabela 58. Cultivar Petroline: resultados de produção e avaliação comercial de bulbos, no sistema de semeadura direta, em seis lotes de sementes de cebola (Ano III).

\begin{tabular}{|c|c|c|c|c|c|}
\hline & \multirow{2}{*}{$\begin{array}{l}\text { Número } \\
\text { de bulbos }\end{array}$} & \multicolumn{2}{|c|}{ Avaliação de bulbos } & \multirow{2}{*}{$\begin{array}{c}\text { Produção } \\
\text { média }\end{array}$} & \multirow{2}{*}{$\begin{array}{c}\text { Valor de } \\
\text { produção** }\end{array}$} \\
\hline & & Diâmetro & Massa & & \\
\hline Lotes & (bulbos $/ \mathrm{m}^{2}$ ) & $(\mathrm{cm})$ & $(\mathrm{g})$ & (t/há) & (US\$/ha) \\
\hline 10 & $50,00 a^{*}$ & $54,89 \mathrm{a}$ & $91,74 \mathrm{a}$ & $45,90 \mathrm{a}$ & $9173,50 \mathrm{a}$ \\
\hline 11 & $32,50 \mathrm{a}$ & $52,19 \mathrm{a}$ & $85,27 \mathrm{a}$ & $27,70 \mathrm{a}$ & $5542,39 \mathrm{a}$ \\
\hline 12 & $49,17 \mathrm{a}$ & $52,41 \mathrm{a}$ & $88,59 \mathrm{a}$ & $43,60 \mathrm{a}$ & $8711,60 \mathrm{a}$ \\
\hline 13 & $38,33 \mathrm{a}$ & $52,95 \mathrm{a}$ & $89,44 \mathrm{a}$ & $34,30 \mathrm{a}$ & $6857,26 \mathrm{a}$ \\
\hline 14 & $43,75 \mathrm{a}$ & $57,54 \mathrm{a}$ & $105,36 \mathrm{a}$ & $46,10 \mathrm{a}$ & $9219,22 \mathrm{a}$ \\
\hline 15 & $45,00 \mathrm{a}$ & $54,84 \mathrm{a}$ & $94,40 \mathrm{a}$ & $42,50 \mathrm{a}$ & $8495,55 \mathrm{a}$ \\
\hline CV\% & 21,4 & 6,8 & 14,9 & 24,8 & 24,8 \\
\hline
\end{tabular}

\subsubsection{Sistema de transplante de mudas}

$\mathrm{Na}$ Tabela 59, observam-se os resultados da avaliação de altura de plantas, os quais detectaram aos 28, 84 e 98 dias após a semeadura, menor altura de plantas originadas do lote 3 ; este foi identificado como de potencial inferior nos testes de laboratório e de emergência de plântulas, em casa de vegetação e em campo. Também, aos 84 dias, houve maior altura de plantas resultantes do lote 4 , o qual foi indicado como o de maior vigor, em laboratório e emergência de plântulas em casa de vegetação. Para as avaliações realizadas aos 42 dias, não foram observadas diferenças entre os lotes, assim como após os 98 dias. 
Tabela 59. Cultivar Aurora: resultados de altura de plantas, no sistema de transplante de mudas, em seis lotes de sementes de cebola (Ano III).

\begin{tabular}{cccccccc}
\hline & \multicolumn{7}{c}{ Épocas de avaliação } \\
\cline { 2 - 8 } & $28 \mathrm{~d}$ & $42 \mathrm{~d}$ & $84 \mathrm{~d}$ & $98 \mathrm{~d}$ & $112 \mathrm{~d}$ & $126 \mathrm{~d}$ & $140 \mathrm{~d}$ \\
\hline Lotes & $\ldots \ldots \ldots \ldots \ldots \ldots \ldots \ldots \ldots \ldots \ldots \ldots \ldots \ldots \ldots \ldots \ldots \ldots \ldots \ldots \ldots \ldots \ldots \ldots \ldots \ldots \ldots \ldots \ldots \ldots \ldots \ldots \ldots \ldots \ldots \ldots \ldots \ldots \ldots \ldots \ldots \ldots \ldots \ldots \ldots \ldots \ldots \ldots \ldots \ldots \ldots \ldots$ \\
1 & $10,7 \mathrm{~b}^{*}$ & $18,0 \mathrm{a}$ & $42,1 \mathrm{ab}$ & $58,1 \mathrm{ab}$ & $73,7 \mathrm{a}$ & $78,4 \mathrm{a}$ & $71,6 \mathrm{a}$ \\
2 & $10,8 \mathrm{~b}$ & $18,8 \mathrm{a}$ & $42,8 \mathrm{ab}$ & $57,6 \mathrm{ab}$ & $74,5 \mathrm{a}$ & $72,7 \mathrm{a}$ & $74,8 \mathrm{a}$ \\
3 & $9,1 \mathrm{c}$ & $17,8 \mathrm{a}$ & $38,1 \mathrm{~b}$ & $52,6 \mathrm{~b}$ & $66,6 \mathrm{a}$ & $66,6 \mathrm{a}$ & $75,6 \mathrm{a}$ \\
4 & $12,5 \mathrm{a}$ & $18,5 \mathrm{a}$ & $48,1 \mathrm{a}$ & $58,3 \mathrm{ab}$ & $70,1 \mathrm{a}$ & $76,8 \mathrm{a}$ & $74,1 \mathrm{a}$ \\
5 & $12,0 \mathrm{a}$ & $18,9 \mathrm{a}$ & $44,7 \mathrm{ab}$ & $61,0 \mathrm{a}$ & $80,4 \mathrm{a}$ & $77,1 \mathrm{a}$ & $75,4 \mathrm{a}$ \\
6 & $12,9 \mathrm{a}$ & $17,5 \mathrm{a}$ & $39,7 \mathrm{ab}$ & $52,9 \mathrm{ab}$ & $67,3 \mathrm{a}$ & $75,4 \mathrm{a}$ & $75,5 \mathrm{a}$ \\
$\mathrm{CV} \%$ & 4,0 & 5,9 & 9,6 & 6,3 & 9,3 & 10,6 & 9,9 \\
\hline
\end{tabular}

* Comparação de médias dentro de cada coluna (teste de Tukey a 5\% de probabilidade).

Nas Tabelas 60 e 61, observam-se, respectivamente, os resultados das avaliações de diâmetro na região do colo e de massa de matéria seca. Verificou-se que, aos 28 e 42 dias após a semeadura, houve diferenças significativas entre os lotes; aos 28 dias, as plantas provenientes dos lotes 1 e 3 apresentaram os menores valores para estes parâmetros, enquanto as plantas desenvolvidas dos lotes 4 e 6 atingiram os maiores valores.

Entretanto, aos 42 dias, verificou-se somente o menor e maior diâmetro das plantas originadas dos lotes 1 e 4 , respectivamente; também, detectou-se o menor acumulo de matéria seca das plantas originadas dos lotes 1 e 3 e, o maior, das plantas produzidas a partir do lote 4. Vale ressaltar que estes resultados corroboraram os obtidos em testes de laboratório e de emergência de plântulas em casa de vegetação e em campo, ao indicar os menores e maiores valores, respectivamente, para os lotes 3 e 4 . 
Tabela 60. Cultivar Aurora: resultados de diâmetro na região do colo, no sistema de transplante de mudas, em seis lotes de sementes de cebola (AnoIII).

\begin{tabular}{cccccccc}
\hline & \multicolumn{7}{c}{ Épocas de avaliação } \\
\cline { 2 - 8 } & $28 \mathrm{~d}$ & $42 \mathrm{~d}$ & $84 \mathrm{~d}$ & $98 \mathrm{~d}$ & $112 \mathrm{~d}$ & $126 \mathrm{~d}$ & $140 \mathrm{~d}$ \\
\hline Lotes & $\ldots \ldots \ldots \ldots \ldots \ldots \ldots \ldots \ldots \ldots \ldots \ldots \ldots \ldots \ldots \ldots \ldots \ldots \ldots \ldots \ldots \ldots \ldots \ldots \ldots \ldots \ldots \ldots \ldots \ldots \ldots \ldots \ldots \ldots \ldots \ldots \ldots \ldots \ldots \ldots \ldots \ldots \ldots \ldots \ldots \ldots \ldots \ldots \ldots \ldots$ \\
1 & $0,25 \mathrm{c}^{*}$ & $0,34 \mathrm{~b}$ & $1,09 \mathrm{a}$ & $1,45 \mathrm{a}$ & $1,98 \mathrm{a}$ & $2,53 \mathrm{a}$ & $3,83 \mathrm{a}$ \\
2 & $0,27 \mathrm{~b}$ & $0,38 \mathrm{ab}$ & $1,18 \mathrm{a}$ & $1,50 \mathrm{a}$ & $1,93 \mathrm{a}$ & $2,80 \mathrm{a}$ & $4,05 \mathrm{a}$ \\
3 & $0,24 \mathrm{c}$ & $0,36 \mathrm{ab}$ & $0,98 \mathrm{a}$ & $1,36 \mathrm{a}$ & $2,03 \mathrm{a}$ & $2,03 \mathrm{a}$ & $3,85 \mathrm{a}$ \\
4 & $0,30 \mathrm{a}$ & $0,40 \mathrm{a}$ & $1,12 \mathrm{a}$ & $1,48 \mathrm{a}$ & $1,83 \mathrm{a}$ & $2,58 \mathrm{a}$ & $4,00 \mathrm{a}$ \\
5 & $0,28 \mathrm{ab}$ & $0,39 \mathrm{a}$ & $1,14 \mathrm{a}$ & $1,38 \mathrm{a}$ & $1,90 \mathrm{a}$ & $2,73 \mathrm{a}$ & $3,50 \mathrm{a}$ \\
6 & $0,29 \mathrm{a}$ & $0,39 \mathrm{a}$ & $1,03 \mathrm{a}$ & $1,28 \mathrm{a}$ & $1,70 \mathrm{a}$ & $2,45 \mathrm{a}$ & $3,88 \mathrm{a}$ \\
$\mathrm{CV} \%$ & 3,1 & 5,3 & 13,0 & 9,9 & 14,5 & 19,0 & 13,8 \\
\hline
\end{tabular}

* Comparação de médias dentro de cada coluna (teste de Tukey a 5\% de probabilidade).

Tabela 61. Cultivar Aurora: resultados de massa de matéria seca, no sistema de transplante de mudas, em seis lotes de sementes de cebola (Ano III).

\begin{tabular}{|c|c|c|c|c|c|c|c|}
\hline & \multicolumn{7}{|c|}{ Épocas de avaliação } \\
\hline & $28 \mathrm{~d}$ & $42 d$ & $84 d$ & $98 \mathrm{~d}$ & $112 d$ & $126 \mathrm{~d}$ & $140 \mathrm{~d}$ \\
\hline Lotes & ...................... & ....... & ....... & $\ldots . \mathrm{g} \ldots .$. & …............ & …......... & ................. \\
\hline 1 & $0,018 c^{*}$ & $0,061 \mathrm{~b}$ & $1,314 \mathrm{a}$ & $2,959 \mathrm{a}$ & $6,683 \mathrm{a}$ & 9,453 a & $15,218 \mathrm{a}$ \\
\hline 2 & $0,020 \mathrm{bc}$ & $0,064 \mathrm{ab}$ & $1,588 \mathrm{a}$ & $2,855 \mathrm{a}$ & $6,165 \mathrm{a}$ & $10,288 \mathrm{a}$ & $13,953 a$ \\
\hline 3 & $0,016 \mathrm{c}$ & $0,058 \mathrm{~b}$ & $1,043 \mathrm{a}$ & $2,583 \mathrm{a}$ & $6,393 \mathrm{a}$ & $7,868 \mathrm{a}$ & $13,555 \mathrm{a}$ \\
\hline 4 & $0,025 \mathrm{a}$ & $0,075 \mathrm{a}$ & $1,619 \mathrm{a}$ & $3,244 \mathrm{a}$ & $5,523 \mathrm{a}$ & $10,032 \mathrm{a}$ & $16,378 \mathrm{a}$ \\
\hline 5 & $0,023 \mathrm{ab}$ & $0,067 \mathrm{ab}$ & $1,481 \mathrm{a}$ & $2,924 \mathrm{a}$ & $6,580 \mathrm{a}$ & $10,953 \mathrm{a}$ & $12,455 \mathrm{a}$ \\
\hline 6 & $0,026 \mathrm{a}$ & $0,063 \mathrm{ab}$ & $1,121 \mathrm{a}$ & $2,540 \mathrm{a}$ & $4,485 \mathrm{a}$ & $9,313 \mathrm{a}$ & $14,928 \mathrm{a}$ \\
\hline CV\% & 9,7 & 9,2 & 30,3 & 19,8 & 22,9 & 33,3 & 20,1 \\
\hline
\end{tabular}

* Comparação de médias dentro de cada coluna (teste de Tukey a 5\% de probabilidade). 
Porém, a partir dos 84 dias após a semeadura, não foram mais observadas diferenças estatísticas entre os lotes, da mesma forma constatada para o sistema de semeadura direta.

Contudo, para o sistema de transplante de mudas, o potencial fisiológico dos lotes influenciou diretamente o desenvolvimento inicial das plantas do cultivar Aurora, até a fase de formação de mudas, estendendo-se após o transplante, até aos 84 dias após a semeadura.

Para o cultivar Petroline, encontram-se na Tabela 62, os resultados da avaliação de altura de plantas, onde se detectaram diferenças significativas entre os lotes somente aos 28 e aos 112 dias após a semeadura; estas diferenças acusaram a menor altura para as plantas provenientes dos lotes 10 e 13 e, maior, para as dos lotes 11 e 14, de maneira compatível aos resultados dos testes de laboratório e de emergência de plântulas em casa de vegetação e em campo.

Tabela 62. Cultivar Petroline: resultados de altura de plantas, no sistema de transplante de mudas, em seis lotes de sementes de cebola (Ano III).

\begin{tabular}{|c|c|c|c|c|c|c|c|}
\hline & \multicolumn{7}{|c|}{ Épocas de avaliação } \\
\hline & $28 d$ & $42 \mathrm{~d}$ & $84 d$ & $98 d$ & $112 \mathrm{~d}$ & $126 d$ & $140 \mathrm{~d}$ \\
\hline \multicolumn{8}{|l|}{ Lotes } \\
\hline 10 & $9,8 b^{*}$ & $17,9 \mathrm{a}$ & $41,8 \mathrm{a}$ & $55,2 \mathrm{a}$ & $68,1 \mathrm{ab}$ & $76,0 \mathrm{a}$ & $78,7 \mathrm{a}$ \\
\hline 11 & $12,4 \mathrm{a}$ & $19,2 \mathrm{a}$ & $37,1 \mathrm{a}$ & $50,3 \mathrm{a}$ & $71,2 \mathrm{ab}$ & $71,2 \mathrm{a}$ & $71,9 \mathrm{a}$ \\
\hline 12 & $10,8 \mathrm{ab}$ & $19,1 \mathrm{a}$ & $38,3 \mathrm{a}$ & 59,6 a & $71,8 \mathrm{ab}$ & $79,7 \mathrm{a}$ & $77,4 \mathrm{a}$ \\
\hline 13 & $9,9 \mathrm{~b}$ & $18,1 \mathrm{a}$ & $39,2 \mathrm{a}$ & $49,5 \mathrm{a}$ & $61,8 \mathrm{~b}$ & $70,8 \mathrm{a}$ & $67,5 \mathrm{a}$ \\
\hline 14 & $11,9 \mathrm{ab}$ & $21,2 \mathrm{a}$ & $44,8 \mathrm{a}$ & $57,3 \mathrm{a}$ & $77,2 \mathrm{a}$ & $76,4 \mathrm{a}$ & $79,5 \mathrm{a}$ \\
\hline 15 & $11,6 \mathrm{ab}$ & $20,0 \mathrm{a}$ & $38,7 \mathrm{a}$ & $57,9 \mathrm{a}$ & $65,8 \mathrm{ab}$ & $79,1 \mathrm{a}$ & $71,0 \mathrm{a}$ \\
\hline $\mathrm{CV} \%$ & 9,0 & 7,7 & 16,1 & 12,5 & 9,2 & 11,0 & 10,3 \\
\hline
\end{tabular}

* Comparação de médias dentro de cada coluna (teste de Tukey a 5\% de probabilidade). 
Os resultados referentes às avaliações de diâmetro na região do colo e de massa de matéria seca estão apresentados nas Tabelas 63 e 64, respectivamente.

Para o diâmetro na região do colo, detectaram-se diferenças significativas aos 28, 42, 98 e 112 dias após a semeadura, indicando maiores valores para as plantas produzidas a partir do lote 14, seguido das do lote 11, aos 28 dias e, menores para as plantas oriundas dos lotes 10 e 13, de maneira semelhante aos resultados observados nos testes de classificação do vigor de plântulas, de envelhecimento acelerado com solução salina (72 horas), de deterioração controlada ( $24 \%$ de água) e de emergência de plântulas em casa de vegetação e em campo; nos resultados de massa de matéria seca, com exceção da avaliação aos 98 dias após a semeadura, observaram-se estas mesmas diferenças.

Tabela 63. Cultivar Petroline: resultados de diâmetro na região do colo, no sistema de transplante de mudas, em seis lotes de sementes de cebola (Ano III).

\begin{tabular}{|c|c|c|c|c|c|c|c|}
\hline & \multicolumn{7}{|c|}{ Épocas de avaliação } \\
\hline & $28 \mathrm{~d}$ & $42 \mathrm{~d}$ & $84 \mathrm{~d}$ & $98 \mathrm{~d}$ & $112 \mathrm{~d}$ & $126 \mathrm{~d}$ & $140 \mathrm{~d}$ \\
\hline Lotes & . & . & . & $. \mathrm{cm} \ldots . . .$. & ………. & ................ & ……....... \\
\hline 10 & $0,23 b^{*}$ & $0,37 \mathrm{bcd}$ & $1,03 \mathrm{a}$ & $1,15 \mathrm{~b}$ & $1,63 \mathrm{~b}$ & $2,28 \mathrm{a}$ & $3,27 \mathrm{a}$ \\
\hline 11 & $0,29 \mathrm{a}$ & $0,39 \mathrm{abc}$ & $1,15 \mathrm{a}$ & $1,30 \mathrm{ab}$ & $1,75 \mathrm{ab}$ & $2,23 \mathrm{a}$ & $3,13 \mathrm{a}$ \\
\hline 12 & $0,27 \mathrm{ab}$ & $0,36 \mathrm{~cd}$ & $1,11 \mathrm{a}$ & $1,25 \mathrm{ab}$ & $1,88 \mathrm{ab}$ & $2,53 \mathrm{a}$ & $3,45 \mathrm{a}$ \\
\hline 13 & $0,24 \mathrm{~b}$ & $0,36 \mathrm{~d}$ & $1,05 \mathrm{a}$ & $1,18 \mathrm{ab}$ & $1,68 \mathrm{~b}$ & $2,18 \mathrm{a}$ & $3,13 \mathrm{a}$ \\
\hline 14 & $0,30 \mathrm{a}$ & $0,40 \mathrm{a}$ & $1,19 \mathrm{a}$ & $1,39 \mathrm{ab}$ & $2,25 \mathrm{a}$ & $2,23 \mathrm{a}$ & $3,28 \mathrm{a}$ \\
\hline 15 & $0,26 \mathrm{ab}$ & $0,39 a b$ & $1,14 \mathrm{a}$ & $1,49 \mathrm{a}$ & $1,60 \mathrm{~b}$ & $2,38 \mathrm{a}$ & $3,25 \mathrm{a}$ \\
\hline $\mathrm{CV} \%$ & 7,5 & 3,3 & 10,6 & 10,8 & 12,3 & 17,8 & 15,2 \\
\hline
\end{tabular}

* Comparação de médias dentro de cada coluna (teste de Tukey a 5\% de probabilidade). 
Tabela 64. Cultivar Petroline: resultados de massa de matéria seca, no sistema de transplante de mudas, em seis lotes de sementes de cebola (Ano III).

\begin{tabular}{cccccccc}
\hline & \multicolumn{7}{c}{ Épocas de avaliação } \\
\cline { 2 - 7 } & $28 \mathrm{~d}$ & $42 \mathrm{~d}$ & $84 \mathrm{~d}$ & $98 \mathrm{~d}$ & $112 \mathrm{~d}$ & $126 \mathrm{~d}$ & $140 \mathrm{~d}$ \\
\hline Lotes & $\ldots \ldots \ldots \ldots \ldots \ldots \ldots \ldots \ldots \ldots \ldots \ldots \ldots \ldots \ldots \ldots \ldots \ldots \ldots \ldots \ldots \ldots \ldots \ldots \ldots \ldots \ldots \ldots \ldots \ldots \ldots \ldots \ldots \ldots \ldots \ldots \ldots \ldots \ldots \ldots \ldots \ldots \ldots \ldots \ldots \ldots \ldots \ldots \ldots \ldots \ldots \ldots \ldots \ldots \ldots$ \\
10 & $0,014 \mathrm{~d}^{*}$ & $0,058 \mathrm{bc}$ & $1,212 \mathrm{a}$ & $1,950 \mathrm{a}$ & $4,225 \mathrm{~b}$ & $7,893 \mathrm{a}$ & $14,088 \mathrm{a}$ \\
11 & $0,023 \mathrm{ab}$ & $0,071 \mathrm{ab}$ & $1,268 \mathrm{a}$ & $2,179 \mathrm{a}$ & $5,575 \mathrm{ab}$ & $7,558 \mathrm{a}$ & $13,253 \mathrm{a}$ \\
12 & $0,018 \mathrm{bcd}$ & $0,066 \mathrm{abc}$ & $1,160 \mathrm{a}$ & $2,394 \mathrm{a}$ & $5,985 \mathrm{ab}$ & $9,405 \mathrm{a}$ & $13,878 \mathrm{a}$ \\
13 & $0,016 \mathrm{~cd}$ & $0,055 \mathrm{c}$ & $1,153 \mathrm{a}$ & $1,803 \mathrm{a}$ & $4,208 \mathrm{~b}$ & $6,473 \mathrm{a}$ & $12,285 \mathrm{a}$ \\
14 & $0,026 \mathrm{a}$ & $0,076 \mathrm{a}$ & $1,625 \mathrm{a}$ & $2,728 \mathrm{a}$ & $8,532 \mathrm{a}$ & $7,180 \mathrm{a}$ & $16,045 \mathrm{a}$ \\
15 & $0,021 \mathrm{abc}$ & $0,074 \mathrm{a}$ & $1,503 \mathrm{a}$ & $3,078 \mathrm{a}$ & $4,100 \mathrm{~b}$ & $8,918 \mathrm{a}$ & $12,508 \mathrm{a}$ \\
$\mathrm{CV} \%$ & 13,6 & 10,0 & 33,1 & 25,6 & 27,8 & 32,4 & 31,1 \\
\hline
\end{tabular}

* Comparação de médias dentro de cada coluna (teste de Tukey a 5\% de probabilidade).

Assim, para este cultivar, observaram-se diferenças significativas até aos 112 dias após a semeadura, ao contrário do cultivar Aurora, no qual as diferenças foram detectadas somente até aos 84 dias; isto ocorreu, provavelmente, pela maior diferenciação no potencial fisiológico verificada entre os lotes do cultivar Petroline, além do maior avanço do processo de deterioração das sementes neste ano experimental.

É importante considerar, também, que no sistema de semeadura direta as diferenças significativas foram observadas apenas até aos 56 dias após a semeadura, para ambos cultivares, enquanto que no sistema de transplante de mudas, estas diferenças prolongaram-se até aos 112 dias para o cultivar Petroline; este fato pode ser explicado pela instalação do sistema de transplante de mudas ter sido realizada em aproximadamente um mês antes do sistema de semeadura direta, coincidindo, aos 112 dias, com o aumento da temperatura e do fotoperíodo propícios para o início do processo de bulbificação. 
No entanto, constatou-se que as relações entre o vigor das sementes e o desempenho das plantas em campo, mesmo sendo verificadas maiores diferenças entre os lotes, não foram refletidas na produção final, para ambos cultivares; estes resultados estão apresentados nas Tabelas 65 e 66, para os cultivares Aurora e Petroline, respectivamente.

Estas informações estão de acordo com Ocana Gil et al. (1991), os quais observaram diferenças iniciais entre lotes de sementes de cebola, em sistema de transplante de mudas, mas não verificaram influência na produção de bulbos.

Tabela 65. Cultivar Aurora: resultados de produção e avaliação comercial de bulbos, no sistema de semeadura direta, em seis lotes de sementes de cebola (Ano III).

\begin{tabular}{|c|c|c|c|c|c|}
\hline & \multirow{2}{*}{$\begin{array}{l}\text { Número } \\
\text { de bulbos }\end{array}$} & \multicolumn{2}{|c|}{ Avaliação de bulbos } & \multirow{2}{*}{$\begin{array}{c}\text { Produção } \\
\text { média }\end{array}$} & \multirow{2}{*}{$\begin{array}{c}\text { Valor de } \\
\text { produção** }\end{array}$} \\
\hline & & Diâmetro & Massa & & \\
\hline Lotes & (bulbos $/ \mathrm{m}^{2}$ ) & $(\mathrm{cm})$ & $(\mathrm{g})$ & $(\mathrm{t} / \mathrm{ha})$ & (US\$/ha) \\
\hline 1 & $65,00 a^{*}$ & $52,27 \mathrm{a}$ & $100,50 \mathrm{a}$ & $65,30 \mathrm{a}$ & $13065,00 \mathrm{a}$ \\
\hline 2 & $63,33 \mathrm{a}$ & $54,64 \mathrm{a}$ & $105,01 \mathrm{a}$ & $66,50 \mathrm{a}$ & $13300,63 \mathrm{a}$ \\
\hline 3 & $60,00 \mathrm{a}$ & $53,32 \mathrm{a}$ & $98,82 \mathrm{a}$ & $59,30 \mathrm{a}$ & $11858,70 \mathrm{a}$ \\
\hline 4 & $68,33 \mathrm{a}$ & $53,74 \mathrm{a}$ & $102,67 \mathrm{a}$ & $70,20 \mathrm{a}$ & $14031,23 \mathrm{a}$ \\
\hline 5 & 60,83 a & $59,55 \mathrm{a}$ & $132,00 \mathrm{a}$ & $80,30 \mathrm{a}$ & $16060,00 \mathrm{a}$ \\
\hline 6 & $60,00 \mathrm{a}$ & 51,68 a & $92,35 \mathrm{a}$ & $55,40 \mathrm{a}$ & $11081,70 \mathrm{a}$ \\
\hline $\mathrm{CV} \%$ & 8,5 & 10,4 & 27,4 & 28,8 & 28,8 \\
\hline
\end{tabular}

* Comparação de médias dentro de cada coluna (teste de Tukey a 5\% de probabilidade). ** Valor médio de produção: US\$200,00/t (FNP - Agrianual, 2001). 
Tabela 66. Cultivar Petroline: resultados de produção e avaliação comercial de bulbos, no sistema de transplante de mudas, em seis lotes de sementes de cebola (Ano III).

\begin{tabular}{cccccc}
\hline \multirow{2}{*}{ Lotes } & Número & \multicolumn{2}{c}{ Avaliação de bulbos } & Produção & $\begin{array}{c}\text { Valor de } \\
\text { de bulbos }\end{array}$ \\
\cline { 2 - 4 } & Diâmetro & Massa & Média & produção** \\
\hline 10 & $63,33 \mathrm{a}^{*}$ & $55,70 \mathrm{a}$ & $106,40 \mathrm{a}$ & $67,40 \mathrm{a}$ & $13477,33 \mathrm{a}$ \\
11 & $62,50 \mathrm{a}$ & $49,49 \mathrm{a}$ & $77,11 \mathrm{a}$ & $48,20 \mathrm{a}$ & $9638,13 \mathrm{a}$ \\
12 & $66,67 \mathrm{a}$ & $50,31 \mathrm{a}$ & $85,71 \mathrm{a}$ & $57,10 \mathrm{a}$ & $11427,33 \mathrm{a}$ \\
13 & $62,50 \mathrm{a}$ & $52,56 \mathrm{a}$ & $85,33 \mathrm{a}$ & $53,30 \mathrm{a}$ & $10665,94 \mathrm{a}$ \\
14 & $63,33 \mathrm{a}$ & $51,91 \mathrm{a}$ & $88,82 \mathrm{a}$ & $56,30 \mathrm{a}$ & $11250,85 \mathrm{a}$ \\
15 & $55,00 \mathrm{a}$ & $52,33 \mathrm{a}$ & $88,29 \mathrm{a}$ & $48,60 \mathrm{a}$ & $9711,35 \mathrm{a}$ \\
$\mathrm{CV} \%$ & 13,5 & 11,8 & 25,0 & 25,5 & 25,5 \\
\hline
\end{tabular}

* Comparação de médias dentro de cada coluna (teste de Tukey a 5\% de probabilidade). ** Valor médio de produção: US\$200,00/t (FNP - Agrianual, 2001).

Assim, como também verificado nos demais anos experimentais, considerou-se que a partir do aumento de competição entre as plantas, associado à interação entre respostas de genótipo e de fatores ambientais, o efeito do vigor da semente sobre o vegetal é atenuado, corroborando assim, Carvalho (1986) e TeKrony \& Egli (1991).

Portanto, as diferenças entre os lotes, seguramente detectadas em testes para a avaliação do potencial fisiológico das sementes, exerceram efeito significativo sobre o desempenho inicial das plantas, para ambos cultivares e sistemas de cultivo. Esses efeitos, diretamente dependentes do grau das diferenças de qualidade entre os lotes, não se mantiveram com o decorrer do desenvolvimento da cultura e não afetaram diretamente a produção final. 


\subsection{Considerações finais}

Os resultados obtidos nesta pesquisa mostraram que, de uma maneira geral, os testes realizados para avaliação do potencial fisiológico das sementes identificaram, de maneira confiável, diferenças evidentes entre os lotes avaliados.

Entretanto, deve-se destacar que o teste de envelhecimento acelerado com solução salina, durante 72 horas, revelou associação mais estreita com a emergência de plântulas em casa de vegetação e em campo, para ambos cultivares, nos dois anos de condução do experimento; este teste pode ser considerado como alternativa promissora para utilização em programas de controle de qualidade, pois requer metodologia e equipamento semelhantes ao procedimento tradicional.

Da mesma forma, o teste de deterioração controlada, com grau de umidade das sementes ajustado para $24 \%$, também foi considerado eficiente. Assim, apesar de ser mais trabalhoso que o envelhecimento acelerado, exigindo a uniformização controlada do teor de água das sementes, apresenta possibilidade considerável de padronização.

Portanto, ambos testes, baseados praticamente no mesmo princípio, poderão ser utilizados em programas de controle de qualidade de sementes de cebola; no entanto, segundo Marcos Filho (1999a), como o vigor pode ser refletido através de várias características, é mais interessante a combinação de resultados de testes que avaliem diferentes características da semente associadas ao vigor.

Neste sentido, o teste de classificação do vigor de plântulas pode complementar os resultados dos testes de envelhecimento acelerado com solução salina e de deterioração controlada, pois além de também ter sido considerado eficiente na avaliação do potencial fisiológico de sementes de cebola, apresenta facilidade pela execução concomitante com o teste de germinação. 
$\mathrm{O}$ teste de condutividade elétrica, devido à possibilidade de rápida obtenção das informações, em apenas quatro horas de embebição, seria de grande interesse na avaliação do vigor de sementes de cebola; porém, o mesmo apresentou resultados discrepantes, dependendo do cultivar avaliado, exigindo estudos adicionais antes da tomada de uma posição definitiva.

Em relação aos testes de frio e de primeira contagem do teste de germinação, constatou-se que os mesmos proporcionaram respostas menos consistentes para avaliarem o potencial fisiológico de sementes de cebola.

Diante disto, embora observando-se que os testes não foram igualmente eficientes, considerou-se que estas informações poderão contribuir para o aprimoramento de procedimentos que buscam solidez em programas de controle de qualidade de sementes de cebola.

Entretanto, é de fundamental importância, ressaltar a influência do vigor das sementes sobre o desempenho das plantas, visto que, nesta pesquisa, evidenciou-se este fato na fase inicial do desenvolvimento da cultura, para ambos sistemas de cultivo estudados.

Sobretudo, convém lembrar que sementes de cebola possuem quantidade relativamente pequena de reservas armazenadas, diretamente aproveitadas para o desenvolvimento das plântulas; no entanto, no estádio vegetativo, a cultura apresenta baixa capacidade fotossintética, devido ao lento crescimento inicial e ao desenvolvimento ereto das folhas. Assim, durante a fase tipicamente vegetativa da cultura, sementes mais vigorosas poderão impulsionar o crescimento das plântulas e, consequentemente, beneficiar o desempenho das plantas; isto, porém, depende do grau de diferenciação entre os lotes, ou seja, quando as diferenças entre os lotes se acentuam, os efeitos do vigor das sementes se tornam mais evidentes. 
Nesta pesquisa, as relações verificadas entre o vigor de sementes e o desempenho de plantas em campo, foram atenuadas com o decorrer do desenvolvimento da cultura, principalmente quando iniciou o processo de bulbificação, predominando a influência da interação genótipo e ambiente sobre a formação dos bulbos e o rendimento final.

De acordo com Burris (1976), Roberts (1986), TeKrony \& Egli (1991), Ellis (1992), Finch-Savage (1995) e Carvalho \& Nakagawa (2000), em espécies com ciclo relativamente mais curto, especialmente aquelas cujo produto comercial é uma estrutura vegetativa, a influência do vigor das sementes sobre o desempenho das plantas e a produção, pode ser mais acentuada, quando comparadas às espécies produtoras de grãos; isto, em parte, foi comprovado nesta pesquisa, mas o efeito do vigor da semente se revelou mais importante para o desempenho inicial das plantas.

No sistema de semeadura direta, onde se utiliza maior quantidade de sementes para atingir uniformidade do estande, o uso de lotes de potencial fisiológico comprovadamente elevado pode garantir o estabelecimento inicial da população de plantas e o melhor desempenho destas para o início do processo de bulbificação.

No sistema de transplante, as sementes de maior vigor poderão proporcionar melhor formação inicial das mudas, conduzindo ao melhor desempenho no campo, entre as fases de transplantio e formação dos bulbos.

Contudo, pesquisas desta natureza, devem ser intensificadas, visando o aprimoramento de procedimentos para avaliação do potencial fisiológico das sementes de cebola e demais hortaliças consideradas de significativo valor econômico nacional, bem como o esclarecimento dos efeitos do vigor no desempenho das plantas em campo. 


\section{CONCLUSÕES}

A partir das informações obtidas nas condições em que esta pesquisa foi realizada, concluiu-se que:

a) Os testes de envelhecimento acelerado com uso de solução saturada de $\mathrm{NaCl}\left(41^{\circ} \mathrm{C} / 72 \mathrm{horas}\right.$ ), de deterioração controlada (ajuste do grau de umidade das sementes para $24 \%$ de água $/ 45^{\circ} \mathrm{C} / 24$ horas) e de classificação do vigor de plântulas, são considerados adequados para avaliação do potencial fisiológico de sementes de cebola, em programas de controle de qualidade.

b) As relações entre o vigor das sementes de cebola e o desempenho das plantas, manifestam-se durante a fase inicial do desenvolvimento da cultura, principalmente quando as diferenças entre o potencial fisiológico dos lotes são acentuadas.

c) Os efeitos do vigor das sementes sobre o desempenho das plantas não persistem ao final do ciclo da cultura e não afetam diretamente a produção de bulbos, tanto em semeadura direta como no sistema de transplante. 


\section{REFERÊNCIAS BIBLIOGRÁFICAS}

ALSADON, A.; YULE, L.J.; POWELL, A.A. Influence of seed ageing on the germination, vigour and emergence in module trays of tomato and cucumber seeds. Seed Science and Technology, v.23, p.665-672, 1995.

ALVARENGA, E.M.; SILVA, R.F.; ARAÚJO, E.; CARDOSO, A.A. Influência da idade e armazenamento pós-colheita dos frutos na qualidade das sementes de melancia. Horticultura Brasileira, v.2, n.2, p.5-8, 1984.

ANDRADE, R.N.; FORMOSO, A. Análise de sementes de hortaliças. In: ENCONTRO SOBRE PRODUÇÃO DE SEMENTES DE HORTALIÇAS, Brasília, 1991. Anais. Brasília: EMBRAPA, CNPH, 1991. p.113-123. (EMBRAPA. CNPH, Documentos, 8).

ANDRADE, R.N.; SANTOS, D.S.B.; SANTOS, B.G.; MELLO, V.D. Correlação entre testes de vigor em sementes de cenoura armazenadas por diferentes períodos. Pesquisa Agropecuária Gaúcha, v.1, n.2, p.153-162, 1995.

ASSOCIATION OF OFFICIAL SEED ANALYSTS. Seed vigour testing handbook. East Lasing, 1983. 88p. (Handbook on Seed Testing. Contribution, 32). 
BHERING, M.C.; DIAS, D.C.F.S.; GOMES, J.M.; BARROS, D.I. Métodos para avaliação do vigor de sementes de pepino. Revista Brasileira de Sementes, v.22, n.2. p.171-175, 2000.

BRASIL. Ministério da Agricultura e Reforma Agrária. Regras para análise de sementes. Brasília: SNDA, DNDV, CLAV, 1992. 365p.

BURRIS, J.S. Seed/seedling vigor and field performance. Journal of Seed Technology, v.1, n.2, p.58-74, 1976.

CALIARI, M.F.; MARCOS FILHO, J. Comparação entre métodos para a avaliação da qualidade fisiológica de sementes de ervilha (Pisum sativum L.). Revista Brasileira de Sementes, v.12, n.3, p. 52-75, 1990.

CANEPPELE, M.A.B. Influência da embalagem, do ambiente e do período de armazenamento na qualidade da semente de cebola. Viçosa, 1994. 80p. Dissertação (Mestrado) - Universidade Federal de Viçosa.

CARVALHO, N.M. Vigor de sementes. In: CICERO, S.M., MARCOS FILHO, J., SILVA, W.R. Atualização em produção de sementes. Campinas: Fundação Cargill, 1986. p.207-223.

CARVALHO, N.M.; NAKAGAWA, J. Sementes: ciência, tecnologia e produção. Jaboticabal: Funep, 2000. 588p.

DELOUCHE, J.C.; BASKIN, C.C. Acelerated aging techniques for predicting the relative storability of seed lots. Seed Science and Technology, v.1, n.2, p.427-452, 1973. 
DIAS, D.C.F.S.; VIEIRA, A.N.; BHERING, M.C. Condutividade elétrica e lixiviação de potássio para avaliação do vigor de sementes de hortaliças: feijão vagem e quiabo. Revista Brasileira de Sementes, v.20, n.2, p.408-413, 1998.

EGLI, D.B.; TeKRONY, D.M.; WIRALAGA, R.A. Effect of soybean seed vigor and size on seedling growth. Journal of Seed Technology, v.14, p.1-12, 1990.

ELLIS, R.H. Seed and seedling vigour in relation to crop growth and yield. Plant Growth Regulation, v.11, p.249-255, 1992.

FERREIRA, M.D.; CASTELLANE, P.D. Cultura da cebola: recomendações gerais. 2. ed., Guaxupé: Cooxupé, 1988. 9p. (Boletim Técnico Olericultura, 1).

FINCH-SAVAGE, W.E. Influence of seed quality on crop establishment, growth and yield. In: BASRA, A.S. (Ed.). Seed quality: basic mechanisms and agricultural implications. New York: Food Products Press, 1995. cap.11, p.361-384.

FNP CONSULTORIA \& COMÉRCIO. AGRIANUAL 2001: anuário da agricultura brasileira. São Paulo, 2001. 350p.

FONTES, P.C.R. Cultura da cebola. Viçosa: UFV, 1998. 40p. (Cadernos Didáticos, 26).

GAMIELY, S.; SMITTLE, D.A.; MILLS, H.A.; BANNA, G.I. Onion seed size, weight and elemental content affect germination and bulb yield. Hortscience, v.25, n.5, p.522-523, 1990. 
GEORGE, R.A.T. Vegetable seed production. London: Longman, 1985. cap.14, p.270-287: Alliaceae.

GUEDES, A .C.; NASCIMENTO, W.M. Efeito do tempo de frigorificação das raízes na produção e qualidade de sementes de cenoura, cv. Brasília. Horticultura Brasileira, v.6, n.2, p.7-9, 1988.

GUIMARÃES, J.R.M.; MALAVASI, M.M.; LOPES, H.M. Definição do protocolo do teste de condutividade elétrica para avaliação do vigor de sementes de alface. Informativo ABRATES, v.3, n.3, p.138, 1993.

HAMPTON, J.G.; COOLBEAR, P. Potencial versus actual seed performance can vigour testing provide an answer? Seed Science and Technology, v.18, p.215-228, 1990.

HAMPTON, J.G.; LUNGWANGWA, A.L.; HILL, K.A. The bulk conductivity test for Lotus seed lots. Seed Science and Technology, v.22, n.1, p.177-180, 1994.

HANUMAIAH, L.; ANDREWS, C.H. Effects of seed size in cabbage and turnip on performance of seeds, seedlings and plants. Proceedings of the Association of Oficial Seed Analysts, v.63, p.117-125, 1973.

IDIARTE, H.G. Relação do envelhecimento acelerado na qualidade fisiológica de sementes de cebola. Piracicaba, 1995. 84p. Dissertação (Mestrado) - Escola Superior de Agricultura "Luiz de Queiroz”, Universidade de São Paulo. 
INTERNATIONAL SEED TESTING ASSOCIATION. Handbook of vigour test methods. 3. ed. Zurich, 1995. 117p.

JIANHUA, Z.; McDONALD, M.B. The saturated salt accelerated aging for small-seeded crops. Seed Science and Technology, v.25, p.123-131, 1996.

KHAH, E.M.; ROBERTS, E.H.; ELLIS, R.H. Effects of seed ageing on growth and yield of spring wheat at different plant population densities. Field Crops Research, v.20, p.175-190, 1989.

LIMA, D. de. Avaliação da viabilidade e vigor de sementes de cebola (Allium cepa L.). Pelotas, 1993. 61p. Dissertação (Mestrado) - Universidade Federal de Pelotas.

LOEFFLER, N.L.; MEIER, J.L.; BURRIS, J.S. Comparasion of two cold test procedures for use in maise drying studies. Seed Science and Technology, v.13, n.3, p.653-658, 1985.

LOEFFLER, T.M.; TeKRONY, D.M.; EGLI, D.B. The bulk conductivity test as an indicator of soybean seed quality. Journal of Seed Technology, v.12, n.1, p.37-53, 1988.

MARCOS FILHO, J. Testes de vigor: importância e utilização. In: KRZYZANOWSKI, F.C.; VIEIRA, R.D.; FRANÇA NETO, J.B. (Ed.). Vigor de sementes: conceitos e testes. Londrina: ABRATES, 1999a. cap.1, p.1-21. 
MARCOS FILHO, J. Teste de envelhecimento acelerado. In: KRZYZANOWSKI, F.C.; VIEIRA, R.D.; FRANÇA NETO, J.B. (Ed.). Vigor de sementes: conceitos e testes. Londrina: ABRATES, 1999b. cap.3, p.1-24.

MATTHEWS, S. Controlled deterioration: a new vigour test for crop seeds. In: HEBBLETHWAITE, P.D. Seed production. London: Butterworths, 1980. p.647-660.

MATTHEWS, S.; BRADNOCK, W.T. The detection of seed samples of wrinkleseeded peas (Pisum sativum L.) of potentially low planting value. Proceedings of the International Seed Testing Association, v.32, p.553$563,1967$.

McCORMAC, A.C.; KEEFE, P.D. Cauliflower seed vigour: imbibition effects. Journal of Experimental Botany, v.41, p.893-899, 1990.

MELLO, S.C.; SPINOLA, M.C.M.; MINAMI, K. Métodos de avaliação da qualidade fisiológica de sementes de brócolos. Scientia Agricola, v.56, n.4, p.1151-1155, out./dez. 1999. Suplemento.

MENDONÇA, E.A.F.; RAMOS, N.P.; FESSEL, S.A.; SADER, R. Teste de deterioração controlada em sementes de brocoli (Brassica oleraceae L.) var. italica. Revista Brasileira de Sementes, v.22, n.1, p.280-287, 2000.

MIRANDA, Z.F.S. Avaliação da qualidade de sementes de berinjela (Solanum melongena L.). Pelotas, 1987. 46p. Dissertação (Mestrado) - Universidade Federal de Pelotas. 
MIRANDA, Z.F.S.; MELLO, V.D.C., SANTOS, D.S.B.; TILLMANN, M.A.A.; SANTOS, A.M.; SILVA, J.B. Avaliação da qualidade de sementes de berinjela. Revista Brasileira de Sementes, v.14, p.125-129, 1992.

NAKAGAWA, J. Testes de vigor baseados no desempenho das plântulas. In: KRZYZANOWSKI, F.C.; VIEIRA, R.D.; FRANÇA NETO, J.B. (Ed.). Vigor de sementes: conceitos e testes. Londrina: ABRATES, 1999. cap.2, p.1-24.

NASCIMENTO, W.M.; BARROS, B.C.; PESSOA, H.B. Teste de envelhecimento acelerado em sementes de tomate. Revista Brasileira de Sementes, v.15, n.2, p.251-253, 1993.

NASCIMENTO, W.M.; PESSOA, H.B.S.V.; BOITEUX, L.S. Qualidade fisiológica de sementes de milho doce submetidas a diferentes processos de colheita, debulha e beneficiamento. Pesquisa Agropecuária Brasileira, v.29, p.1211-1214, 1994.

OCANA GIL, M.; WERNER, C.P.; CROWTHER, T.C. Seed quality effects in bulb onions (Allium cepa L.). Annals of Applied Biology, v.118, p.663-669, 1991.

PANOBIANCO, M.; MARCOS FILHO, J. Comparação entre métodos para avaliação da qualidade fisiológica de sementes de pimentão. Revista Brasileira de Sementes, v.20, n.2, p.306-310, 1998.

PANOBIANCO, M.; MARCOS FILHO, J. Envelhecimento acelerado e deterioração controlada em sementes de tomate. Scientia Agricola, v.58, n.3, p.525-531, jul./set. 2001. 
PANOBIANCO, M.; VIEIRA, R.D.; KRZYZANOWSKI, F.C.; FRANÇA NETO, J.B. Electrical conductivity of soybean seed and correlation with seed coat lignin content. Seed Science and Technology, v.27, p.945-949, 2000.

PEDROSA, J.F.; OLIVEIRA, G.M.; BEZERRA NETO, F.; MONTEIRO, M. Influência da idade e armazenamento do fruto na produção e qualidade de sementes de Cucurbita maxima L. Horticultura Brasileira, v.5, n.2, p.15-17, 1987.

PIANA, Z.; TILLMANN, M.A.A.; MINAMI, K. Avaliação da qualidade fisiológica de sementes de cebola e sua relação com a produção de mudas vigorosas. Revista Brasileira de Sementes, v.17, n.2, p.149-153, 1995.

POWELL, A.A. The controlled deterioration test. In: VENTER, H.A. van de (Ed.). Seed vigour testing seminar. Copenhagen: The International Seed Testing Association, 1995. p.73-87.

POWELL, A.A.; MATTHEWS, S. Evaluation of controlled deterioration, a new vigour test for small seed vegetables. Seed Science and Technology, v.9, p.633-640, 1981.

POWELL, A.A.; MATTHEWS, S. Prediction of the storage potential of onion seed under commercial storage conditions. Seed Science and Technology, v.12, p.641-647, 1984.

POWELL, A.A.; FERGUSON, A.J.; MATTHEWS, S. Identificationof vigour differences among combining pea (Pisum sativum) seed lots. Seed Science and Technology, v.25, p.443-464, 1997. 
RECH, E.G.; VILLELA, F.A.; TILLMANN, M.A.A. Avaliação rápida da qualidade fisiológica de sementes de ervilha. Revista Brasileira de Sementes, v.21, n.2, p.1-9, 1999.

RIBEIRO, F.C.; CARVALHO, N.M. The saturated salt accelerated aging method seems to act leniently on carrot, lettuce and broccoli seeds germination. In: INTERNATIONAL SEED TESTING CONGRESS - SEED SYMPOSIUM, 26, Angers, 2001. Abstracts. Zurich, ISTA, 2001. p.39-40.

ROBERTS, E.H. Quantifying seed deterioration. In: McDONALD Jr., M.B.; NELSON, C.J. (Ed.). Physiology of seed deterioration. Madison: ASA, CSSA, SSSA, 1986. p.101-123. (Special Publication, 11).

RODO, A.B.; PANOBIANCO, M.; MARCOS FILHO, J. Metodologia alternativa do teste de envelhecimento acelerado para sementes de cenoura. Scientia Agricola, v.57, n.2, p.289-292, abr./jun. 2000.

RODO, A.B.; TILLMANN, M.A.A.; VILLELA, F.A. Testes de vigor na avaliação da qualidade fisiológica de sementes de tomate. Revista Brasileira de Sementes, v.20, n.1, p.23-28, 1998.

ROSSETO, C.A.V. Estudos sobre a absorção de água e o desempenho de sementes de soja. Piracicaba, 1995. 144 p. Tese (Doutorado) - Escola Superior de Agricultura “Luiz de Queiroz”, Universidade de São Paulo.

SHADBOLT, C.A.; HOLM, L.G. Some quantitative aspects of weed competition in vegetable crops. Weeds, v. 4, n.2, p. 111-123, Apr. 1956. 
SILVA, M.A.S.; TORRES, S.B.; CARVALHO, I.M.S. Teste de envelhecimento acelerado em sementes de maxixe (Cucumis anguria L.). Revista Brasileira de Sementes, v.20, n.1, p.212-214, 1998.

SMITH, O.E.; WELCH, N.C.; LITTLE, T.M. Studies on lettuce seed quality: I. Effect of seed size and weight on vigour. Journal of American Society for Horticultural Science, v.98, p.529-533, 1973.

SPINOLA, M.C.M.; CALIARI, M. F.; MARTINS, L.; TESSARIOLI NETO, J. Comparação entre métodos para avaliação do vigor de sementes de cenoura. Revista Brasileira de Sementes, v.20, n.2, p.301-305, 1998.

STRADIOTO NETO, J.; GARCIA, A.; MACIEL, V.S.; LUCCA FILHO, O.A. Efeito da qualidade fisiológica e sanitária das sementes sobre a produção de mudas de cebola. Pesquisa Agropecuária Brasileira, v.27, n.4, p.575-580, 1992.

STRYDOM, A.; van de VENTER, H.A. Comparison of seed vigour tests for cabbage (Brassica oleracea L.) var. capitata L. Seed Science and Technology, v.26, n.3, p.579-585, 1998.

STUMPF, C.L. Potencial de armazenamento de sementes de cebola enlatadas com baixos teores de umidade. Pelotas, 1993. 77p. Dissertação (Mestrado) Universidade Federal de Pelotas.

TeKRONY, D.M.; EGLI, D.B. Relationship of seed vigor to crop yield: a review. Crop Science, v.31, p.816-822, 1991. 
THOMAZELLI, L.F.; SILVA, R.F.; SEDIYANA, C.S. Como conservar a qualidade de sementes de cebola. Agropecuária Catarinense, v.3, n.4, p.7-8, 1990.

THORNTON, J.M.; POWELL, A.A.; MATTHEWS, S. Investigation of the relationship between seed leachate conductivity and the germination of Brassica seed. Annals of Applied Biology, v.17, p.129-135, 1990.

TORRES, S.B. Qualidade fisiológica de sementes de pimentão (Capsicum annuит L.) através do teste de estresse hídrico. Revista Brasileira de Sementes, v.18, n.2, p.246-250, 1996.

TORRES, S.B. Comparação entre diferentes testes de vigor e a correlação com a emergência no campo de sementes de cebola. Revista Brasileira de Sementes, v.20, n.1, p.65-69, 1998.

TORRES, S.B.; CARVALHO, I.M.S. Teste de envelhecimento acelerado em sementes de quiabo (Abelmoschus esculentus (L.) Moench). Revista Brasileira de Sementes, v.20, n.1, p.209-211, 1998.

TORRES, S.B.; MINAMI, K. Qualidade fisiológica de sementes de pimentão. Scientia Agricola, v. 57, n.1, p.109-112, jan./mar. 2000.

TORRES, S.B.; CASEIRO, R.F.; RODO, A.B.; MARCOS FILHO, J. Testes de vigor em sementes de maxixe (Cucumis anguria $\mathrm{L}$.) com ênfase ao teste de condutividade elétrica. Revista Brasileira de Sementes, v.20, n.2, p.480-483, 1998. 
TORRES, S.B.; SILVA, M.A.; CARVALHO, I.M.S.; QUEIROZ, M.A. Correlação entre testes de vigor em sementes de maxixe. Pesquisa Agropecuária Brasileira, v.34, p.1075-1080, 1999.

VIEIRA, J.E.A. Portaria $\mathbf{n}^{\mathbf{0}}$ 529: norma de identidade, qualidade, acondicionamento, embalagem e apresentação de cebola. Brasília: Ministério da Agricultura, 1995. 7p.

VIEIRA, R.D; KRZYZANOWSKI, F.C. Teste de condutividade elétrica. In: KRZYZANOWSKI, F.C.; VIEIRA, R.D.; FRANÇA NETO, J.B. (Ed.). Vigor de sementes: conceitos e testes. Londrina: ABRATES, 1999. cap.4, p.1-20.

WICKS, G.A.; JOHNSTON, D.N.; NULAND, D.S.; KINBACHER, E.J. Competition between annual weeds and sweet spanish onions. Weed science, v.21, n.5, p.436-439, Sep. 1973.

ZONTA, E.P.; MACHADO, A.A. Sistema de análise estatística para microcomputadores-SANEST. Pelotas: UFPel, 1984. 109p. 